\title{
Expedition 315 methods ${ }^{1}$
}

\author{
Expedition 315 Scientists $^{2}$
}

\section{Chapter contents}

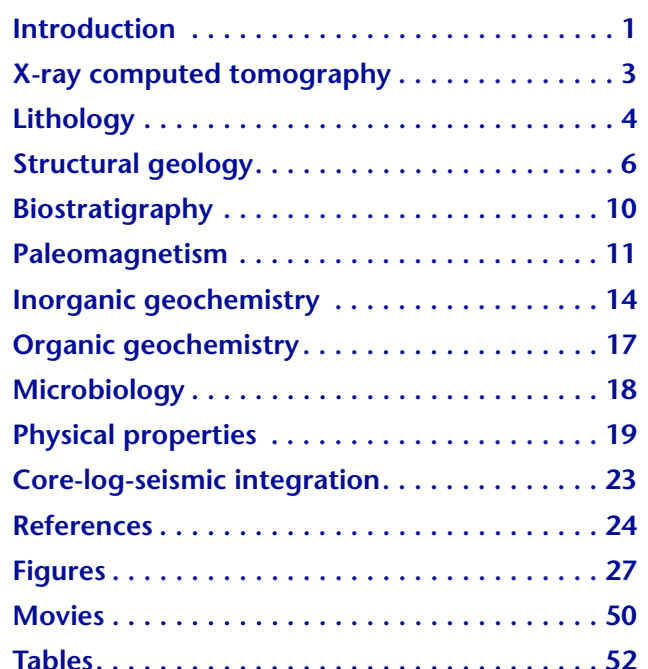

'Expedition 315 Scientists, 2009. Expedition 315 methods. In Kinoshita, M., Tobin, H., Ashi, J., Kimura, G., Lallemant, S., Screaton, E.J., Curewitz, D., Masago, H., Moe, K.T., and the Expedition 314/315/316 Scientists, Proc. IODP, 314/315/316: Washington, DC (Integrated Ocean Drilling Program Management International, Inc.). doi:10.2204/iodp.proc.314315316.122.2009 ${ }^{2}$ Expedition 314/315/316 Scientists' addresses.

\section{Introduction}

This chapter includes information on shipboard methods that will help the reader understand the basis for our preliminary interpretations and help the interested investigator select samples for further analysis.

\section{Authorship of site chapters}

The separate sections of the site chapters were written by the following shipboard scientists (authors are listed in alphabetical order; no seniority is implied):

Principal results: Expedition 315 Scientists

$\mathrm{X}$-ray computed tomography: Lewis

Lithology: Calves, Guo, Hashimoto, Underwood

Structural geology: Behrmann, Byrne, Kanagawa, Lewis

Biostratigraphy: Boeckel, Hayashi

Paleomagnetism: Kanamatsu, Pares

Inorganic geochemistry: Hulme, Tomaru

Organic geochemistry: Saito

Microbiology: Kaksonen

Physical properties: Famin, Henry, Hirono, Kopf, Likos, Schmidt-Schierhorn, Zhu

Core-log-seismic integration: Henry

\section{Reference depths}

Seafloor depths and cored intervals below seafloor (core depth below seafloor [CSF]) are determined by drill pipe measurement. When using Integrated Ocean Drilling Program (IODP) Method A, core expansion lengths overlap and are not scaled. We sometimes had more core recovery than coring advance (usually $9.5 \mathrm{~m}$ ), especially in shallow sediments. These core lengths are linearly compressed to adjust to the coring advance and are labeled CSF-B to indicate core depth below seafloor calculated using IODP Method B (compression). Drilling engineers prefer to use pipe length to present the depth as drillers depth below rig floor (DRF). This measurement can be converted to CSF by subtracting water depth and the height of the rig floor from the sea surface. In some contexts referring to logging-while-drilling (LWD) results (as in "Core-log-seismic integration"), logging depths are presented as LWD depth below seafloor (LSF), which is also based on drill pipe measurement below seafloor. 


\section{Numbering of sites, holes, cores, sections, and samples}

Sites drilled by the D/V Chikyu are numbered consecutively from the first site with a prefix "C." A site refers to one or more holes drilled while the ship was positioned within $300 \mathrm{~m}$ of the first hole. The first hole drilled at a given site is assigned the site number modified by the suffix " $\mathrm{A}$," the second hole takes the site number and suffix " $\mathrm{B}$," and so forth. These suffixes are assigned regardless of recovery, as long as penetration takes place. During IODP Expedition 315, we drilled at Sites C0001 and C0002, both of which had been previously drilled during IODP Expedition 314. Therefore, hole names start with "E" for Site C0001 and "B" for Site C0002.

Each cored interval is generally $9.5 \mathrm{~m}$ long, which is the length of a core barrel. Coring intervals may be shorter and may not necessarily be adjacent if separated by intervals that were drilled but not cored. The core depth interval assigned to an individual core begins with the depth below seafloor at which the coring operation began and extends to the depth at which the coring operation ended for that core.

A recovered core is typically divided into $1.5 \mathrm{~m}$ long sections that are numbered serially from 1 beginning at the top. When the recovered core is shorter than the cored interval, the top of the core is equated with the top of the cored interval by convention in order to achieve consistency in handling analytical data derived from the cores. Also by convention, material recovered from the core catcher is placed in a separate section during core description, labeled core catcher (CC), and placed below the last (bottom) section recovered in the liner. The core catcher is placed at the top of the cored interval in cases where material is only recovered in the core catcher.

Samples removed from a core section are designated by distance measured in centimeters from the top of the section to the top and bottom of each sample removed from that section. A full identification number for a sample consists of the following information: expedition, site, hole, core number, core type, section number, and top to bottom interval in centimeters measured from the top of the section. For example, a sample identification of "315-C0001H-3R$2,20-25 \mathrm{~cm}$," represents a sample removed from the interval between 20 and $25 \mathrm{~cm}$ below the top of Section 2. Core $3 \mathrm{R}$ designates that this core was taken using the rotary core barrel (RCB) in Hole C0001H during Expedition 315. All IODP core identifiers indicate core type. The following abbreviations are used: $\mathrm{H}=$ hydraulic piston coring system (HPCS; equivalent to the advanced piston corer), $\mathrm{X}=\mathrm{ex}$ tended shoe coring system (ESCS; equivalent to the extended core barrel), and $\mathrm{R}=\mathrm{RCB}$.

\section{Core handling}

As soon as a core is retrieved on deck, a sample is taken from the core catcher and, if sedimentary, sent to the paleontological laboratory for an initial age assessment. The Curator immediately measures the total length of the recovered core and informs the Wellsite Geologist. The Wellsite Geologist then registers the core number in the shipboard database J-CORES together with the drilling advance and other additional drilling information. The core liner with the core inside is marked into section lengths by the Curator, each section is numbered, and the core is cut into sections. Usually all of Section 4 is dedicated to interstitial water analyses. Therefore, Section 4 is frequently significantly shorter than 1.5 $\mathrm{m}$. Its length varies from 20 to $45 \mathrm{~cm}$ depending on depth. This short section is immediately removed from the core cutting area and scanned with the Xray computed tomography (CT) scanner to investigate internal structures in order to avoid losing unique tectonic or sedimentary features.

For safety monitoring, small $\left(\sim 5 \mathrm{~cm}^{3}\right)$ plugs of sediment are taken from the bottom of Section 1 for headspace gas analysis. Each section is then sealed at the top and bottom with color-coded plastic caps and vinyl tape. A blue end cap marks the top of a section, a clear cap marks the bottom, and a yellow cap marks the end of a section from which a wholeround sample has been removed. The sample code (e.g., IW for interstitial water) is written on the yellow cap. Core sections are then carried into the laboratory, and the length of the core sections and any samples taken are logged into the J-CORES database.

In the laboratory, X-ray CT images are taken for all core sections. As mentioned above, a short section for interstitial water analysis is given top priority for $\mathrm{X}$-ray CT scanning. A structural geologist and a sedimentologist examine section's internal structures with real-time axial images to judge whether the section can be squeezed or not. If they find any important structures inside, the section is preserved and another whole-round sample candidate is taken for interstitial water analysis. Other sections are scanned with the X-ray CT in turn. After taking X-ray CT images, microbial whole-round samples are taken from a nonstructured less-disturbed horizon based on information gained from the X-ray CT images. Samples for anelastic strain recovery measurement are also taken at this time. 
After core sections equilibrate to ambient room temperature $(\sim 3 \mathrm{~h})$, they are run through the multisensor core logger (MSCL). For soft sediments, thermal conductivity measurements are then made (see "Physical properties"). After these nondestructive measurements, whole-round samples that are not time sensitive are taken. At the same time, $1 \mathrm{~cm}$ thick "cluster" slices are taken next to the wholeround sampling intervals. This thin round slice is divided into several pieces for different analytical purposes: X-ray diffraction (XRD; bulk), moisture and density (MAD), some organic chemistry analyses, and some shore-based analyses. This cluster sample provides a set of physical and chemical data for each sampling horizon, which enables more comprehensive geologic interpretation.

Cores are subsequently split lengthwise into working and archive halves. The archive half is used for nondestructive measurements: visual core description, paleomagnetism, digital photo image scanning, and color spectroscopy. Samples are taken from the working half for shipboard physical property measurements (see "Physical properties") before being sampled for additional shipboard and postcruise studies. Finally, core sections are wrapped in plastic bags (heat shrink wrap) and transferred to cold-storage space aboard the drilling vessel. Following the expedition, cores are transported to the Kochi Core Center in Kochi, Japan.

\section{X-ray computed tomography}

X-ray CT imaging provided real-time constraints for Expedition 315 core logging and sampling strategies. The following explanation of our methods was derived from the "cookbook" prepared by CDEX/ JAMSTEC for onboard use (X-Ray CT Scanner, version 3.00, 31 July 2007) and practical experience. The cookbook is based on GE Healthcare (2006), Mees et al. (2003), and Nakano et al. (2000).

The X-ray CT instrument on the Chikyu is a GE Yokogawa Medical Systems LightSpeed Ultra 16 capable of generating sixteen $0.625 \mathrm{~mm}$ thick slice images every $0.6 \mathrm{~s}$, the time for one revolution of the Xray source around the sample (see Table $\mathbf{T} 1$ for operating parameters). As a result of this high scanning rate, $1.5 \mathrm{~m}$ sections of core were typically imaged in $<3 \mathrm{~min}$. Data generated for each core consist of coreaxis-normal planes of X-ray attenuation values with dimensions of $512 \times 512$ pixels. Data were stored as Digital Imaging and Communication in Medicine (DICOM) formatted files.

\section{Background}

The theory behind X-ray CT has been well established through medical research and is only briefly outlined here. X-ray intensity (I) varies as a function of X-ray path length and the linear attenuation coefficient (LAC) of the target material as

$$
I=I_{0} \times e^{-\mu L},
$$

where

$$
\begin{aligned}
& I=\text { transmitted X-ray intensity, } \\
& I_{0}=\text { initial X-ray intensity, } \\
& \mu=\text { LAC of the target material, and } \\
& L=\text { X-ray path length through the material. }
\end{aligned}
$$

LAC is a function of the chemical composition and density of the target material. The basic measure of attenuation, or radiodensity, is the CT number given in Hounsfield units (HU) and is defined as

$$
\text { CT number }=\left[\left(\mu_{t}-\mu_{w}\right) / \mu_{w}\right] \times 1000,
$$

where

$$
\begin{aligned}
& \mu_{\mathrm{t}}=\text { LAC for the target material and } \\
& \mu_{\mathrm{w}}=\text { LAC for water. }
\end{aligned}
$$

The distribution of attenuation values mapped to an individual slice comprises the raw data that are used for subsequent image processing. Successive twodimensional slices yield a representation of attenuation values in three-dimensional (3-D) pixels referred to as voxels. Visualizations are generally accomplished by varying the manner in which the distribution of CT number is assigned to 256 shades of gray or a color pallet. Onboard analysis of CT images was done primarily using the OsiriX 32-bit DICOM viewer (version 2.7.5) running on a G5 Macintosh (OS 10.4).

Analytical standards used during Expedition 315 were air $(\mathrm{CT}$ number $=-1000)$, water $(\mathrm{CT}$ number $=$ $0)$, and aluminum $(2467<$ CT number $<2487)$ in an acrylic core mock-up. The schedule for running these was fully implemented on 3 December 2007. All three standards were run once daily after air calibration, and once each week the three standards were run both before and after air calibration. For each standard analysis the CT number was determined for a $24.85 \mathrm{~mm}^{2}$ area at fixed coordinates near the center of the cylinder (Table T2).

\section{X-ray CT scan data usage}

X-ray CT scans were used routinely during Expedition 315 to 
- Provide an assessment of core and core-liner integrity,

- Determine the appropriateness of whole-round samples,

- Identify potentially subtle features and/or features that might warrant special handling during visual core description and sampling, and

- Measure orientations and identify crosscutting relationships.

CT scans provided first-hand information regarding the integrity of sample cores and core liners. Cores that experienced gas expulsion during depressurization could be readily identified (Fig. F1), as could cores in which extensive drilling-induced brecciation had occurred (Fig. F2). In several instances, core liners buckled into the sample along the core axis, displacing the sample, and in one case a liner partially delaminated and became entangled in a serpentine manner within the sample (Movie M1). CT scans also provided a fast and practical means of assessing the coherence of core intervals that contained abundant natural structures and were therefore targeted for additional paleomagnetic analyses.

All whole-round core sections were screened to avoid destructive testing on core samples that might contain critical structural features. This also ensured minimal drilling disturbance of whole-round samples (essential for microbiology as well as physical and mechanical properties) and an assessment of whole-round homogeneity. X-ray CT scanning was done immediately after core cutting so that timesensitive whole-round samples (e.g., those for interstitial water and microbiological analyses) could be included in this screening process.

The value of X-ray CT scans to identify sedimentary and tectonic features prior to visual core description was quickly recognized (Movie M2). Three-dimensional structure orientation could easily be determined from CT sections, whereas performing the same measurement on the cores generally required cutting orthogonal faces. Furthermore, structures could be classified as a function of their CT contrast, which is presumably related to porosity changes or chemical alteration within shear zones. Observations were noted in the structural geology CT log sheets (Fig. F3) and are commonly referred to in the visual core description sheets.

$\mathrm{X}$-ray CT images have multiple uses, from early assessment of cores to description and synthesis. For this reason, several hundred gigabytes of CT data were durably stored on a local database at the OsiriX interpretation station. All X-ray CT data will be available after the moratorium at the SI07 Web site (sio7.jamstec.go.jp).

\section{Lithology \\ Visual core descriptions}

We followed conventional Ocean Drilling Program (ODP) and IODP procedures for recording sedimentologic information on visual core description (VCD) forms on a section-by-section basis (Mazzullo and Graham, 1988). Core descriptions were transferred to section-scale templates using shipboard database software J-CORES and then converted to core-scale depictions using Strater software. Texture (defined by the relative proportions of sand, silt, and clay) follows the classification of Shepard (1954). The classification scheme for siliciclastic lithologies follows Mazzullo et al. (1988).

The Graphic Lithology column on each VCD plots to scale all beds that are at least $2 \mathrm{~cm}$ thick. Graphic patterns do not show persistent interlayers $<2 \mathrm{~cm}$ thick, but such intervals are identified as laminae in the Sedimentary Structures column. It is difficult to discriminate between the dominant lithologies of silty clay and clayey silt without quantitative grain size analysis, so we grouped this entire range of textures into the category "silty clay" on all illustrations. We did not use separate patterns for more heavily indurated examples of the same lithologies (e.g., silty clay versus silty claystone) because the dividing line is arbitrary. Figure F4 displays graphic patterns for all lithologies encountered during Expedition 315 . Also shown are symbols for internal sedimentary structures, soft-sediment deformation structures, and severity of core disturbance in both soft sediment and indurated sedimentary rock.

\section{Smear slides}

Smear slides are useful for identifying and reporting basic sediment attributes (texture and composition), but the results are not quantitative. We estimated the abundances of biogenic, volcaniclastic, and silicilclastic constituents with the help of a visual comparison chart (Rothwell, 1989). Errors can be large, however, especially for fine silt and clay-size fractions, and reproducibility among different sedimentologists is poor. Smear slide analysis also tends to underestimate the amount of sand-size grains because they are difficult to incorporate evenly onto the slide. Thus, it would be misleading to report values as absolute percentages. Instead, our descriptive results are tabulated as visual percentage estimates, with values grouped into the following range categories:

$$
\begin{aligned}
& \mathrm{D}=\text { dominant }(>50 \%) . \\
& \mathrm{A}=\text { abundant }(>20 \%-50 \%) . \\
& \mathrm{C}=\text { common }(>5 \%-20 \%) . \\
& \mathrm{P}=\text { present }(>1 \%-5 \%) .
\end{aligned}
$$


$\mathrm{R}=\operatorname{rare}(0.1 \%-1 \%)$.

$\mathrm{T}=$ trace $(<0.1 \%)$.

The relative abundance of major components was also validated by X-ray diffraction (see "X-ray diffraction"), and the absolute weight percent of carbonate was verified by coulometric analysis (see "Organic geochemistry").

The sample location for each smear slide was entered into the J-CORES database with a sample code of SS using the Samples application. The position of each specimen is shown on the VCD slide editor column of the VCD application. We tabulated data in an Excel spreadsheet because data entry into J-CORES is prohibitively time-consuming and the program will not accept ranges of values for individual compositional categories.

\section{X-ray diffraction}

We completed routine XRD analyses of bulk powders using a PANalytical CubiX PRO (PW3800) diffractometer. Our principal goal was to estimate relative weight percentages of total clay minerals, quartz, plagioclase, and calcite using peak areas. Most of the samples were selected from intervals adjacent to whole-round samples, and most are part of sampling clusters with physical properties and carbonate. A few additional samples were collected periodically from such unusual lithologies as carbonatecemented claystone and volcanic ash. Samples were freeze-dried, crushed with a ball mill, and mounted as random bulk powders. The instrument settings were as follows:

Generator $=45 \mathrm{kV}$ and $40 \mathrm{~mA}$.

Tube anode $=\mathrm{Cu}$.

Wavelength $=1.54060 \AA\left(\mathrm{K}_{\alpha 1}\right)$ and $1.54443 \AA\left(\mathrm{K}_{\alpha 2}\right)$.

Step spacing $=0.005^{\circ} 2 \theta$.

Scan step time $=0.648 \mathrm{~s}$.

Divergent slit $=$ automatic.

Irradiated length $=10 \mathrm{~mm}$.

Scanning range $=2^{\circ} 2 \theta$ to $60^{\circ} 2 \theta$.

Spinning $=$ yes.

In order for our results to match those of ODP Leg 190 as closely as possible, the choice was made to use MacDiff version 4.2.5 software (www.ccp14.ac.uk/ ccp/ccp14/ftp-mirror/krumm/Software/macintosh/macdiff/MacDiff.html) for data processing. Each peak's upper and lower limits were adjusted following the guidelines shown in Table T3. Calculations of relative mineral abundance utilized a matrix of normalization factors derived from integrated peak areas and singular value decomposition (SVD) (Table T4). As described by Fisher and Underwood (1995), calibration of SVD factors depends on the analysis of known weight-percent mixtures of min- eral standards that are appropriate matches for natural sediments. SVD normalization factors were recalculated during Expedition 315 after the diffractometer's high-voltage power supply was replaced. Bulk powder mixtures for the Nankai Trough are the same as those reported by Underwood et al. (2003): quartz (Saint Peter sandstone), feldspar (Carich albite), calcite (Cyprus chalk), smectite (Camontmorillonite), illite (Clay Mineral Society IMt-2, 2M1 polytype), and chlorite (Clay Mineral Society CCa-2). Examples of diffractograms for standard mixtures are shown in Figure F5.

Average errors (SVD-derived estimates versus true weight percent) are total clay minerals $=3.5 \%$, quartz $=2.1 \%$, plagioclase $=0.8 \%$, and calcite $=$ $1.5 \%$. In spite of its precision with standard mixtures, the SVD method is only semiquantitative and results for natural specimens should be interpreted with some caution. One of the fundamental problems with any bulk powder XRD method is the difference in peak response between poorly crystalline minerals at low diffraction angles (e.g., clay minerals) and highly crystalline minerals at higher diffraction angles (e.g., quartz and plagioclase). Contents of clay minerals are best characterized by measuring the peak area, whereas peak intensity may be easier and more accurate to quantify quartz, feldspar, and calcite. Analyzing oriented aggregates enhances basal reflections of the clay minerals, but this step is time consuming and requires isolation of the clay-size fraction to be effective. Errors also propagate as more minerals and peaks are added to the procedure. For clay mineral assemblages, the two options are to individually measure one peak for each mineral and add the estimates together (thereby propagating the error) or to measure a single composite peak at $19.4^{\circ}$ to $20.4^{\circ} 2 \theta$. Another source of error is contamination of mineral standards by impurities such as quartz (e.g., the illite standard contains $\sim 20 \%$ quartz). For trace quantities of a mineral and peaks with low intensity, use of negative SVD normalization factors may result in negative values of absolute weight percent. In such cases, we inserted the numerical value of $0.1 \%$ as a proxy for "trace."

In the final assessment, calculated values of a mineral's weight percent should only be regarded as relative percentages within a four-component system of clay minerals + quartz + plagioclase + calcite. How close those estimates are to their absolute percentages within the mass of total solids will depend on the abundance of amorphous solids (e.g., biogenic opal and volcanic glass), as well as the total of all other minerals that occur in minor or trace quantities. For most natural samples, the absolute errors are probably between $5 \%$ and $10 \%$. Thus, the primary 
value of bulk powder XRD data should be to identify spatial and temporal trends in sediment composition and to assist with core-log integration.

\section{Structural geology}

One of the main objectives of Expedition 315 was to document the structural geology of the uppermost $\sim 1000 \mathrm{~m} \mathrm{CSF}$ at the site proposed for deep drilling $(\sim 2.5 \mathrm{~km})$ during Stage 2 of the Nankai Trough Seismogenic Zone Experiment (NanTroSEIZE). The deep drilling program will cross a major thrust in the accretionary prism (referred to as the "megasplay," as it merges at depth with the main décollement of the subducting plate boundary), and Site C0001 was planned to provide the first information on the composition and structural architecture of the hanging wall of this major thrust. Documentation of the structures at this site is also necessary to understand the deformation history and associated geochemical and physical processes related to the growth of the prism in this area. Deformational structures, therefore, may be critical to understanding the megasplay thrust and its role in seismogenesis along this margin.

With this in mind, we tried to document each structure observed in the split cores. In many cases, X-ray CT images of whole-round (i.e., unsplit) cores were used to identify structural features and better understand their 3-D geometry. Structural data, however, were only collected on split cores. Collected data were hand logged onto a printed form at the core table and then typed into both a spreadsheet and the JCORES database. Where possible, structural data were also corrected for rotations related to drilling.

\section{Observations and data collection}

Core observations and measurements followed previous ODP procedures (e.g., ODP Legs 131, 170, and 190) by using a modified plastic protractor (Fig. F6) and included taking notes on a descriptive core log designed and printed during the first days of the expedition (Fig. F7; see 315_STRUCTURE in "Supplementary material"). During Expedition 315, however, we also had access to CT images of the cores for the first time ever in ocean drilling, and we collected essentially all of the data from the working half, rather than the archive half, of the split core. CT images were regularly used to aid in identifying structures and defining their 3-D form and distribution in the core. Using the working half of the split core provided greater flexibility in removing-and cutting, if necessary-pieces of the core for more careful study and measurement. Thin sections, X-ray fluorescence samples, and XRD samples could also be tagged or collected as we described the core.

Orientations of planar and linear features in cored sediments were determined relative to the core axis, which represents vertical in the core reference frame, and the "double line" marked on the working half of the split core liner, which represents north $\left(\right.$ or $0^{\circ}$ and $360^{\circ}$ ) in the core reference frame. To determine the orientation of a plane, two apparent dips of the planar feature were measured in the core reference frame and converted to a plane represented by either a strike and dip or a dip and dip direction. This conversion was accomplished using a spreadsheet, as described in "Orientation data analysis based on the spreadsheet." This approach had the advantage of increasing data processing efficiency and reducing errors in transferring and retyping data (e.g., by using both R. Allmendinger's Stereonet program and a spreadsheet). One apparent dip was typically represented by the intersection of the planar feature with the split face of the core and was quantified by measuring the dip direction and angle in the core reference frame. Typical apparent dip measurements had a trend of $090^{\circ}$ or $270^{\circ}$ and ranged in plunge from $0^{\circ}$ to $90^{\circ}$. The second apparent dip was usually represented by the intersection of the planar feature and a cut or fractured surface at a high angle to the split face of the core axis. In many cases this was a surface either parallel or perpendicular to the core axis. In the former cases, the apparent dip lineation would trend $000^{\circ}$ or $180^{\circ}$ and plunge from $0^{\circ}$ to $90^{\circ}$; in the latter cases, the trend would range from $000^{\circ}$ to $360^{\circ}$ and plunge $0^{\circ}$. Linear features observed in the cores were always associated with planar structures (typically faults or shear zones), and their orientations were determined by measuring either the trend and plunge in the core reference frame or the rake (or pitch) on the associated plane. All data were recorded on the log sheet with appropriate depths and descriptive information.

A range of planar deformation structures was observed in Expedition 315 cores. Most can be classified as primarily belonging to one of three types of structures: faults, shear zones (or deformation bands), and "vein structures." This is not meant to imply that all structures are only one type-in fact, many structures show features characteristic of all three types-but at this preliminary stage, and with limited thin section and other microscopic analyses, we chose to use a limited number of broad categories. Of course, descriptive modifiers and sketches provide additional information as to the similarities and differences of individual structures. Faults are relatively planar, narrow zones of deformation characterized by a single band of concentrated deforma- 
tion at the scale of the core and CT image. Faults also typically show clear evidence of displacement, including offset markers (e.g., bedding, burrows, or small pumice fragments), fault drag, and slickensided rough or polished surfaces. Faults are bright in CT images, suggesting a higher density than that of the adjacent matrix. However, a systematic study of deformation structures and brightness (i.e., CT number) was not undertaken, so there may well be significant variations in brightness, and therefore density, within and between various structures. Shear zones (or deformation bands) are generally wider than faults and are typically composed of multiple sets or bands of concentrated deformation. In many cases, the outer edges of a shear zone are sharp and more planar than the anastamosing surfaces of deformation within the zone. CT images also suggest a range of densities within individual zones as well as between different shear zones. Vein structures include a variety of structures, many of which have been recognized during previous ocean drilling expeditions and have been interpreted as dewatering structures. This category of structures includes the classic sigmoidal-shaped suite of thin mud-filled veins first documented by Brothers et al. (1996), Cowan (1982), and Ogawa (1980), as well as other veinlike structures that appear darker than the surrounding sediment and brighter (or denser) in CT images. These other veinlike structures include single planar to subplanar features several millimeters thick but associated with only limited displacements and rare to poorly developed slickenlines. In some cases, veinlike structures extend subparallel to the core axis for decimeters; in other cases, they occur at moderate to low angles to the core axis and have limited extent. Apparent offsets in the split core include both normal and thrust displacements. Kink bands are another type of structure observed in cored sediments, but well-developed kink bands appear to be relatively rare. In fact, only two occurrences are documented, although more detailed analysis may show that some of the structures classified as faults or deformation bands evolved from kink or kinklike structures.

Slickenlines represent the only linear structures observed in the cored sediments and are often associated with steps or, less commonly, spoon-shaped indentations on the faulted or sheared surface, producing an asymmetry that reflects the sense of slip during deformation. For a review of sense of shear criteria associated with mesoscopic brittle deformation of rocks, see Petit (1987) and Angelier (1994). Steps were interpreted as extension cracks (or " $R$ " shears activated as extension cracks) that connect en echelon " $\mathrm{P}$ " shears within the fault or shear zone. In some cases, the combined set of P shears and extension cracks provides an indication of shear sense; in other cases, extension cracks or P shears alone were used as evidence for slip sense. Spoonshaped indentations were interpreted as $\mathrm{R}$ shears with the fault or shear zone and indicated a sense-ofslip synthetic to the main fault or shear zone. Slickenlines and associated shear sense indictors therefore provided critical information regarding slip direction during deformation.

Paleomagnetic data were routinely used to correct drilling-induced rotations of cored sediments. Rotations were induced during RCB coring, as is common in ocean drilling, and unexpectedly with the HPCS. Rotations of the core liner used in the HPCS, including any retrieved sediments, were apparently induced as the cutting shoe was removed on the rig floor (see "Paleomagnetism"); the sense and magnitude of rotations observed in the sediments are at least consistent with this interpretation. The core liner may have also twisted and rotated as the cutting shoe was installed before coring, but this remains to be investigated. To correct for these rotations, we identified sections of cored sediment that were relatively coherent and continuous-that is, sections that were interpreted to have rotated as a single piece during drilling or core liner removal. These coherent sections were then matched with paleomagnetic data from the appropriate depth intervals and used to unrotate the planar and linear structures preserved in the core section. In cases where core sections were not continuous (generally this included core sections $<10 \mathrm{~cm}$ in length), individual samples were placed in a core liner at $20 \mathrm{~cm}$ intervals, which is the sampling length of the long-core cryogenic magnetometer on the Chikyu.

\section{Orientation data analysis based on the spreadsheet}

A spreadsheet template was developed and used during Expedition 315 to calculate orientation data in both core and geographic reference frames from the linear data collected from the cores (e.g., Fig. F8; see 315_STRUCTURE in "Supplementary material"). The core reference frame is defined such that the upcore direction is vertical upward, the core-splitting plane is east-west vertical, and the double-lined side of the working half points toward north (Fig. F9).

\section{Calculation of plane orientation}

For a bedding or fault plane, two apparent dips on two different surfaces (e.g., the split core surface, which is east-west vertical, and the horizontal or north-south vertical surface) were measured in the core reference frame as azimuths (measured clockwise from north, looking down) and plunges (Fig. 
F10). A coordinate system was defined in such a way that the positive $x-, y$-, and $z$-directions coincide with north, east, and vertical downward, respectively (Fig. F9). If the azimuths and plunges of the two apparent dips are given as $\left(\alpha_{1}, \beta_{1}\right)$ and $\left(\alpha_{2}, \beta_{2}\right)$, respectively, as in Figure F10, then the unit vectors representing these two lines, $v_{1}$ and $v_{2}$, are

$$
v_{1}=\left(\begin{array}{c}
l_{1} \\
m_{1} \\
n_{1}
\end{array}\right)=\left(\begin{array}{c}
\cos \alpha_{1} \cos \beta_{1} \\
\sin \alpha_{1} \cos \beta_{1} \\
\sin \beta_{1}
\end{array}\right)
$$

and

$$
v_{2}=\left(\begin{array}{c}
l_{2} \\
m_{2} \\
n_{2}
\end{array}\right)=\left(\begin{array}{c}
\cos \alpha_{2} \cos \beta_{2} \\
\sin \alpha_{2} \cos \beta_{2} \\
\sin \beta_{2}
\end{array}\right) .
$$

The unit vector normal to this plane, $v_{\mathrm{n}}$ (Fig. F10), is then defined as follows:

$$
v_{\mathrm{n}}=\left(\begin{array}{c}
l_{\mathrm{n}} \\
m_{\mathrm{n}} \\
n_{\mathrm{n}}
\end{array}\right)=\frac{v_{1} \times v_{2}}{\left|v_{1} \times v_{2}\right|},
$$

where

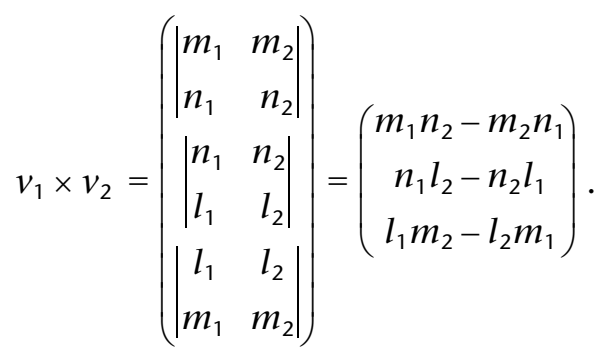

The azimuth, $\alpha_{n}$, and plunge, $\beta_{n}$, of $v_{n}$ are given by

$$
\alpha_{\mathrm{n}}=\tan ^{-1}\left(m_{\mathrm{n}} / l_{\mathrm{n}}\right), \beta_{\mathrm{n}}=\sin ^{-1} n_{\mathrm{n}} .
$$

The dip direction, $\alpha_{d}$, and dip angle, $\beta$, of this plane are $\alpha_{n}$ and $90^{\circ}+\beta_{n}$, respectively, when $\beta_{n}$ is $<0^{\circ}$ (Fig. F11A). They are $\alpha_{n} \pm 180^{\circ}$ and $90^{\circ}-\beta_{n}$, respectively, when $\beta_{\mathrm{n}}$ is $\geq 0^{\circ}$ (Fig. F11B). The right-hand rule strike of this plane, $\alpha_{s}$, is then given by $\alpha_{d}-90^{\circ}$ (Fig. F11).

\section{Calculation of slickenline rake}

For a fault with slickenlines, the apparent rake angle of the slickenline, $\phi_{a}$, was measured on the fault surface from either the $090^{\circ}$ or $270^{\circ}$ direction of the split-core surface trace (Fig. F12). Fault orientation was measured as described above. Provided that $v_{\mathrm{n}}$ and $v_{\mathrm{c}}$ are unit vectors normal to the fault and split core surfaces, respectively, the unit vector of this in- tersection line, $v$, is perpendicular to both $v_{\mathrm{n}}$ and $v_{\mathrm{c}}$ (Fig. F12) and is therefore defined as follows:

$$
v_{\mathrm{i}}=\left(\begin{array}{c}
l_{\mathrm{i}} \\
m_{\mathrm{i}} \\
n_{\mathrm{i}}
\end{array}\right)=\frac{v_{\mathrm{n}} \times v_{\mathrm{c}}}{\left|v_{\mathrm{n}} \times v_{\mathrm{c}}\right|}
$$

where

$$
v_{\mathrm{c}}=\left(\begin{array}{l}
1 \\
0 \\
0
\end{array}\right)
$$

and

$$
v_{\mathrm{n}} \times v_{\mathrm{c}}=\left(\begin{array}{cc}
\left|\begin{array}{cc}
m_{\mathrm{n}} & 0 \\
n_{\mathrm{n}} & 0
\end{array}\right| \\
\left|\begin{array}{ll}
n_{\mathrm{n}} & 0 \\
l_{\mathrm{n}} & 1
\end{array}\right| \\
\left|\begin{array}{ll}
l_{\mathrm{n}} & 1 \\
m_{\mathrm{n}} & 0
\end{array}\right|
\end{array}\right)=\left(\begin{array}{c}
0 \\
n_{\mathrm{n}} \\
-m_{\mathrm{n}}
\end{array}\right)
$$

Knowing the right-hand rule strike of the fault plane, $\alpha_{s}$ (Figs. F11, F13), the unit vector, $v_{s}$, toward this direction is then

$$
v_{\mathrm{s}}=\left(\begin{array}{c}
\cos \alpha_{\mathrm{s}} \\
\sin \alpha_{\mathrm{s}} \\
0
\end{array}\right) .
$$

The rake angle of the intersection line, $\phi_{\mathrm{i}}$, measured from the strike direction is given by

$$
\phi_{\mathrm{i}}=\cos ^{-1}\left(v_{\mathrm{s}} \times v_{\mathrm{i}}\right)
$$

because

$$
v_{\mathrm{s}} \cdot v_{\mathrm{i}}=\left|v_{\mathrm{s}} \| v_{\mathrm{i}}\right| \cos \phi_{\mathrm{i}}=\cos \phi_{\mathrm{i}}, \therefore\left|v_{\mathrm{s}}\right|=\left|v_{\mathrm{i}}\right|=1 .
$$

The rake angle of the slickenline, $\phi$, from the strike direction is $\phi_{i} \pm \phi_{a}$, depending on the direction the apparent rake was measured from and the direction the fault plane dips toward. $\phi_{\mathrm{a}}$ should be subtracted from $\phi_{i}$ when the fault plane dips west and $\phi_{a}$ was measured from either the upcore or $090^{\circ}$ direction (Fig. F13A) or when the fault plane dips toward east and $\phi_{a}$ was measured from either the downcore or $090^{\circ}$ direction (Fig. F13B). On the other hand, $\phi_{\mathrm{a}}$ should be added to $\phi_{\mathrm{i}}$ when the fault plane dips toward east and $\phi_{\mathrm{a}}$ was measured from either the upcore or $270^{\circ}$ direction (Fig. F13C) or when the fault plane dips west and $\phi_{a}$ was measured from either the downcore or $270^{\circ}$ direction (Fig. F13D). 


\section{Azimuth correction using paleomagnetic data}

Provided that a core is vertical, its magnetization is primary, and its bedding is horizontal, its paleomagnetic declination, $\alpha_{p}$, indicates magnetic north when its inclination, $\beta_{p}$, is $\geq 0^{\circ}$ (Fig. F14A), whereas it indicates magnetic south when $\beta_{p}$ is $<0^{\circ}$ (Fig. F14B). The dip direction and strike of a plane in the geographic reference frame, $\alpha_{d}{ }^{*}$ and $\alpha_{s}{ }^{*}$, are therefore

$$
\alpha_{d}^{*}=\alpha_{d}-\alpha_{p}
$$

and

$$
\alpha_{s}^{*}=\alpha_{s}-\alpha_{p}
$$

when

$$
\beta_{p} \geq 0^{\circ}
$$

and are

$$
\alpha_{d}^{*}=180^{\circ}+\alpha_{d}-\alpha_{p}
$$

and

$$
\alpha_{s}^{*}=180^{\circ}+\alpha_{s}-\alpha_{p}
$$

when

$$
\beta_{\mathrm{p}}<0^{\circ} .
$$

\section{J-CORES structural database}

Structural data entered in the J-CORES database VCD program include a visual (macroscopic and/or microscopic) description of core structures at a given section index and a record of planar structures in the core reference frame. Tablet PCs equipped with a wireless interface and writing recognition software were provided to allow data input directly from the core description tables. However, we found it more efficient to record the data on paper logs first (Fig. F15) and then transfer the data into the J-CORES database at a later time (see "J-CORES in practice for the structural geologist"). Data were also entered into a spreadsheet for postacquisition processing.

Data entry through the VCD program proceeds as follows:

1. Select expedition, site, hole, core, and section for which data will be read/written.

2. Select data to work with (e.g., CT image, structure description) and click Hire and OK.

3. Select a structure ID (e.g., bedding, fault) or create a new structure identifier (ID).

4. Select the section interval in which the structure is observed.
5. Fill the parameters related to this particular structure (comments and planar data; Fig. F15).

After saving, data are automatically uploaded to the Chikyu server and can be retrieved afterward as text or as an Excel file for processing. It is important to note that scientists are only allowed to write data in their own field of research and for their expedition (for example, an Expedition 315 structural geologist can only input structural data for Expedition 315). Any logged-in user has "read" access to the entire database.

\section{J-CORES in practice for the structural geologist}

Using the VCD program for real-time logging at the core table proved to be difficult for four main reasons. First, drawings are critical for structural description, yet they cannot be entered into the program via the tablet PC. Second, the handwriting recognition software is prone to errors. For example, the number 90 is commonly interpreted as the word "go," which yields an error message in the numberonly plane parameters box. This is particularly inconvenient because in a core reference frame the number 90 is used very often. Confusion also occurs between the numbers 1 and 7, which is somewhat more pernicious because it does not automatically yield an error message. Third, some numbers or combinations of numbers make the software systematically freeze, even if entered through a keyboard. Indeed, $\sim 3 \%$ of our fault data could not be entered into J-CORES because of apparent bugs. When such bugs are encountered, the data saved in the last $10 \mathrm{~min}$ are usually lost because apparently their upload to the server is not instantaneous. Finally, the J-CORES VCD program is not well adapted for documenting multiple data that are linked or genetically related (e.g., fault planes, slickenlines, and sense-of-slip data; fold axes and axial planes; and bedding and current lineations). There are two options for working around this limitation while inputting fault data (Fig. F15). The first option is to use one structure ID (e.g., "normal fault") and plane orientation and then enter the slickenline data in the comment box of the structure. In this case, the slickenline data are not exportable as an Excel spreadsheet. The second option is to enter two structure IDs ("normal fault" and "slickenline") at the same depth interval. In this case both data may be exported, but as separate sets (i.e., the slickenline is not bound to the fault). In very deformed sections, it becomes almost impossible to know which slickenline belongs to which fault. In addition, the rake data of the slickenline must also be entered into the comment box because conversion of rake data into trend/plunge data is not supported by the program. 
During Expedition 315, J-CORES proved to be a useful tool for data comparison and integration. We used the VCD program to develop a general overview of fault and shear zone densities throughout the cores. It was also used as a quick core photo display tool, convenient for the recognition of coherent intervals appropriate for paleomagnetic reconstruction work or for a quick recall of CT scan images.

\section{How to improve future versions of J-CORES for structural geologists}

Practical experience garnered during Expedition 315 reveals a number of positive and negative aspects of J-CORES. Specific recommendations for improvement are as follows:

- Enhance the handwriting recognition software,

- Provide a means to record sketches,

- Correct the bugs related to the entry of numerical data,

- Increase the frequency and/or speed of data uploads to offset data loss as a result of crashes,

- Allow fault data to include kinematic information (i.e., lineation orientation and sense) as a single set in any format (strike, dip; dip direction, dip; strike, dip, dip quadrant; or slickenline rake or trend),

- Allow direct copy and paste of the data to and from the J-CORES database (e.g., from the JCORES database to Excel and vice versa), and

- Reduce the number of icons to click on for one action (e.g., skip Apply before Save when entering a new structure).

\section{Biostratigraphy \\ Calcareous nannofossils}

Calcareous nannofossil biostratigraphic classification of sedimentary sequences recovered during Expedition 315 follows the recent review by Raffi et al. (2006), who astrobiochronologically calibrated Pleistocene to late Oligocene calcareous nannofossil datum events. Astrochronological age estimates for the Neogene rely on the geologic timescale developed by the International Commission on Stratigraphy (ICS) in 2004 (Lourens et al., 2004). Included biohorizons are based on standard nannofossil zonations established by Martini (1971) and Okada and Bukry (1980) with zonal modifications by Young (1999). Size-defined species of the genera Gephyrocapsa and Reticulofenestra were placed into size categories as proposed by Young (1999) instead of referring to species names, which vary widely among different authors. Consequently, in the late Pleistocene the abundance change between Gephyrocapsa spp. (>3.5 $\mu \mathrm{m})$ and Emiliania huxleyi was used instead of the crossover between Gephyrocapsa caribbeanica and E. huxleyi.

Biostratigraphic event zonal markers for the Cenozoic are shown in Figure F16, along with events defining zonal boundaries and additional biohorizons. In Table T5, well-dated nannofossil datums used during Expedition 315 are listed.

\section{Methods}

For nannofossil analyses, the core catcher sections of each core were sampled. Samples from other sections were sometimes included when nannofossils were not abundant in core catcher material. Preparation of smear slides for light microscope examination followed standard procedures. Taxon identification was carried out under plane- and cross-polarized light using a Zeiss Axio Imager.A1m microscope at 1250x magnification. Abundance, preservation, and zonal data for each sample investigated were recorded in the J-CORES database. To determine species abundance, specimens in 10-20 fields of view were counted, depending on overall nannofossil abundance. Moreover, the slide was scanned along its entire long axis for additional taxa. The following scale was used to estimate the relative abundances of individual taxa present in each sample:

$$
\begin{aligned}
& \mathrm{B}=\text { barren (none). } \\
& \mathrm{R}=\text { rare }(<0.1 \%) . \\
& \mathrm{F}=\text { few }(0.1 \% \text { to }<1 \%) . \\
& \mathrm{C}=\text { common }(1 \% \text { to }<10 \%) . \\
& \mathrm{A}=\text { abundant }(10 \%-50 \%) . \\
& \mathrm{D}=\text { dominant }(>50 \%) .
\end{aligned}
$$

Assessments of calcareous nannofossil preservation were based on the following criteria:

$\mathrm{P}$ = poor, severe dissolution, fragmentation and/ or overgrowth has occurred; primary features may have been destroyed, and many specimens can not be identified at the species level.

$\mathrm{M}$ = moderate, dissolution and/or overgrowth are evident; besides frequently broken nannofossils, the number of delicate forms is reduced.

$\mathrm{G}=$ good, little or no evidence of dissolution and/or overgrowth; diagnostic characteristics are preserved and nearly all species ( 95\%) can be identified.

$\mathrm{VG}=$ very good, no evidence of dissolution and/or overgrowth; diagnostic characteristics are preserved and all specimens can be identified. 
Some of the additional samples from core sections were only scanned for biostratigraphic key species without recording the abundances of the entire assemblage. These samples were not included in the range charts (see the "Expedition 314 Site C0001" chapter) but may be listed in the table of nannofossil events (Table T5).

\section{Planktonic foraminifers}

The planktonic foraminifer zonation of Blow (1969) and astronomically calibrated biohorizons of Neogene planktonic foraminifers compiled by the ICS in 2004 (Lourens et al., 2004) were applied for this expedition. In addition, useful biohorizons were employed from literature in the field and converted in age to the current geomagnetic polarity timescale (GPTS).

The last occurrence (LO) of Globigerinoides ruber rosa was located at $0.12 \mathrm{Ma}$ in the Indian and Pacific Oceans by Thompson et al. (1979) and confirmed by others (i.e., Li et al., 2005, at ODP Site 1143, South China Sea). The LOs of Neogloboquadrina asanoi and Globoquadrina dehiscens and the first occurrence (FO) of Globoconella inflata modern form were correlated with geomagnetic polarities at ODP Sites 1150 and 1151 off northeast Japan (Motoyama et al., 2004). The coiling direction change of Pulleniatina spp. from sinistral to dextral has been reported just above Chron C2n (Olduvai) in the Boso Peninsula of central Honshu, Japan (Oda, 1977). The FOs of Truncorotalia crassaformis hessi, Truncorotalia tosaensis, and Pulleniatina primalis; the first consistent occurrence of Neogloboquadrina acostaensis; and the LO of Paragloborotalia mayeri were compiled by Berggren et al. (1995) and converted in age to the current GPTS. These biozones and biohorizons are shown in Table T6 and Figure F16.

\section{Methods}

About $10 \mathrm{~cm}^{3}$ of sediment from core catcher sections was collected for foraminifer analyses. Soft sediment samples were disaggregated using hydrogen peroxide solution. Firm mudstone samples were treated by the sodium tetraphenylborate method (Hanken, 1979). After samples were macerated, each sample was wetsieved through a screen (63 $\mu \mathrm{m}$ opening). Planktonic foraminiferal specimens $>125 \mu \mathrm{m}$ were taken from the dried residues. Semiquantitative estimates of species were made of the relative abundance as follows:

$$
\begin{aligned}
+= & \text { present }(<4 \% \text { or species from samples yielding } \\
& <100 \text { total individuals). } \\
R= & \text { rare }(4 \% \text { to }<8 \%) . \\
C= & \text { common }(8 \% \text { to } 16 \%) . \\
A= & \text { abundant }(>16 \%) .
\end{aligned}
$$

Preservation of each sample was recorded by the following criteria:

$\mathrm{P}=$ poor, dissolution of surface structure and fragmentation are observed; most individuals cannot be identified at the species level.

$\mathrm{M}=$ moderate, dissolution and fragmentation are commonly evident; some individuals are hard to identify.

$\mathrm{G}=$ good, no dissolution; fragmentation of individuals has slightly occurred.

Abundance and preservation data for each sample investigated were uploaded into the J-CORES database.

\section{Paleomagnetism}

\section{Laboratory instruments}

The Paleomagnetism laboratory on board the Chikyu is located on the starboard side of the core processing deck. Most of the equipment is housed in a large $(7.3 \mathrm{~m} \times 2.8 \mathrm{~m} \times 1.9 \mathrm{~m})$ magnetically shielded room, with its long axis parallel to the ship transverse. The total magnetic field inside the room generally equals $1 \%$ of Earth's magnetic field. The room is large enough to comfortably handle standard IODP core sections $(\sim 150 \mathrm{~cm})$. The shielded room houses the equipment, instruments, and ancillary items described in this section.

\section{Superconducting rock magnetometer}

The 760-8.1 cm long-core superconducting rock magnetometer (2G Enterprises) unit is $\sim 6 \mathrm{~m}$ long. A $1.5 \mathrm{~m}$ split core liner passes through a magnetometer, an alternating-field (AF) demagnetizer, and an anhysteretic remanent magnetizer. The system includes three sets of superconducting pickup coils, two for transverse movement measurement ( $x$ - and $y$-axes) and one for axial moment measurement ( $z$ axis). These pickup coils have a large volume of uniform response to a small magnetic dipole. When a sample is inserted into the pickup coil region, persistent currents are generated in all three pickup coils. To prevent magnetic noise from being picked up from sources other than samples inserted into the system, both the pickup and coil structures and the direct-current superconducting quantum interference device (DC-SQUID) sensors have superconducting shields placed around them. The noise level of the magnetometer is $<10^{-4} \mathrm{~mA} / \mathrm{m}$ for a $10 \mathrm{~cm}^{3}$ volume sample. The superconducting rock magnetometer (SRM) dewar system has a capacity of 90 L of liquid helium. The magnetometer includes an automated sample handler system (2G804) consisting of aluminum and fiberglass channels designated 
to support and guide long core movement. The core itself is positioned in a nonmagnetic fiberglass carriage that is pulled through the channels by a pull rope attached to a geared high-torque stepper motor.

A 2 G600 sample degaussing system is coupled to the SRM to allow automatic demagnetization of samples up to $300 \mathrm{mT}$ with a standard air-cooled solenoid (model 2G601S) and up to $180 \mathrm{mT}$ with a transverse split pair (model 2G601T). The system is completely controlled by an external computer. Because it is used with the automatic sample handler, a complete sequence of measure and degauss cycles can be completed without removing the long core from the holder.

A 2 G615 anhysteretic remanent magnetization (ARM) system is included to enable magnetization of rock samples during demagnetization. Magnetization is achieved by applying a direct current (DC) magnetic field in the range of 0 to \pm 4 Gauss during the degaussing process.

\section{Spinner magnetometer}

A spinner magnetometer, model SMD-88 (Natsuhara Giken Co., Ltd.) is also available for remanent magnetization measurement. The noise level is $\sim 5 \times 10^{-7}$ $\mathrm{mAm}^{2}$. The measurable range is from $5 \times 10^{-6}$ to $3 \times$ $10^{-1} \mathrm{mAm}^{2}$. Five standard samples with different intensities are prepared to calibrate the magnetometer. Standard $2.5 \mathrm{~cm}$ diameter $\times 2.1 \mathrm{~cm}$ long samples can be measured in three or six positions, the hole sequence taking $\sim 1$ and 2 min, respectively. Remanent intensity of Expedition 315 samples prevented the use of the spinner magnetometer.

\section{Alternating-field demagnetizer}

The alternating-field demagnetizer DEM-95 (Natsuhara Giken Co., Ltd.) is set for demagnetization of standard discrete samples of rock or sediment. The unit is equipped with a sample tumbling system to uniformly demagnetize up to an AF peak of $180 \mathrm{mT}$.

\section{Anhysteretic remanent magnetization}

The DTECH alternating-field demagnetizer D-2000 is available to impart ARM to discrete samples, in which a DC magnetic field is produced continuously across the AF demagnetizer coil. The user can select the demagnetization interval over which the field is applied (maximum AF $=200 \mathrm{mT}$, maximum DC field $=1.5 \mathrm{mT}$ ), producing partial anhysteretic remanent magnetization.

\section{Thermal demagnetizer}

The thermal demagnetizer TDS-1 (Natsuhara Giken Co., Ltd.) has a single chamber for thermal demagne- tization of dry samples over a temperature range from room temperature to $800^{\circ} \mathrm{C}$. The boat holds up to 8 or 10 cubic or cylindrical samples, depending on the exact size. The oven requires a closed system of cooling water, which is conveniently placed next to the shielded room. A fan next to the $\mu$-metal cylinder that houses the heating system is used to cool samples to room temperature. The measured magnetic field inside the chamber is $\leq 10 \mathrm{nT}$.

\section{Anisotropy of magnetic susceptibility system}

The Kappabridge KLY 3, designed for anisotropy of magnetic susceptibility (AMS) measurement, is also available. Data are acquired from spinning measurements around three different axes. Deviatoric susceptibility tensor can then be computed. An additional measurement for bulk susceptibility completes the sequence. Sensitivity for AMS measurement is $2 \times$ $10^{-8}(\mathrm{SI})$. Intensity and frequency of field applied are $300 \mathrm{~A} / \mathrm{m}$ and $875 \mathrm{~Hz}$, respectively. This system also includes the temperature control unit (CS-3) for temperature variation of low-field magnetic susceptibility of samples.

\section{Pulse magnetizer}

The pulse magnetizer MMPM10 (Magnetic Measurement Ltd.) can produce a high magnetic field. A maximum field of $9 \mathrm{~T}$ with a $7 \mathrm{~ms}$ pulse duration can be produced by the $1.25 \mathrm{~cm}$ diameter coil. The 3.8 $\mathrm{cm}$ coil generates a maximum field of $2.9 \mathrm{~T}$. During Expedition 315, this apparatus was not operative.

\section{Fluxgate magnetometer}

The Walker portable three-axis fluxgate magnetometer (model FGM-5DTAA) measures small ambient fields with a range of $\pm 100 \mu \mathrm{T}$ and a sensitivity of 1 nT. The sensor fits into small spaces, such as the sample access tube of the cryogenic magnetometer. The magnetometer was also used to monitor the total field in the shielded room and as a thermal demagnetizer.

\section{Hall-effect magnetometer}

A Hall-effect magnetometer (model MG-5DP), capable of measuring DC and alternating current fields over three orders of magnitude $( \pm 0.01, \pm 0.1$, and \pm 1 $\mathrm{T}$ ), is available for calibrating demagnetization coils and measuring strong DC fields.

\section{Methods}

Remanent magnetization was measured using the shipboard long-core cryogenic magnetometer. Continuous core measurements were typically made at 5 $\mathrm{cm}$ intervals with $20 \mathrm{~cm}$ long headers and trailers. 
The response curve from the sensor coils of the cryogenic magnetometer was measured and corresponds to a region $\sim 20 \mathrm{~cm}$ wide (Fig. F17); therefore, only measurements taken every $20 \mathrm{~cm}$ are independent from each other. Measurements at core and section ends, whole-round locations and voids, and within intervals of drilling-related core disturbance were not measured or were removed during data processing. The background noise of the instrument, as well as the liquid helium boil-off, seem to be amplified by the ship's movement compared to shore-based instruments, and the first background noise estimate was $\sim 10^{-10} \mathrm{Am}^{2}$. The relatively large volume of core material within the sensing region compensates for the relatively high background noise, and with very few exceptions sediment magnetization was well above instrumental noise level.

\section{Sampling coordinates}

The standard IODP core coordinate system was used, where $+x$ is the vertical upward direction when the core (archive half) is on its curved side, $+y$ is the direction to the left along the split-core surface when looking upcore, and $+Z$ is the downcore direction (Fig. F18). Coordination of the ship's long-core magnetometer is shown in Figure F18, along with standard IODP core coordination. The "flipping" function of the control software (Long Core version 3.4) enables $180^{\circ}$ rotation of the $x$ - and $y$-axes about the $z$-axis. By switching, working and archive halves can be measured in the same coordination. AF demagnetization on the archive halves was performed routinely with the inline AF demagnetizer at typical fields of up to 20 or $30 \mathrm{mT}$ in order to avoid compromising future shore-based paleomagnetic studies. Occasionally we reached $80 \mathrm{mT}$, the maximum AF attainable field, on samples taken from working halves from intervals where a more precise direction was needed for structural correction purposes. Such a high $\mathrm{AF}$ value was required to overcome the drillinginduced overprint (see "Paleomagnetism" in the "Expedition 315 Site C0001" chapter).

\section{Paleomagnetic core reorientation}

Azimuthal orientation of drilled core material is of great importance when modeling directional properties of rock formations. Paleomagnetism can be used to determine the core azimuth by providing a reference direction from the drilled rocks. Paleomagnetic core reorientation has been used successfully for a number of years (e.g., Fuller, 1969; Kodama, 1984; Shibuya et al., 1991; Pares et al., 2007, in press). The procedure is based on determining the direction of stable remanent magnetization (either viscous rema- nent magnetization or primary magnetization) with respect to a common reference line that is scribed the length of the core. Provided that the reference magnetic pole is known, the orientation of the paleomagnetic vector is then used to restore the core azimuth. The horizontal component of the mean characteristic remanent magnetization (ChRM) direction makes an angle with the reference line, which specifies the rotation of the core relative to the geographic coordinates.

To restore core orientation to geographic coordinates, the mean paleomagnetic direction is computed for samples sharing a common reference line. We have systematically used the archive half, which is marked at the bottom with a single reference line (the working half has a double line). After visual inspection of the AF demagnetization plots, we determined whether the blanket demagnetization at the highest peak (typically $20 \mathrm{mT}$ ) truly reflects the ChRM of the sediments. Measurements made on the uppermost and lowermost $20 \mathrm{~cm}$ have been typically disregarded to avoid end-core effects.

Our assumptions are as follows:

- The true paleomagnetic direction points to present-day geographic north. A given section has enough measurements to average secular variation.

- Bedding is horizontal or subhorizontal.

- Core is vertical.

- Sedimentary unit is in situ and has not experienced any vertical axis rotation.

Physical properties of the cored sediment, including voids, drilling disturbance, and flow-in, have determined to large extent the applicability of the paleomagnetic method for core reorientation. Hence, our "mean directions" are based on the statistical analysis of individual sections (from $\sim 30$ to $150 \mathrm{~cm}$ long) only when there is no visual evidence for general core disturbance or twisting. Even so, we noticed seemingly undeformed core sections that showed evidence of severe core twisting (Fig. F19). We think that the origin of such core twisting, when using the HPCS, is related to the extraction of the liner from the barrel when the core is on board. In order to extract the liner, operators have to first remove the shoe, which requires twisting counterclockwise.

For intervals of particular interest for structural geology (see "Structural geology") we have taken two different approaches for core reorientation:

1. Discrete samples: small cubic $\left(8 \mathrm{~cm}^{3}\right)$ samples were cut from the working half in order to determine paleomagnetic direction. We used the "discrete sample" option of the SRM magnetom- 
eter. This allows automatically measuring up to six samples, $20 \mathrm{~cm}$ apart.

2. Biscuits: for homogeneous segments containing structures that had to be reoriented (see "Structural geology"), we measured entire (up to $\sim 15$ $\mathrm{cm})$ core segments. In this case, we measured the samples as "continuous samples" in the SRM, also $20 \mathrm{~cm}$ apart.

\section{Magnetic reversal stratigraphy}

Magnetic polarity was calculated using inclinationonly data from continuous core measurements. Site C0001 has a latitude of $33^{\circ} 14.5^{\prime}$, which translates into an expected inclination of $\sim 52^{\circ}$ for at least Neogene and Quaternary sediments. This inclination is high enough to base the polarity interpretation (normal or reversed) on the sign of the magnetic inclination (positive or negative).

Typical steps used to establish magnetic reversal stratigraphy included the following:

1. Visually inspect the demagnetization plots using the Long Core software.

2. Obtain remanent magnetization directions after $20 \mathrm{mT}$ or the highest (blanket) demagnetization step and group them by sections.

3. Locate disturbed and "flow-in" intervals in core descriptions and discard those intervals from the data set; also, for RCB cored sediments, determine the position of "biscuits" in order to group the paleomagnetic data accordingly.

4. Exclude the top and bottom $\sim 15 \mathrm{~cm}$ (response of the pick up coils is $\sim 20 \mathrm{~cm}$ ).

5. Check that there are at least four consecutive data points (= measuring intervals) with the same inclination sign to define a polarity chron.

Whenever possible, we offer an interpretation of the magnetic polarity, with the naming convention following that of correlative anomaly numbers prefaced by the letter C (Tauxe et al., 1984). Normal polarity subchrons are referred to by adding suffixes (e.g., n1, $\mathrm{n} 2$, etc.) that increase with age. For the younger part of the timescale (Pliocene-Pleistocene) we often use traditional names to refer to the various chrons and subchrons (e.g., Brunhes, Jaramillo, Olduvai, etc.). In general, polarity reversals occurring at core ends have been treated with extreme caution.

The ages of the polarity intervals used during Expedition 315 are a composite of four previous magnetic polarity timescales (Gradstein et al., 2004) (Table T7; Fig. F16).

\section{Discrete samples}

Discrete sampling ("routine sampling") was completed for shore-based detailed studies. On average, about one standard sample $\left(\sim 8 \mathrm{~cm}^{3}\right)$ was taken every $60 \mathrm{~cm}$, but the actual spacing largely depends on the properties of the core material (e.g., flow-in, coring disturbances, etc.) and the preliminary paleomagnetic record obtained with the pass-through magnetometer. A few pilot specimens were demagnetized on board using both AF and thermal demagnetization. Results are shown in the corresponding summary.

\section{Data reduction and software}

Data visualization is possible because of the Long Core software that controls the SRM. However, that facility doesn't allow any computation of ChRM directions. The following programs have been used to interpret data (Tauxe, 1998):

- "plotdmag" makes orthogonal and equal area projections of input demagnetization data.

- "boodi" calculates bootstrap statistics for a group of vectors.

- "plotdi" makes equal area plots of data, with uncertainties.

- "pca" calculates a best-fit line through specified data.

- "incfish" estimates the Fisher mean inclination and 95\% confidence bounds from inclinationonly data using the method of McFadden and Reid (1982).

\section{Inorganic geochemistry Interstitial water collection}

Shipboard interstitial water samples were generally obtained from 20 to $45 \mathrm{~cm}$ long whole-round cores from the bottom of the third section of each core (labeled "Section 4"). Three whole-round cores were collected from the uppermost $10 \mathrm{~m}$. These cores consisted of a clay matrix, and core recovery was adequate to produce at least five sections. Whole-round samples were sectioned and capped upon core recovery in the core cutting area and taken to the laboratory for immediate X-ray CT scanning. Provided no significant sedimentary or tectonic structures were observed in X-ray CT images, these samples were placed in a nitrogen-filled glove bag and flushed with nitrogen gas three times before squeezing. When there were too many samples to process immediately, samples were sealed in a small nitrogenfilled plastic bag and stored in a $4^{\circ} \mathrm{C}$ refrigerator until further processing. 
The core liner was extracted from a whole-round core while it remained in a nitrogen-filled glove bag. The surface of each whole-round core was carefully scraped to avoid sediments that had potentially been contaminated from seawater, drilling fluid, oxidation, and smearing in the core liner. The clean inner parts of the core were then placed into a Manheimtype titanium squeezer (Manheim, 1966) and squeezed with a laboratory hydraulic press at gauge pressures up to $24,000 \mathrm{lb}$ (with a piston diameter of 5 $\mathrm{cm}$, this translates to a pressure of $\sim 55 \mathrm{MPa})$. Interstitial water was passed through two rinsed filter papers fitted on two to four 300 mesh stainless steel screens at the bottom of the squeezer. Fluids from the squeezing process passed through a $0.45 \mu \mathrm{m}$ disposable filter into an acid-washed $(10 \% \mathrm{HCl}) 50 \mathrm{~mL}$ plastic syringe. Interstitial water was subsampled for shipboard and shore-based analyses. All high-density polyethylene (HDPE) sample vials intended for minor and trace element analysis were cleaned by immersion in $55^{\circ} \mathrm{C} 10 \%$ trace metal grade $12 \mathrm{~N} \mathrm{HCl}$ for a minimum of $24 \mathrm{~h}$ and were subsequently rinsed with Millipore $18.2 \mathrm{M} \Omega \cdot \mathrm{cm}$ Type 1 ultrapure (MilliQ) water and dried in a class 100 laminar flow clean hood.

All samples designated for shipboard minor and trace element analysis were acidified with subboiled $6 \mathrm{~N} \mathrm{HCl}$ at a ratio of $4 \mathrm{~mL}$ of subboiled $6 \mathrm{~N} \mathrm{HCl}$ per liter of sample at least $24 \mathrm{~h}$ prior to inductively coupled plasma-atomic emission spectroscopy (ICPAES) or inductively coupled plasma-mass spectrometry (ICP-MS) analysis to dissolve any metallic oxide precipitates that may have formed after squeezing. Subsamples were collected for shore-based isotopic $(\mathrm{O}, \mathrm{H}, \mathrm{Sr}, \mathrm{Cl}, \mathrm{Li}, \mathrm{B}, \mathrm{I}$, and $\mathrm{S})$, rare earth elements (REE), Cd, Y, transition metals, and U series analyses. These subsamples were stored in detergent or acidwashed HDPE bottles (REE, Cd, and Y samples were acidified with subboiled $6 \mathrm{~N} \mathrm{HCl}$ at a ratio of $4 \mathrm{~mL}$ of subboiled $6 \mathrm{~N} \mathrm{HCl}$ per liter of sample within a few days of sampling). Additional subsamples were distributed for analyses of dissolved organic/inorganic carbon in crimp-cap glass vials with $\mathrm{HgCl}_{2}$ and $\mathrm{HOSO}_{2} \mathrm{NH}_{2}$ and analyses of volatile fatty acids in precombusted glass vials that were transferred to a freezer held at $-20^{\circ} \mathrm{C}$.

\section{Interstitial water analysis}

Interstitial water samples were routinely analyzed for salinity as total dissolved solutes with an RX-5000 $\alpha$ refractometer (Atago) and for $\mathrm{pH}$ and alkalinity by Gran titration with a Metrohm autotitrator soon after interstitial water was extracted. The volume of titrant used for each analysis was recorded for future reference. Chloride concentration was measured on a $100 \mu \mathrm{L}$ subsample by titration using silver nitrate $\left(\mathrm{AgNO}_{3}\right)$ in a $0.2 \mathrm{M}$ sodium nitrate $\left(\mathrm{NaNO}_{3}\right)$ solution. International Association for the Physical Sciences of the Ocean (IAPSO) standard seawater was used as a quality control measure by repeated analysis until the relative standard deviation was a maximum of $0.8 \%$.

Sulfate and bromide concentrations were measured by ICS-1500 ion chromatography (Dionex) using subsamples that were diluted 1:100 $(10 \mu \mathrm{L}$ in $990 \mu \mathrm{L})$ with Milli-Q water. This dilution provided quality peak detection for chloride, bromide, and sulfate. Chloride data were used only to check the quality of the dilution step. IAPSO standard seawater aliquots $(2.5,5,7.5$, and $10 \mu \mathrm{L}$ in a total of $1000 \mu \mathrm{L})$ were analyzed at the beginning and end of each run as a quality control measure and to monitor potential drift in sensitivity throughout a particular run.

Dissolved phosphate concentration was measured using a colorimetric method with the aid of an UV2550PC spectrophotometer (Shimadzu) at an absorbance of $885 \mathrm{~nm}$. Because the concentration of phosphate in the analysis solution must be $<10 \mu \mathrm{M}$, an appropriate aliquot of sample or standard solution $(100$ or $600 \mu \mathrm{L})$ was diluted to $1.1 \mathrm{~mL}$ with Milli-Q water $(1000$ or $500 \mu \mathrm{L})$ in a plastic tube. The $2 \mathrm{~mL}$ mixed solution (ammonium molybdate, sulfuric acid, ascorbic acid, and potassium antimonyl tartrate) was added to the tube and was well mixed; the tube was capped and kept at room temperature to develop color. A calibration curve was provided from a series of phosphate standard solutions $\left(\mathrm{KH}_{2} \mathrm{PO}_{4}\right)$ of $25,50,50,75,100,200$, and $250 \mu \mathrm{M}$ with a reproducibility better than $0.3 \%$.

Dissolved ammonium concentration was also determined with the UV-2550PC spectrophotometer at an absorbance of $640 \mathrm{mM}$. Either 0.1 or $0.05 \mathrm{~mL}$ of sample aliquot was diluted with 1 or $2 \mathrm{~mL}$ Milli-Q water, $0.5 \mathrm{~mL}$ phenol ethanol, $0.5 \mathrm{~mL}$ sodium nitroprusside, and $1 \mathrm{~mL}$ oxidization solution (sodium hypochlorite and alkaline citrate) in a capped plastic tube and was kept in the dark at room temperature for $>3 \mathrm{~h}$ to develop color. A calibration curve was provided from a series of ammonium standard solutions $\left(\mathrm{NH}_{4} \mathrm{Cl}\right)$ of $0.5,1.0,2.0,5.0$, and $10 \mathrm{mM}$ with a reproducibility better than $0.3 \%$.

Concentrations of sodium, magnesium, calcium, potassium, strontium, lithium, iron, manganese, barium, silicon, and boron were obtained by ICP-AES using an Ultima2 (Horiba Jobin Yvon) designed with a radial viewing plasma orientation and two Czerny Turner monochrometers for parallel analysis of sample elements and internal standards. The major ions $(\mathrm{Na}, \mathrm{Mg}, \mathrm{Ca}$, and $\mathrm{K})$ were diluted by a factor of 501 
by addition of a $30 \mu \mathrm{L}$ sample to $15 \mathrm{~mL}$ of $0.15 \mathrm{~N}$ nitric acid spiked with Y (10 ppm Y in a 1\% ultrapure double-distilled nitric acid solution). Standardization of the major ions was achieved by successive dilution of IAPSO standard seawater to $100 \%, 75 \%, 50 \%$, and $25 \%$ relative to the $1: 501$ primary dilution ratio. Because of the extremely high dilution ratio, no attempts were made to adjust for variable matrix effects. In the case of high $(>1 \mathrm{mM})$ concentrations of $\mathrm{Sr}$ and $\mathrm{Li}$ in samples, additional dilutions of IAPSO standard seawater were prepared and spiked with a range of $\mathrm{Li}$ and $\mathrm{Sr}$ primary standards to measure these elements along with the major cations. The minor ions ( $\mathrm{Sr}, \mathrm{Li}, \mathrm{Fe}, \mathrm{Mn}, \mathrm{Ba}, \mathrm{Si}$, and $\mathrm{B}$ ) were diluted by a factor of $20(0.5 \mathrm{~mL}$ sample with $9.5 \mathrm{~mL}$ of the same $10 \mathrm{ppm}$ Y solution described above). Because of the high concentration of matrix salts in the pore water samples at a 1:20 dilution, matrix matching of the calibration standards was necessary. The matrix solution that approximated IAPSO standard seawater major ion concentrations was prepared from the following salts in $1 \mathrm{~L}$ of Milli-Q water acidified with 4 $\mathrm{mL}$ of ultrapure double-distilled $6 \mathrm{~N} \mathrm{HCl}: 27 \mathrm{~g} \mathrm{NaCl}$, $3.8 \mathrm{~g} \mathrm{MgCl} 1.0 \mathrm{~g} \mathrm{CaCO}_{3}$, and $0.75 \mathrm{~g} \mathrm{KCl}$. No sulfate was added to the matrix because the pore water sulfate concentrations decreased rapidly in the first few cores. There was some concern that the salts used for the matrix were not trace metal grade, but analysis of the matrix solution revealed that the concentrations of minor elements in the matrix were less than or equal to the lowest standards analyzed and did not significantly affect the signal-to-noise ratio of the measurements. Because the matrix solution was not a true blank, the procedural blank used was a dilution of 1\% ultrapure nitric acid in the $\mathrm{Y}$ solution and only the slope of the calibration curve was used for quantification. A stock standard solution was prepared from ultrapure primary standards (SPC Science PlasmaCAL) in $1 \%$ ultrapure $15 \mathrm{~N}$ nitric acid. The relative concentrations of elements in the stock standard were adjusted based on results from Legs 131 and 190 because these samples were taken from sediments from similar geological conditions. The stock solution was then diluted in the same $1 \%$ nitric acid solution to concentrations of $50 \%, 25 \%, 10 \%, 5 \%$, and $1 \%$. A $1.25 \mathrm{~mL}$ aliquot of each stock solution was added to $8.75 \mathrm{~mL}$ of matrix to produce a series of standards that could be diluted using the same method as the samples for consistency. A copious supply of stock and matrix solutions was prepared during this expedition for use on the next expedition so that the analytical results of the two expeditions will be comparable. The final matrix-matched $100 \%$ standard solution contained the following concentrations of elements: $3000 \mu \mathrm{M} \mathrm{B}, 400 \mu \mathrm{M} \mathrm{Li}$, $1000 \mu \mathrm{M} \mathrm{Si}, 50 \mu \mathrm{M} \mathrm{Mn}, 50 \mu \mathrm{M}$ Fe, $400 \mu \mathrm{M}$ Sr, and
$200 \mu \mathrm{M} \mathrm{Ba}$. Because values of many of these elements in IAPSO standard seawater are either below detection limits (e.g., Fe and Mn) or variable, a 10\% matrix matched standard was repeatedly analyzed to calculate the precision of the method.

Several trace elements (V, Mn, Fe, Cu, Zn, Mo, Rb, $\mathrm{Cs}, \mathrm{Pb}$, and $\mathrm{U}$ ) were analyzed using an Agilent 7500ce ICP-MS equipped with an octopole reaction system to reduce polyatomic and double-charge interferences. To calibrate for interferences by the major ions $\mathrm{Na}, \mathrm{Cl}, \mathrm{K}, \mathrm{Ca}$, and $\mathrm{S}$ on some of the transition metals $(\mathrm{ClO}$ and $\mathrm{SOH}$ on $\mathrm{V}, \mathrm{Na}$ and $\mathrm{CaOH}$ on $\mathrm{Cu}$, and $\mathrm{S}$ on $\mathrm{Zn}$ ), solutions were prepared containing these elements at concentrations similar to IAPSO standard seawater values. These solutions were analyzed at the beginning of each run and an interference correlation was applied based on the average counts per second (cps) measured on the standard solutions divided by the abundance of the interfering elements. This ratio was multiplied by the known concentration of the major ions in the samples based on previous analysis, and the result was subtracted from the measured cps of the sample. Before diluting the samples, a $100 \mu \mathrm{L}$ aliquot of 500 $\mathrm{ppb}$ in standard was added to the empty analysis vials. Samples were then diluted into these vials to $3 \%$ in $1 \% \mathrm{HNO}_{3}(150 \mu \mathrm{L}$ sample with $4.85 \mathrm{~mL} 1 \%$ $\mathrm{HNO}_{3}$ ) based on previous determination of the detection limits and low concentrations of the elements of interest. A primary standard solution was made that matched the maximum range of predicted concentrations based on published results of deepsea pore fluid compositions in a variety of settings. The composition of the standard is as follows: 20 ppb V; 40 ppb $\mathrm{Cu}, \mathrm{Mo}, \mathrm{Pb}$, and U; 140 ppb Zn; 500 $\mathrm{ppb} \mathrm{Rb}$; and 5 ppb Cs. This primary standard was diluted in $1 \%$ ultrapure $15 \mathrm{~N}$ nitric acid to relative concentrations of $50 \%, 25 \%, 10 \%, 5 \%$, and $1 \%$. These standards were then diluted to $3 \%$, similar to the samples, with the addition of $150 \mu \mathrm{L}$ of a $560 \mathrm{mM}$ $\mathrm{NaCl}$ solution and $4.7 \mathrm{~mL}$ of $1 \% \mathrm{HNO}_{3}$ to account for matrix suppression of the plasma ionization efficiency. The $25 \%$ standard was diluted this way and analyzed every eight samples throughout every analysis series for precision and in order to correlate results from different analysis dates. Blanks were also analyzed every eight samples, and the detection limits were determined as three times the standard deviation of a procedural blank of Milli-Q water acidified with $4 \mathrm{~mL}$ of subboiled $6 \mathrm{~N} \mathrm{HCl}$ per liter. No standard reference material was available on the ship to verify the accuracy of the analysis. Accuracy was determined by analyzing 31 (40\%) of the interstitial water samples collected during the expedition using a high-resolution ICP-MS (Finnigan Element 2) at 
Moss Landing Marine Laboratories (Hulme et al., 2008). Generally, ship- and shore-based analyses agreed for $\mathrm{Cu}, \mathrm{Mo}, \mathrm{Pb}$, and $\mathrm{U}$. Minor adjustments to the shipboard $\mathrm{Rb}(10 \%)$ and Cs (20\%) were necessary. Shipboard V and Zn data were different from shore-based data and standard reference material by a factor of two, possibly indicating an issue with shipboard standards. Shore-based analysis also provides a measure of $Y$ concentration. Shore-based data are shown in tables and figures for both sites (see the "Expedition 315 Site C0001" and "Expedition 315 Site C0002" chapters).

\section{Oxygen and hydrogen isotopes}

Interstitial water was also measured for its stable isotopic compositions of oxygen $\left(\delta^{18} \mathrm{O}\right)$ and hydrogen $(\delta \mathrm{D})$ as primary shore-based analyses after the expedition. $\delta^{18} \mathrm{O}$ and $\delta \mathrm{D}$ values were determined with the mass spectrometer, Delta Plus XP with Gas Bench II (Thermo Finnigan), at New Energy Resources Research Center, Kitami Institute of Technology, Japan. Results were calculated in permil delta notation against the Vienna standard mean ocean water (VSMOW) with analytical precisions better than $0.1 \%$ for $\delta^{18} \mathrm{O}$ and better than $1 \%$ for $\delta \mathrm{D}$.

\section{GRIND method}

A method of pore water extraction for sediments with porosities $<40 \%$ was used during Expedition 315 . This method was initially developed by Cranston (1991) and later used by Wheat et al. (1994) to assess pore fluid composition under conditions where it was impossible to extract a sufficient supply for chemical analysis. During whole-round sampling of the uppermost 200 to $400 \mathrm{~m} \mathrm{CSF}$, a series of subsamples of $\sim 5$ to $10 \mathrm{~cm}$ of sediments were taken from samples when there was excess material after pore fluid extraction. These were taken to compare the GRIND results to traditional pore water extraction methods. Samples were initially scraped clean of the outer portions within the glove bag, wrapped in plastic wrap, and sealed in nitrogen-filled plastic bags. These were stored at $4^{\circ} \mathrm{C}$ for a period of 3 to 5 days.

Following the Cranston (1991) method, Milli-Q water was bubbled with nitrogen gas for a period of 48 $\mathrm{h}$ to remove dissolved oxygen. This water was then spiked with $10 \mathrm{ppm}$ In standard to a final concentration of $100 \mathrm{ppb}$. This concentration was chosen in order to reach a diluted concentration of $1 \mathrm{ppb}$ for ICP-MS analysis at 1\% dilution. The purpose of the In standard was to calculate the degree of mixing between the interstitial waters and the distilled water that is added as part of the method. Sealed samples were placed in a nitrogen-filled glove bag along with ball mill cylinders and the In solution. The samples were unsealed, broken into small pieces, and placed in the ball mill cylinders with three ceramic milling balls. Depending on the dryness of the samples and the volume of sample in the cylinders, between 1.5 and $3 \mathrm{~mL}$ of In solution was added prior to milling. A $3 \mathrm{~mL}$ subsample of the In solution was taken after each set of mills were filled. The milling cylinders were covered within the glove bag and taken immediately to the mill for grinding. The mill was operated at 400 rotations per minute (rpm) for a period of $5 \mathrm{~min}$, and afterward the containers were placed back into the glove bag. The milling cylinders were opened in the glove bag and the ground samples were squeezed using the same methods described above. The volume of In solution added to the sample, the volume recovered after squeezing, the time of sample processing, and the corresponding In solution subsample were recorded for each sample.

\section{Infrared thermal observation}

Because the dissociation of gas hydrates is an endothermic reaction, observation of low-temperature anomalies on the surface of the core liner provides a means to identify sections that contain or contained gas hydrate. Therefore, infrared thermal observation of the surface of the core liner was used during ODP Legs 201 and 204 and IODP Expedition 311 to identify the distribution of gas hydrates immediately before core disturbance because of their dissociation.

During Expedition 315, a handheld infrared camera, the ThermaCAM SC640 (FLIR Systems), was used to visualize temperature distributions of the surface of several core liners before cores were sectioned in the core cutting area. The initial purpose of thermal imaging is to rapidly identify gas hydrate-bearing sections for immediate sampling and for stabilizing and storing the gas hydrate in liquid nitrogen for future shore-based analyses. Infrared images were acquired from the cores between 0 and $450 \mathrm{~m}$ CSF, which are within the gas hydrate stability zone.

\section{Organic geochemistry}

Shipboard organic geochemical analyses included volatile hydrocarbon contents $\left(\mathrm{C}_{1}-\mathrm{C}_{4}\right)$; inorganic carbon and carbonate contents; and elemental analyses of total carbon, nitrogen, and sulfur. Procedures used during Expedition 315 follow Pimmel and Claypool (2001).

\section{Gas analysis}

A $5 \mathrm{~cm}^{3}$ sediment sample was collected with a cut-off plastic syringe, usually from the exposed end of Sec- 
tion 1 , and was extruded into a $20 \mathrm{~mL}$ glass vial. The vial was placed in an oven at $70^{\circ} \mathrm{C}$ for $30 \mathrm{~min}$. The evolved gases were analyzed using an Agilent $6890 \mathrm{~N}$ gas chromatograph (GC) equipped with a flame ionization detector (FID). This system determined the concentration of $\mathrm{C}_{1}-\mathrm{C}_{4}$ hydrocarbons with an FID. Chromatographic response on the GC was calibrated against five different authentic standards with variable quantities of low molecular weight hydrocarbons. When heavier molecular weight hydrocarbons $\left(\mathrm{C}_{3}\right.$ and higher) were detected, gas samples were analyzed on the natural gas analyzer (NGA). The NGA system consists of an Agilent 6890N GC equipped with four different columns, two detectors, both an FID and a thermal conductivity detector (TCD), and WASSON.ECE instrumentation. The NGA was used to measure $\mathrm{C}_{1}-\mathrm{C}_{13}$ hydrocarbons and nonhydrocarbons $\left(\mathrm{CO}, \mathrm{CO}_{2}, \mathrm{O}_{2}\right.$, and $\mathrm{N}_{2}$ ). Compositions of gases in sediments were analyzed in at least one horizon per core.

\section{Inorganic carbon}

Inorganic carbon concentrations were determined using a Coulometrics $5012 \mathrm{CO}_{2}$ coulometer. About $10-12 \mathrm{mg}$ of freeze-dried ground sediment was weighed and reacted with $2 \mathrm{M} \mathrm{HCl}$. The liberated $\mathrm{CO}_{2}$ was titrated, and the change in light transmittance was monitored with a photodetection cell. The weight percentage of calcium carbonate was calculated from the inorganic carbon content, assuming that all evolved $\mathrm{CO}_{2}$ was derived from dissolution of calcium carbonate, by the following equation based on molecular weight ratio:

$$
\mathrm{CaCO}_{3}(\mathrm{wt} \%)=8.33 \times \mathrm{IC}(\mathrm{wt} \%),
$$

where IC = inorganic carbon. All carbonate minerals were treated as $\mathrm{CaCO}_{3}$. Standard deviation for the samples is less than $\pm 0.12 \mathrm{wt} \%$.

\section{Elemental analysis}

Total carbon, nitrogen, and sulfur concentrations were determined using a Thermo Finnigan Flash EA 1112 CHNS analyzer with calibration using the synthetic standard sulfanilamide, which contains $\mathrm{C}$ (41.81 wt\%), $\mathrm{N}(16.27 \mathrm{wt} \%)$, and $\mathrm{S}(18.62 \mathrm{wt} \%)$. About $10-20 \mathrm{mg}$ freeze-dried ground sediment was weighed and placed in a tin container for carbon and nitrogen analyses. For sulfur analysis, the same amount of freeze-dried sediment was weighed and put in a tin container with the same amount of $\mathrm{V}_{2} \mathrm{O}_{5}$. Sediment samples were combusted at $1000^{\circ} \mathrm{C}$ in a stream of oxygen. Nitrogen oxides were reduced to $\mathrm{N}_{2}$, and the mixture of $\mathrm{CO}_{2}, \mathrm{~N}_{2}$, and $\mathrm{SO}_{2}$ was sepa- rated by GC and detected by TCD. Total organic carbon content was calculated by subtraction of inorganic carbon from total carbon. Standard deviation of carbon, nitrogen, and sulfur for the samples is less than $\pm 0.1 \%$. Accuracy for carbon and sulfur analysis was confirmed using two Geological Society of Japan reference samples. Analytical accuracy for JMS-1 $(\mathrm{C}=$ $1.69 \mathrm{wt} \%$ and $\mathrm{S}=1.32 \mathrm{wt} \%)$ is $1.66 \pm 0.2 \mathrm{wt} \%(\mathrm{~N}=$ 12) for carbon and $1.28 \pm 0.06 \mathrm{wt} \%(N=11)$ for sulfur. Analytical accuracy for JMS-2 (C = $0.39 \mathrm{wt} \%$ and $\mathrm{S}=0.29 \mathrm{wt} \%)$ is $0.34 \pm 0.02 \mathrm{wt} \%(N=9)$ for carbon and $0.29 \pm 0.04 \mathrm{wt} \%(N=7)$ for sulfur. This accuracy includes weighing errors.

\section{Microbiology}

\section{Core handling and sampling}

\section{Whole-round cores}

Microorganisms in deep-sea sediments are expected to be sensitive to chemical and physical changes, particularly changes in oxygen, temperature, and pressure. Therefore, the core sections designated for microbiological sampling were transferred as quickly as possible from the rig floor to a refrigerator and were kept as whole sections until processed. However, because of the danger of explosion of core liners because of expanding sediment, some cores had to be kept on the rig floor for up to $3 \mathrm{~h}$ before X-ray CT scanning. Whole-round cores for microbiological analysis were cut based on X-ray CT scans. Our aim was to minimize potential contamination by selecting sections with minimal disturbance, such as voids or cracks. Three types of whole-round cores (10-20 $\mathrm{cm})$ were taken for microbiological analysis. The first type was subsampled on board for cell counting, cultivation assays, and deoxyribonucleic acid (DNA) and ribonucleic acid (RNA) isolation. The second type was taken for cultivation studies. These cores were brought quickly to an anaerobic glove box (Coy Laboratory Products, Inc.), placed into an anaerobic pouch (Mitsubishi Gas Chemical Co., Inc.) with AnaeroPack (Mitsubishi Gas Chemical Co., Inc.), sealed with a plastic clip, and stored at $4^{\circ} \mathrm{C}$ for shore-based studies. The third type was subsampled for cell counting and then immediately placed into a plastic bag and stored at $-80^{\circ} \mathrm{C}$ for onshore DNA-, RNA-, and intact polar lipids-based molecular analyses.

\section{Subsampling of soft and hard sediments}

Subsampling of soft-sediment whole-round cores was conducted with autoclaved tip-cut $5 \mathrm{~mL}$ syringes after scraping off the sediment surface with an ethanolwiped spatula. Subsampling was restricted to sediments at or near the center of the cores because core 
liners are not sterile and outer core surfaces are contaminated during drilling (Smith et al., 2000). For subsampling of semiconsolidated sediment, intact rock pieces were selected. The surface was washed with ethanol and/or scraped off with an ethanol-wiped spatula, and the rock was crushed with a hammer in an aluminum bag or ethanol-wiped aluminum folio.

\section{Subsample treatment}

Subsamples taken for DNA and RNA isolation were immediately frozen at $-80^{\circ} \mathrm{C}$. Subsamples taken for cell counting were fixed with $2 \%$ paraformaldehyde in phosphate-buffered saline (PBS; Invitrogen, $\mathrm{pH}$ adjusted to 7.6) overnight, washed two times with PBS, and finally stored in PBS:ethanol $(1: 1)$ at $-20^{\circ} \mathrm{C}$. Subsamples taken for cultivation assays were immediately placed into anaerobic serum bottles containing $35 \mathrm{~g} / \mathrm{L}$ of Sigma sea salts (pH adjusted to 7.2) under counterflow of sterile-filtered (pore size $=0.22$ $\mu \mathrm{m})$ nitrogen. The slurries were homogenized by repeated shaking and vortexing and were stored at $4^{\circ} \mathrm{C}$. Subsamples of the slurries were used for cultivating heterotrophic sulfate-reducing bacteria in a modified DSMZ medium 1040 (Table T8). Acetate, lactate, pyruvate, and ethanol (10 $\mathrm{mM})$ were used as organic carbon and electron sources. Liquid cultures were incubated at different temperatures $\left(9^{\circ}, 37^{\circ}\right.$, $50^{\circ}$, and $70^{\circ} \mathrm{C}$ ) until the end of the expedition. Incubation will be continued on shore.

\section{Drilling mud sampling}

As it was not possible to do perfluorocarbon tracer contamination tests on board, preused drilling muds (seawater gel and kill mud) were used as control samples for microbiological analysis. Seawater gel $(\mathrm{pH}=$ 12.3) is a seawater-based bentonite mud used for drilling and coring throughout entire sections. It contains $0.5 \mathrm{~m}^{3}$ seawater, $0.5 \mathrm{~m}^{3}$ drill water, $60.0 \mathrm{~kg}$ bentonite, $2.0 \mathrm{~kg}$ caustic soda, and $2.0 \mathrm{~kg}$ lime. Kill mud is a freshwater-based, barite-weighted mud used to suspend or abandon the hole. It was not used before or during coring in this expedition. Kill mud (pH 11.3) contains $1 \mathrm{~m}^{3}$ drill water, $60.0 \mathrm{~kg}$ bentonite, $1.0 \mathrm{~kg}$ caustic soda, $2.0 \mathrm{~kg}$ XCD-polymer, and $40.0 \mathrm{~kg}$ barite. The density of both drilling muds is $1.05 \mathrm{~g} / \mathrm{cm}^{3}$. Mud samples were taken into autoclaved glass bottles and subsampled for cell counting, culturing, and molecular analysis. Subsamples for cell counting were fixed as described above. Subsamples for culturing and molecular analysis were stored at $4^{\circ} \mathrm{C}$ and $-80^{\circ} \mathrm{C}$, respectively.

\section{Cell detection by fluorescence microscopy}

Selected samples of fixed cells were stained on board with double-stranded DNA-binding SYBR Green I stain for detecting cells (Lunau et al., 2005). Before staining, the fixed sediment slurry was vortexed and diluted in PBS:methanol (9:1). The mixture was sonicated at $50 \mathrm{~W}$ for $1 \mathrm{~min}$ with an ultrasonic homogenizer UH-50 (SMT Co., Ltd), and sediment particles were removed by centrifuging at $100 \mathrm{~g}$ for $2 \mathrm{~min}$. An aliquot of the supernatant was mixed with $5 \mathrm{~mL}$ PBS and filtered through a black $0.2 \mu \mathrm{m}$ pore-sized polycarbonate filter. The filter was washed twice with PBS and placed on an object glass. A coverslip was mounted on the filter with $8 \mu \mathrm{L}$ of SYBR Green I staining solution. Cells were viewed with an epifluorescence microscope (ZEISS Axioplan 2 imaging microscope), and images were taken with a ZEISS AxioCam HRc camera and AxioVision AC software.

\section{Physical properties}

Continuous physical property measurements provide basic information to assist characterization of lithologic units and states of consolidation and deformation, as well as correlation of cored materials with downhole logging data. First, X-ray CT images were captured for all core sections. Then, gamma ray attenuation (GRA) density, magnetic susceptibility, natural gamma radiation, $P$-wave velocity, and electrical resistivity were measured using an MSCL system (Geotek Ltd., London, UK) for whole-round core sections (MSCL-W) after thermal equilibration at room temperature, $\sim 20^{\circ} \mathrm{C}$. After MSCL-W measurements, thermal conductivity measurements were carried out on whole-round core sections for soft sediments and on split working-half cores for hard sediments and rocks. Digital photo image scanning and color spectrophotometry were carried out on the split surfaces of archive-half cores using the photo image capture logger (MSCL-I) and the color spectrophotometer (MSCL-C), respectively. MAD were measured on discrete subsamples collected from working-half core samples, as well as from clusters next to whole-round samples. Sediment shear strength was measured on working halves using vane shear and a penetrometer. $P$-wave velocity and electrical conductivity were measured in three orthogonal directions in $20 \mathrm{~mm}$ cubic samples. Details about each measurement are given below.

\section{MSCL-W}

\section{Gamma ray attenuation density}

A thin gamma ray beam was produced by a ${ }^{137} \mathrm{Cs}$ gamma ray source at a radiation level of $370 \mathrm{MBq}$ within a lead shield with a $5 \mathrm{~mm}$ collimator. The gamma ray detector comprised a scintillator and an integral photomultiplier tube. Calculation of bulk 
density from gamma ray attenuation was by the following equation:

$$
\rho=1 /(\mu \times d) \times \ln \left(I_{0} / I\right),
$$

where

$$
\begin{aligned}
& \rho=\text { sediment bulk density } \\
& \mu=\text { Compton attenuation coefficient, } \\
& d=\text { sample thickness, } \\
& I_{0}=\text { gamma source intensity, and } \\
& I=\text { measured intensity through the sample. }
\end{aligned}
$$

Because $\mu$ and $I_{0}$ are treated as constants, $\rho$ can be calculated from $I$. We used a set of aligned aluminum cylinders of various thicknesses, surrounded by distilled water in a sealed core liner used for drilling, for calibration. Gamma counts were taken through each cylinder for long count time (60 s), and $\ln (I)$ was plotted against $\rho \times d$. Here $\rho$ of each aluminum cylinder was $2.7 \mathrm{~g} / \mathrm{cm}^{3}$, and $d$ was $1,2,3,4,5$, or $6 \mathrm{~cm}$. The relationship between $I$ and $\rho \times d$ can be expressed as follows:

$$
\ln (I)=A(\rho \times d)^{2}+B(\rho \times d)+C,
$$

where $A, B$, and $C$ are coefficients determined during calibration. These coefficients varied slightly during the expedition. The MSCL provided the values of $I$ and $d$, and $\rho$ was calculated with the equation above.

This density measurement was conducted every 4 $\mathrm{cm}$ for $4 \mathrm{~s}$. The spatial resolution was $5 \mathrm{~mm}$, so each data point reflects the properties of the closest $5 \mathrm{~mm}$ interval.

Porosity $(\phi)$ is calculated from MSCL density assuming a solid grain density $\left(\rho_{\mathrm{s}}\right)$ of $2.7 \mathrm{~g} / \mathrm{cm}^{3}$ and a pore fluid density $\left(\rho_{\mathrm{f}}\right)$ of $1.024 \mathrm{~g} / \mathrm{cm}^{3}$ :

$$
\phi=\left(\rho_{\mathrm{s}}-\rho\right) /\left(\rho_{\mathrm{s}}-\rho_{\mathrm{f}}\right) .
$$

\section{Magnetic susceptibility}

Magnetic susceptibility is the degree to which a material can be magnetized by an external magnetic field. A loop sensor (MS2C; Bartington Instruments Ltd.) with an $8 \mathrm{~cm}$ loop diameter was used for magnetic susceptibility measurements. An oscillator circuit in the sensor produces a low-intensity $\left(8.0 \times 10^{-4}\right.$ $\mathrm{mA} / \mathrm{m}$ RMS) nonsaturating, alternating magnetic field $(0.565 \mathrm{kHz})$. Any material near the sensor that has a magnetic susceptibility causes a change in the oscillator frequency. This pulse frequency is then converted into magnetic susceptibility values. The spatial resolution of the loop sensor is $\sim 4 \mathrm{~cm}$ and accuracy is $5 \%$.
Like GRA density data, magnetic susceptibility data were obtained at $4 \mathrm{~cm}$ intervals with a $41 \mathrm{~s}$ acquisition time.

\section{Natural gamma radiation}

Natural gamma ray (NGR) emissions were recorded from all core sections to determine variations in the radioactive counts of the samples and for correlation with downhole NGR measurements. A lead-shielded counter, optically coupled to a photomultiplier tube and connected to a bias base that supplied high-voltage power and a signal preamplifier, was used. Two horizontal and two vertical sensors were mounted in a lead cube-shaped housing. Most X-ray emissions from rocks and sediment were produced by the decay of ${ }^{40} \mathrm{~K},{ }^{232} \mathrm{Th}$, and ${ }^{238} \mathrm{U}$, three long-period isotopes. Spatial resolution was $120-170 \mathrm{~mm}$, and NGR was measured every $15 \mathrm{~cm}$ for a $30 \mathrm{~s}$ period. Background radiation noise was $38 \mathrm{cps}$, measured by inserting a blank filled with distilled water.

\section{$\boldsymbol{P}$-wave velocity}

The basic relationship for sonic velocity is

$$
\mathrm{v}=d / t
$$

where

$$
\begin{aligned}
& d=\text { distance traveled through the core and } \\
& t=\text { traveltime though the core. }
\end{aligned}
$$

$P$-wave velocity transducers are mounted on the MSCL system and measure $d$ and $t$ horizontally throughout the whole core. Total traveltime measured between the transducers includes three types of "delay" as

$$
\begin{aligned}
t_{\text {delay }}= & \text { delay related to transducer faces and elec- } \\
& \text { tronic circuitry, } \\
t_{\text {pulse }}= & \text { delay related to the peak detection proce- } \\
& \text { dure, and } \\
t_{\text {liner }}= & \text { transit time through the core liner. }
\end{aligned}
$$

The effects of delays are calibrated using a core liner filled with pure water. For routine measurements on whole-round cores in core liners,

$$
v_{\text {core }}=\left(d_{\text {core }}^{\prime}-2 d_{\text {liner }}\right) /\left(t_{0}-t_{\text {pulse }}-t_{\text {delay }}-2 t_{\text {liner }}\right) \times 1000,
$$

where

$$
\begin{aligned}
& v_{\text {core }}=\text { corrected velocity through core }(\mathrm{km} / \mathrm{s}), \\
& d_{\text {core }}^{\prime}=\text { measured diameter of core and liner }(\mathrm{mm}), \\
& d_{\text {liner }}=\text { liner wall thickness }(\mathrm{mm}), \text { and } \\
& t_{0} \quad=\text { measured total travel time }(\mu \mathrm{s}) .
\end{aligned}
$$




\section{Electrical resistivity}

The noncontact resistivity sensor on the MSCL system operates by inducing a high-frequency magnetic field in the core from a transmitter coil, which in turn induces electrical currents in the core which are inversely proportional to the resistivity. Very small magnetic fields regenerated by the electrical current are measured by a receiver coil. To measure these very small magnetic fields accurately, a different technique has been developed that compares readings generated from the measuring coils to readings from an identical set of coils operating in air. Electrical resistivity data were obtained at $4 \mathrm{~cm}$ intervals.

\section{Thermal conductivity}

Thermal conductivity measurements were conducted on whole-round core samples from relatively shallow depths $(<230 \mathrm{~m} \mathrm{CSF})$ and on split halves of cores from depths $>230 \mathrm{~m}$ CSF.

A full-space single-needle probe TeKa TK04 unit (Blum, 1997) was utilized to measure thermal conductivity of unconsolidated sediments at three per core interval under conditions of full recovery. A small hole was drilled in the core liner, usually $26 \mathrm{~cm}$ from the top of each section. A $2 \mathrm{~mm}$ diameter temperature probe was inserted into the working half of the core section. At the beginning of each measurement, temperature in the samples was monitored automatically without applying a heater current until the background thermal drift was determined to be $<0.2 \mathrm{mK} / \mathrm{h}$. The heater circuit was then closed, and the temperature increase in the probe was recorded. During each $24 \mathrm{~h}$ period, three standard blocks with thermal conductivities of $0.517,1.237$, and $1.623 \mathrm{~W} /$ $(\mathrm{m} \cdot \mathrm{K})$, respectively, were probed. Measurement results were then plotted against true values, and the slope of the linear regression was obtained. This slope was used to calibrate core sample measurements. The reported thermal conductivity value for each sample is an average of three repeated measurements.

Because sediments become stiffer with increasing depth, thermal conductivity measurements were conducted on the split halves. A QTM-500 quick thermal conductivity was utilized to measure hard samples. At the beginning of each half-space thermal conductivity measurement, a $10 \mathrm{~cm}$ long split-core piece was taken from the working half of the core and placed in seawater at ambient temperature for $15 \mathrm{~min}$. The sample was then wrapped in stretchable plastic wrap. Care was taken to remove any visible air bubbles between the plastic wrap and the sample surface. The half-space probe was placed on a flat surface of the sample, and heating and measure- ments were done automatically. Calibration procedures are same as those used for whole-round samples.

\section{Moisture and density measurements}

MAD of rocks and sediments were calculated by measuring wet mass, dry mass, and dry volume. Approximately $5 \mathrm{~cm}^{3}$ samples were taken from two intervals (at $\sim 25$ and $100 \mathrm{~cm}$ from the top of the section as a convention) for each working-half section. For Hole C0002D cores, samples were taken from one interval for each section. In addition, MAD samples were routinely taken from the "cluster" slices next to wholeround samples (except for whole-round samples for microbiology). If the whole-round sampling location overlapped the regular MAD sampling intervals, no additional sample was taken.

In general, care was taken to sample undisturbed parts of the core and to avoid drill mud. Immediately after the samples were collected, wet sediment mass $\left(M_{\text {wet }}\right)$ was measured. Dry sediment mass $\left(M_{\text {dry }}\right)$ and volume $\left(V_{\text {dry }}\right)$ were measured after drying in a convection oven for $24 \mathrm{~h}$ at $105^{\circ} \pm 5^{\circ} \mathrm{C}$. Wet and dry masses were weighed using paired electronic balances, which compensated for the ship's heave. Dry volume was measured using a helium-displacement pycnometer (Quantachrome penta-pycnometer) with a nominal precision of $\pm 0.04 \mathrm{~cm}^{3}$. Measurements were repeated four times and the average of the last three measurements was used. Bulk density, dry density, and density of the solids, as well as porosity and moisture content, were computed, taking into account the precipitation of dissolved salts during drying (Blum, 1997).

\section{Shear strength measurements}

Undrained shear strength measurements were determined using a semiautomated laboratory vane shear device (Wykeham Farrance, model WF23544) and a pocket penetrometer (Geotest Instrument Co., model E-284B). Measurements were made at discrete locations on the working halves at a frequency of approximately three per core (at $100 \mathrm{~cm}$ from the top of Sections 2, 5, and 7 as a convention). In general, measurements were made adjacent to MAD sampling horizons. Care was taken to conduct tests within undisturbed and homogeneous parts of the core. To minimize disturbance effects resulting from the measurement itself, vane shear tests were generally conducted first, followed by penetrometer tests. Measurements were made with the vane rotation axis and penetrometer penetration direction perpendicular to the split surface. 
Vane shear strength $S_{\mathrm{u}(\mathrm{v})}(\mathrm{kPa})$ is calculated as

$$
S_{\mathrm{u}(\mathrm{v})}=T / K_{\mathrm{v}}
$$

where

$T=$ torque required to fail the material $(\mathrm{N} \cdot \mathrm{m})$ and

$K_{\mathrm{v}}=$ constant depending on vane dimensions $\left(\mathrm{m}^{3}\right)$ (Blum, 1997).

All measurements reported here were obtained using a vane with height and diameter of $12.7 \mathrm{~mm}$. Failure torque was determined by measuring the degrees of rotation of one of four torsional springs and a linear calibration equation (manufacturer specified) relating the rotation angle to torque for the particular spring being used. Selection of the appropriate spring was based on the anticipated shear strength of the material. Vane shear results were generally considered reliable for shear strength values less than $\sim 150$ to $200 \mathrm{kPa}$, above which excessive cracking and separation of the core material occurred.

The pocket penetrometer provides a measure of unconfined compressive strength in units of kilograms per centimeter squared. Compressive strength is calculated from the penetration resistance generated by pushing a cylindrical probe into the split core surface (Blum, 1997). Penetrometer-based shear strength $\left(S_{\mathrm{u}(\mathrm{p})}\right)$ is calculated as measured compressive strength converted to units of kilopascals and divided by two. Shear strength values reported here were calculated from the average of three penetration trials conducted at adjacent points on the core. Typical spatial separation between trials was on the order of $1 \mathrm{~cm}$. All measurements were obtained using a probe with a nominal diameter of $6.4 \mathrm{~mm}$ (0.25 inches). Tests were conducted for shear strength values up to a maximum of $\sim 300 \mathrm{kPa}$.

\section{MSCL-I: photo image logger}

The MSCL-I scans the surface of archive-half cores and creates a digital image. The line-scan camera equips three charge-coupled devices; each chargecoupled device has 1024 arrays. Light reflection from the sample surface passes through the lens and is split into three paths (red, green, and blue) by a beam splitter inside the line-scan camera. Then, each reflection is detected by the corresponding chargecoupled device. Finally, the signals are combined and the digital image is reproduced. Optical distortion downcore is avoided by precise movement of the camera. Spatial resolution is 100 pixels $/ \mathrm{cm}$.

\section{MSCL-C: color spectroscopy logger}

A color spectrophotometer (Konica-Minolta, CM$2600 d)$ is included on the MSCL-C system. The xyz- type aluminum frame allows operators to set a maximum of seven core sections on the tray, and the sensor unit (including the spectrophotometer and small distance measuring system using a laser sensor) moves over each section and down at each measurement point to measure the split archive core surface.

Light reflected from the sample surface is collected in the color spectrophotometer's integration sphere. The instrument's structure allows for the specular component to be included (SCI setting) or excluded (SCE setting). The SCE setting is the recommended mode of operation, especially for sediments, to exclude glare. The light is then divided into wavelengths at a $10 \mathrm{~nm}$ pitch (400-700 $\mathrm{nm}$ ), and the spectral sensors in the sphere convert the light to electrical currents proportional to the intensity of the light. Next, the color spectrum from the sample is normalized by the source light of the reflectance. The obtained spectrum is calibrated with the measurement of a pure white standard, which has a high reflectance true value at visible wavelengths and is measured by the vendor, and a black box (zero calibration). Measurements can be calculated based on the $2^{\circ}$ or $10^{\circ}$ standard observer and any of 11 illuminants.

Color reflectance is categorized as an IODP standard measurement, and the measured color spectrum is normally converted to $L^{*}, a^{*}$, and $b^{*}$ parameters. $L^{*}$, $a^{*}$, and $b^{*}$ provide relative changes in the composition of the bulk material and are widely used to correlate sections from core to core or hole to hole and to analyze the characteristic and cyclicity of lithologic changes.

\section{Anisotropies of $\boldsymbol{P}$-wave velocity and electrical resistivity}

Three directional measurements on discrete samples of $P$-wave velocity and electrical conductivity were performed on RCB cores. Core pieces were cut with a saw equipped with two parallel disks set at $20 \mathrm{~mm}$ spacing. This sample preparation enables measurement of both electrical conductivity and $P$-wave anisotropies. If the core has no (or subhorizontal) apparent stratification or foliation, cubes are cut with faces 1,2 , and 3 orthogonal to the $x$-, $y$ - and $z$-axes of the core reference, respectively. Orientation of the axes is the same as for paleomagnetism, with $Z$ pointing down along the core axis, $x$ - pointing into the working half, and $y$ - in the core face.

The sample is held between two stainless steel electrodes covered with filters soaked in seawater and the complex impedance $(\mathrm{R}+\mathrm{jX})$ is measured at 10 $\mathrm{kHz}$ between opposite cube faces with an Agilent 4263B component analyzer. Three such measure- 
ments may be performed along directions $x, y$, and $z$. The conductance tensor component (e.g., $\sigma_{x}$ ) along a given direction (e.g., $x$ ) is computed from the impedance measured along this direction and sample dimensions according to the formula

$\sigma_{\mathrm{x}}=\left(L_{\mathrm{x}} / L_{\mathrm{y}} L_{\mathrm{z}}\right)\left[\left(R_{\mathrm{x}}-R_{0}\right)-j\left(X_{\mathrm{x}}-X_{0}\right) /\left(R_{\mathrm{x}}-R_{0}\right)^{2}+\left(X_{\mathrm{x}}-X_{0}\right)^{2}\right]$,

where $L$ is the length and $R_{0}$ and $X_{0}$ refer to the measured impedance of the filter. Conductance tensor components $\sigma_{y}$ and $\sigma_{z}$ are obtained by substitution in this formula.

To measure $P$-wave velocity along a given direction, the sample is held with a force of $49 \mathrm{~N}$ (corresponding to a pressure of $120 \mathrm{kPa}$ ) between two transducers covered with rubber spacers. The emitter is connected to a pulse generator (Physical Acoustics C$101-\mathrm{HV})$; the receiver is connected to an oscilloscope synchronized with the pulse generator. The oscilloscope signal is transferred to a computer, and the arrival time is picked and logged automatically. This setup has a delay of $2.10 \mu \mathrm{s}$, which is subtracted from the arrival time to obtain the travel time. The velocity along a given direction is simply given by the length divided by the traveltime.

When three measurements are performed, the orientation of the tensor cannot be known. However, some simplification may be expected if the sample is almost transversely anisotropic around the axis perpendicular to the main foliation or stratification. The two following definitions appear convenient and are given here with electrical conductivity as example. Apparent anisotropy in the horizontal plane is

$$
\alpha_{1}=2\left[\left(\sigma_{x}-\sigma_{y}\right)\left(\sigma_{x}+\sigma_{y}\right)\right] .
$$

Apparent transverse anisotropy is

$$
\alpha_{T}=\left\{\left[\left(\sigma_{x}+\sigma_{y}\right) / 2\right]-\sigma_{z}\right\} /\left\{\left[\left(\sigma_{x}+\sigma_{y}\right) / 2\right]+\sigma_{z}\right\}
$$

for a truly transversely anisotropic medium, and in the core reference frame $(x, y$, and $z)$ the anisotropy ratio $\alpha=\alpha_{1} / \alpha_{T}$ is a function of the dip of the foliation in the sample.

\section{In situ temperature measurement}

In situ temperature measurement was carried out using the advanced piston coring temperature tool (APCT3) (Fig. F20), which is the third-generation tool of its kind used with the HPCS to measure downhole in situ temperatures. The APCT3 consists of three components: electronics, coring hardware, and software. During this expedition, in situ temperature measurement was basically done for every third core during HPCS coring in Holes C0001E and
C0001F from 13.60 to $170.98 \mathrm{~m} \mathrm{CSF}$ and in Hole C0002D from 15.38 to $158.97 \mathrm{~m}$ CSF. The sensor was calibrated for a working range of $0^{\circ}-45^{\circ} \mathrm{C}$.

The electronics fit into a special cutting shoe, which was lowered to the seafloor and shot into the formation. To equilibrate with seafloor temperature, the cutting shoe was held at the mudline for $\sim 5-10 \mathrm{~min}$ before penetration. After shooting, it takes $\sim 10 \mathrm{~min}$ for the sensor to equilibrate to the in situ temperature of the formation. Mud pumps need to be off during temperature equilibration. Shooting the barrel into the formation normally causes a rapid increase in temperature due to frictional heating. After that, temperature decreases with time along a decay curve. Temperature was measured as a time series with a sampling rate of $1 \mathrm{~s}$. Temperature data were logged onto a microprocessor within the downhole tool; when the tool was retrieved, data were downloaded to the computer.

A typical penetration curve exists of three parts: a rise in temperature at the beginning due to frictional heating, a decay curve as the sensor equilibrates to the in situ temperature of the sediment, and another rise while pulling the tool out (Fig. F21). In situ temperature was calculated by using the decay curve after penetration. Therefore, the interval used for calculation was not disturbed, for example, by vibration that causes frictional heating. Data were processed using the program TP-Fit, which runs on Matlab. The theoretical background of the program was provided by M. Heeseman (pers. comm., 2007). In situ temperatures could be calculated by using the decay curve.

\section{Core-log-seismic integration}

No logging was done during Expedition 315. The integration of LWD data with seismic reflection data at sites drilled during Expedition 315 was done during Expedition 314. Reference seismic profiles are prestack depth-migrated lines from the Center for Deep Earth Exploration (CDEX) 3-D block. Depths in the seismic line were fitted to LWD check shot data provided by the Expedition 314 Scientists, and we will rely on their work.

Integration of cores with LWD data relies primarily on lithologic boundaries, magnetic susceptibility, and NGR MSCL data. Details about MSCL measurements are described in "Physical properties." Magnetic susceptibility data were used for correlation between cores from different holes at the same site. NGR data were used for correlation between the cores and the log. The LWD geoVISION resistivity tool was used at Sites C0001 and C0002 and comprises NGR and resistivity measurement and imag- 
ery. Sonic log slowness data, gamma ray density, and neutron porosity are available from the other tools used and may also be compared with MSCL measurements on cores or with measurements on discrete samples (MAD and $P$-wave velocity measurements; see "Physical properties" for details). Core low-field magnetic susceptibility and NGR emissions were measured with the MSCL on whole-round sections every $4 \mathrm{~cm}$ and every 15 or $16 \mathrm{~cm}$, respectively. The magnetic susceptibility core log was of good quality overall and was filtered for voids and disturbed intervals according to the core density from gamma ray attenuation MSCL-W measurements. On HPCS and ESCS cores, magnetic susceptibility measurements made at intervals with measured density $<1500 \mathrm{~kg} /$ $\mathrm{m}^{3}$ (70\% porosity) were discarded. On RCB cores, the threshold was set to $1600 \mathrm{~kg} / \mathrm{m}^{3}$ (65\% porosity).

Mechanical difficulties prevented systematic NGR measurements on whole-round cores. Measurements on the archive half after splitting yield data with a higher noise level, but these data are still usable as a correlation tool. The unit of the MSCL-W gamma emission data is counts per second, and the only calibration is an ambient noise measurement ( 40 cps for MSCL-W). Values below 15 cps (or 55 cps before noise correction) were discarded because they often correspond to voids. Assuming the liner has negligible radioactivity, the ambient noise level should be the same when measuring the whole-round core or the archive half. Considering the symmetry of the gamma ray counting system, which comprises four detectors at $90^{\circ}$ angles, the number of counts from the half core should be half the number of counts from the whole-round cores. Comparison of data acquired on the same cores shows that applying a 38 cps ambient noise correction and a corrective factor of two to the archive half counts yields results consistent with measurements on whole-round cores (Fig. F22).

LSF is the depth reference. There are two definitions of core depth. In the standard definition of CSF (IODP Method A), the depth in the core is added to the depth of the drill bit at the beginning of coring. This definition leads to overlaps between expanded HPCS cores and, sometimes, between RCB cores when drilling fluid and/or cuttings enter the core barrel. The compressed core depth below seafloor (CSF-B; IODP Method B) is also given by J-CORES and corrects the discrepancy between the length of expanded cores and the advance of the drill bit by applying an arbitrary linear correction over the whole length of core. The correlation between core depth below seafloor and LWD depth below seafloor is based on this depth (rather than the Method A depth). Depth transfer functions are defined by lin- ear regression between correlated peaks. Cores with $<5 \mathrm{~m}$ of recovery do not generally provide useful constraints. On intervals with better recovery, several peak-to-peak correlations can sometimes be done within a single RCB core, and the Method B core depth log appears condensed by $5 \%$ to $30 \%$ with respect to LWD data. This indicates that partial recovery can spread over most of the cored interval, in contrast to the assumptions of the Method A depth definition.

\section{References}

Angelier, J., 1994. Fault slip analysis and palaeostress reconstruction. In Hancock, P.L. (Ed.), Continental Deformation: Tarrytown, NY (Pergamon Press), 53-100.

Berggren, W.A., Hilgen, F.J., Langereis, C.G., Kent, D.V., Obradovich, J.D., Raffi, I., Raymo, M.E., and Shackleton, N.J., 1995. Late Neogene chronology: new perspectives in high-resolution stratigraphy. Geol. Soc. Am. Bull., 107(11):1272-1287. doi:10.1130/00167606(1995)107<1272:LNCNPI>2.3.CO;2

Blow, W.H., 1969. Late middle Eocene to Recent planktonic foraminiferal biostratigraphy. In Brönnimann, P., and Renz, H.H. (Eds.), Proc. First Int. Conf. Planktonic Microfossils, Geneva, 1967: Leiden (E.J. Brill), 1:199-422.

Blum, P., 1997. Physical properties handbook: a guide to the shipboard measurement of physical properties of deep-sea cores. ODP Tech. Note, 26. doi:10.2973/ odp.tn.26.1997

Brothers, R.J., Kemp, A.E.S., and Maltman, A.J., 1996. Mechanical development of vein structures due to the passage of earthquake waves through poorly consolidated sediments. Tectonophysics, 260(4):227-244. doi:10.1016/0040-1951(96)00088-1

Cowan, D.S., 1982. Origin of "vein structure" in slope sediments on the inner slope of the Middle America Trench off Guatemala. In Aubouin, J., von Huene, R., et al., Init. Repts. DSDP, 67: Washington, DC (U.S. Govt. Printing Office), 645-650. doi:10.2973/dsdp.proc.67.132.1982

Cranston, R.E., 1991. Testing a higher resolution interstitial-water method for the Ocean Drilling Program. In Barron, J., Larsen, B., et al., Proc. ODP, Sci. Results, 119: College Station, TX (Ocean Drilling Program), 393-399. doi:10.2973/odp.proc.sr.119.173.1991

Fisher, A.T., and Underwood, M.B., 1995. Calibration of an $\mathrm{X}$-ray diffraction method to determine relative mineral abundances in bulk powders using matrix singular value decomposition: a test from the Barbados accretionary complex. In Shipley, T.H., Ogawa, Y., Blum, P., et al., Proc. ODP, Init. Repts., 156: College Station, TX (Ocean Drilling Program), 29-37. doi:10.2973/ odp.proc.ir.156.103.1995

Fuller, M., 1969. Magnetic orientation of borehole cores. Geophysics, 34(5):772-774.

GE Healthcare, 2006. LightSpeed Series Learning and Reference Guide-Multi Slice CT: Waukesha, Wisconsin (GE Healthcare), 936. 
Gradstein, F.M., Ogg, J.G., and Smith, A. (Eds.), 2004. A Geologic Time Scale 2004: Cambridge (Cambridge Univ. Press). http://www.stratigraphy.org/

Hanken, N.-M., 1979. The use of sodium tetraphenylborate and sodium chloride in the extraction of fossils from shales. J. Paleontol., 53(3):738-741.

Hulme, S.M., Wheat, C.G., Coggon, R.M., and McManus, J., 2008. Data report: trace element, Sr isotope, and Ge/ Si composition of fluids and sediments in ridge-flank low-temperature hydrothermal environments. In Fisher, A.T., Urabe, T., Klaus, A., and the Expedition 301 Scientists, Proc. IODP, 301: College Station, TX (Integrated Ocean Drilling Program Management International, Inc.). doi:10.2204/iodp.proc.301.202.2008

Kodama, K.P., 1984. Palaeomagnetism of granitic intrusives from the Precambrian basement under eastern Kansas: orienting drill cores using secondary magnetization components. Geophys. J. R. Astron. Soc., 76:273287.

Li, B., Jian, Z., Li, Q., Tian, J., and Wang, P., 2005. Paleoceanography of the South China Sea since the middle Miocene: evidence from planktonic foraminifera. In Wang, P., and Lipps, J. (Eds.), Marine Micropaleonotology of the South China Sea. Mar. Micropaleontol., 54(12):49-62. doi:10.1016/j.marmicro.2004.09.003

Lourens, L.J., Hilgen, F.J., Laskar, J., Shackleton, N.J., and Wilson, D., 2004. The Neogene period. In Gradstein, F.M., Ogg, J., et al. (Eds.), A Geologic Time Scale 2004: Cambridge (Cambridge Univ. Press), 409-440. http:// www.stratigraphy.org/

Lunau, M., Lemke, A., Walther, K., Martens-Habbena, W., and Simon, M., 2005. An improved method for counting bacteria from sediments and turbid environments by epifluorescence microscopy. Environ. Microbiol., 7(7):961-968. doi:10.1111/j.1462-2920.2005.00767.x

Manheim, F.T., 1966. A hydraulic squeezer for obtaining interstitial waters from consolidated and unconsolidated sediments. Geol. Surv. Prof. Pap. (U.S.), 550-C:256261.

Martini, E., 1971. Standard Tertiary and Quaternary calcareous nannoplankton zonation. In Farinacci, A. (Ed.), Proc. Second Planktonic Conf., Roma, 1970: Rome (Ed. Tecnosci.), 2:739-785.

Mazzullo, J., and Graham, A.G. (Eds.), 1988. Handbook for shipboard sedimentologists. ODP Tech. Note, 8. doi:10.2973/odp.tn.8.1988

Mazzullo, J.M., Meyer, A., and Kidd, R.B., 1988. New sediment classification scheme for the Ocean Drilling Program. In Mazzullo, J.M., and Graham, A.G. (Eds.), Handbook for Shipboard Sedimentologists. ODP Tech. Note, 8:45-67. doi:10.2973/odp.tn.8.1988

McFadden, P.L., and Reid, A.B., 1982. Analysis of paleomagnetic inclination data. Geophys. J. R. Astron. Soc., 69:307-319.

Mees, F., Swennen, R., Van Geet, M. and Jacobs, P., 2003. Applications of X-ray computed tomography in the geosciences. Geol. Soc. Spec. Publ., 215(1):1-6. doi:10.1144/GSL.SP.2003.215.01.01

Motoyama, I., Niitsuma, N., Maruyama, T., Hayashi, H., Kamikuri, S., Shiono, M., Kanamatsu, T., Aoki, K., Mor- ishita, C., Hagino, K., Nishi, H., and Oda, M., 2004. Middle Miocene to Pleistocene magneto-biostratigraphy of ODP Sites 1150 and 1151, northwest Pacific: sedimentation rate and updated regional geological timescale. Isl. Arc, 13(1):289-305. doi:10.1111/j.14401738.2003.00426.x

Nakano, T., Nakashima, Y., Nakamura, K., and Ikeda, S., 2000. Observation and analysis of internal structure of rock using X-ray CT. Chishitsugaku Zasshi, 106(5):363378.

Oda, M., 1977. Planktonic foraminiferal biostratigraphy of the Late Cenozoic sedimentary sequence, central Honshu, Japan. Sci. Rep. Tohoku Univ., Ser. 2, 48(1-2):1-76.

Ogawa, Y., 1980, Beard-like veinlet structure as fracture cleavage in the Neogene siltstone in the Miura and Boso Peninsulas, central Japan. Kyushu Daigaku Rigakubu Kenkyu Hokoku, Chishitsugaku, 13(2):321-327.

Okada, H., and Bukry, D., 1980. Supplementary modification and introduction of code numbers to the low-latitude coccolith biostratigraphic zonation (Bukry, 1973; 1975). Mar. Micropaleontol., 5:321-325. doi:10.1016/ 0377-8398(80)90016-X

Parés, J.M., Hassold, N.J.C., Rea, D.K., and van der Pluijm, B.A., 2007. Paleocurrent directions from paleomagnetic reorientation of magnetic fabrics in deep-sea sediments at the Antarctic Peninsula Pacific margin (ODP Sites 1095, 1101). Mar. Geol., 242(4):261-269. doi:10.1016/ j.margeo.2007.04.002

Parés, J.M., Schleicher, A.M., van der Pluijm, B., and Hickman, S., in press. Paleomagnetic reorientation of San Andreas Fault Observatory at Depth (SAFOD) core. Geophys. Res. Lett.

Petit, J.P., 1987. Criteria for the sense of movement on fault surfaces in brittle rocks. J. Struct. Geol., 9(5-6):597608. doi:10.1016/0191-8141(87)90145-3

Pimmel, A., and Claypool, G., 2001. Introduction to shipboard organic geochemistry on the JOIDES Resolution. ODP Tech. Note, 30. doi:10.2973/odp.tn.30.2001

Raffi, I., Backman, J., Fornaciari, E., Pälike, H., Rio, D., Lourens, L., and Hilgen, F., 2006. A review of calcareous nannofossil astrobiochronology encompassing the past 25 million years. Quat. Sci. Rev., 25(23-24):3113-3137. doi:10.1016/j.quascirev.2006.07.007

Richter, C., Acton, G., Endris, C., and Radsted, M., 2007. Handbook for shipboard paleomagnetists. ODP Tech. Note, 34. doi:10.2973/odp.tn.34.2007

Rothwell, R.G., 1989. Minerals and Mineraloids in Marine Sediments: An Optical Identification Guide: London, UK (Elsevier).

Shepard, F.P., 1954. Nomenclature based on sand-silt-clay ratios. J. Sediment. Petrol., 24(3):151-158.

Shibuya, H., Merrill, D.L., Hsu, V., and Leg 124 Shipboard Scientific Party, 1991. Paleogene counterclockwise rotation of the Celebes Sea-orientation of ODP cores utilizing the secondary magnetization. In Silver, E.A., Rangin, C., von Breymann, M.T., et al., Proc. ODP, Sci. Results, 124: College Station, TX (Ocean Drilling Program), 519_ 523. doi:10.2973/odp.proc.sr.124.169.1991

Smith, D.C., Spivack, A.J., Fisk, M.R., Haveman, S.A., and Staudigel, H., 2000. Tracer-based estimates of drilling- 
induced microbial contamination of deep sea crust. Geomicrobiol. J., 17(3):207-219. doi:10.1080/ 01490450050121170

Tauxe, L., 1998. Paleomagnetic Principles and Practice: Dordrecht, Netherlands (Kluwer Academic).

Tauxe, L., Tucker, P., Peterson, N.P., and LaBrecque, J.L., 1984. Magnetostratigraphy of Leg 73 sediments. In Hsü, K.J., LaBrecque, J.L., et al., Init. Repts. DSDP, 73: Washington, DC (U.S. Govt. Printing Office), 609-621. doi:10.2973/dsdp.proc.73.123.1984

Thompson, P.R., Bé, A.W.H., Duplessy, J.-C., and Shackleton, N.J., 1979. Disappearance of pink-pigmented Globigerinoides ruber at 120,000 $\mathrm{yr} \mathrm{BP}$ in the Indian and Pacific oceans. Nature (London, U. K.), 280(5723):554558. doi:10.1038/280554a0

Underwood, M.B., Basu, N., Steurer, J., and Udas, S., 2003. Data report: normalization factors for semiquantitative X-ray diffraction analysis, with application to DSDP Site
297, Shikoku Basin. In Mikada, H., Moore, G.F., Taira, A., Becker, K., Moore, J.C., and Klaus, A. (Eds.), Proc. ODP, Sci. Results, 190/196: College Station, TX (Ocean Drilling Program), 1-28. doi:10.2973/ odp.proc.sr.190196.203.2003

Wheat, C.G., Boulègue, J., and Mottl, M.J., 1994. A technique for obtaining pore water chemical composition from indurated and hydrothermally altered sediment and basalt: the ground rock interstitial normative determination (grind). In Mottl, M.J., Davis, E.E., Fisher, A.T., and Slack, J.F. (Eds.), Proc. ODP, Sci. Results, 139: College Station, TX (Ocean Drilling Program), 429-437. doi:10.2973/odp.proc.sr.139.234.1994

Young, J.R., 1999. Neogene. In Bown, P.R. (Ed.), Calcareous Nannofossil Biostratigraphy: Dordrecht, The Netherlands (Kluwer Academic), 225-265.

Publication: 5 March 2009

MS 315-122 
Figure F1. OsiriX screen shot of core with high gas content. Gas-filled voids appear as black vesicular texture (Section 315-C0001F-18H-1).

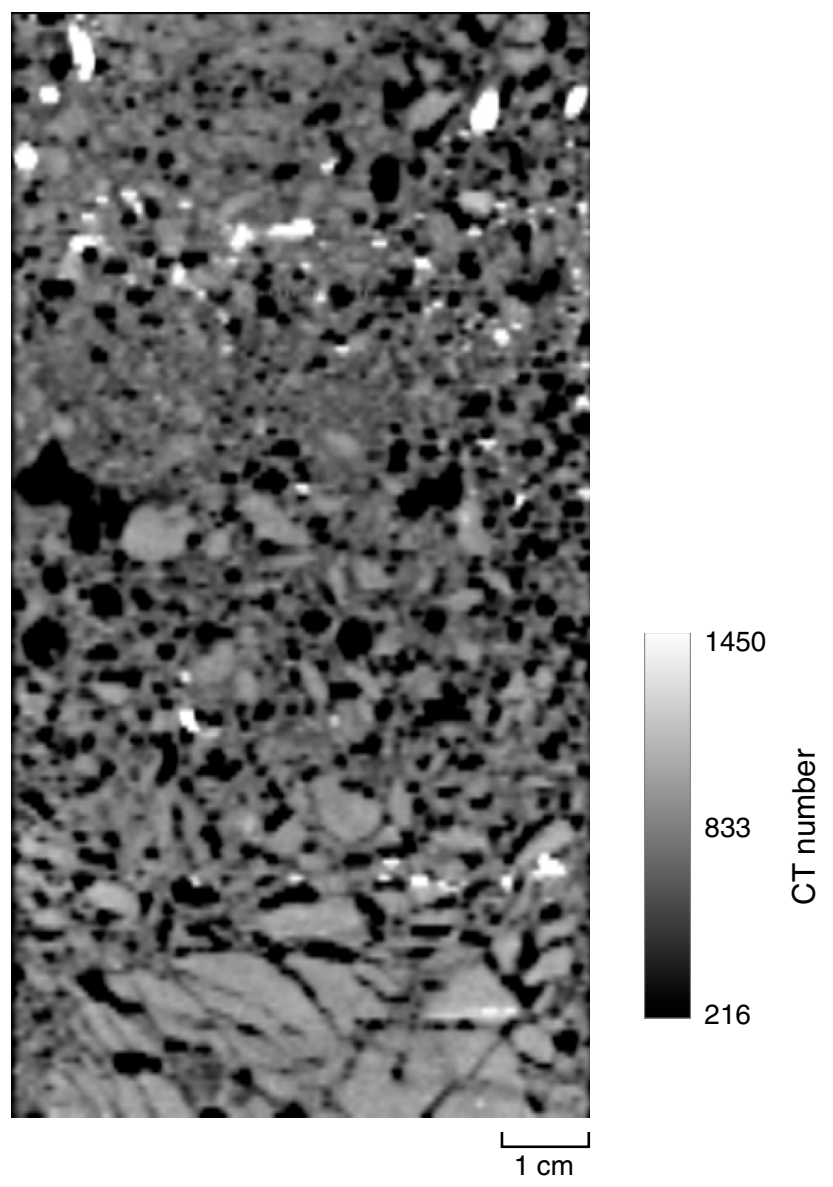


Figure F2. OsiriX screen shot of drilling-induced "biscuits" (Section 315-C0001F-20X-1).

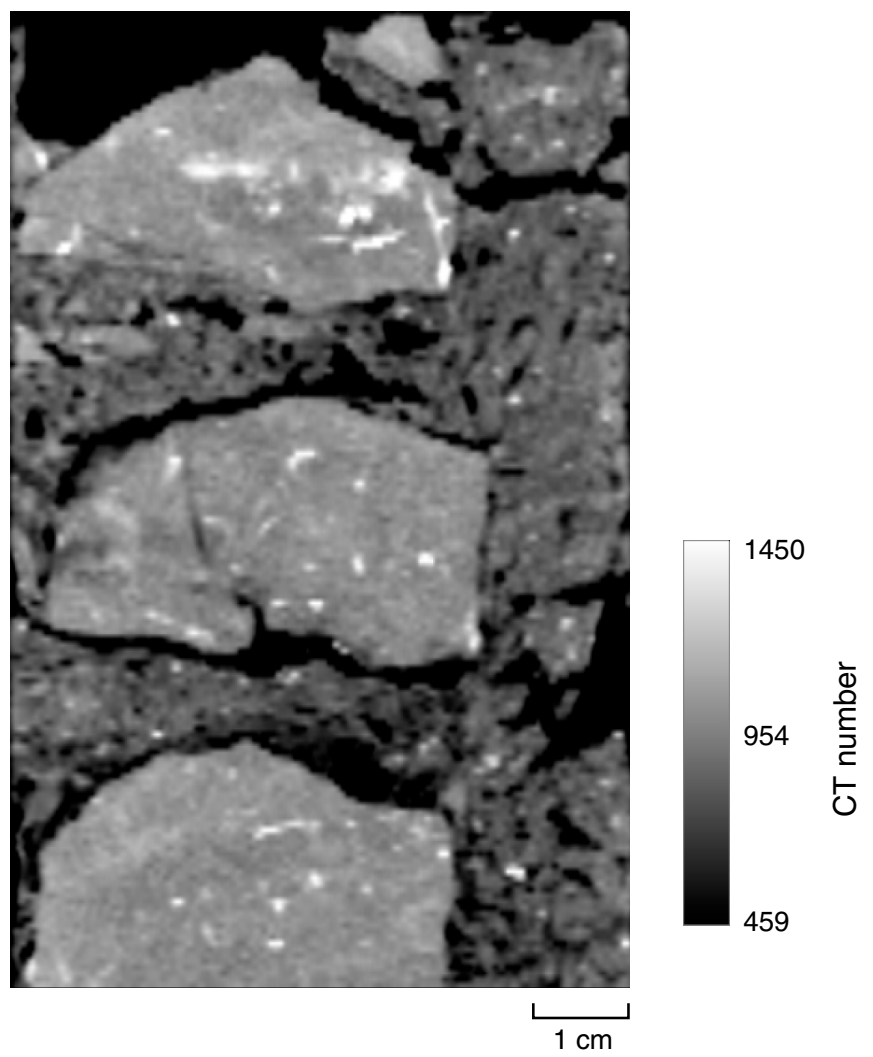


Figure F4. Graphic patterns and symbols used on visual core descriptions during Expedition 315.

\begin{tabular}{l} 
Lithology \\
\hline
\end{tabular}

Fossils

\begin{tabular}{|c|c|}
\hline गेठ & Shell fragment (undiff) \\
\hline & Wood fragment \\
\hline 0 & Bivalves \\
\hline & Organic materials \\
\hline & Foramnifers \\
\hline & Spicules (sponge) \\
\hline
\end{tabular}

Bioturbation

$\begin{array}{ll}\int & \text { Slight bioturbation } \\ \int S & \text { Moderate bioturbation } \\ \int S S & \text { Heavy bioturbation }\end{array}$

Sedimentary structure

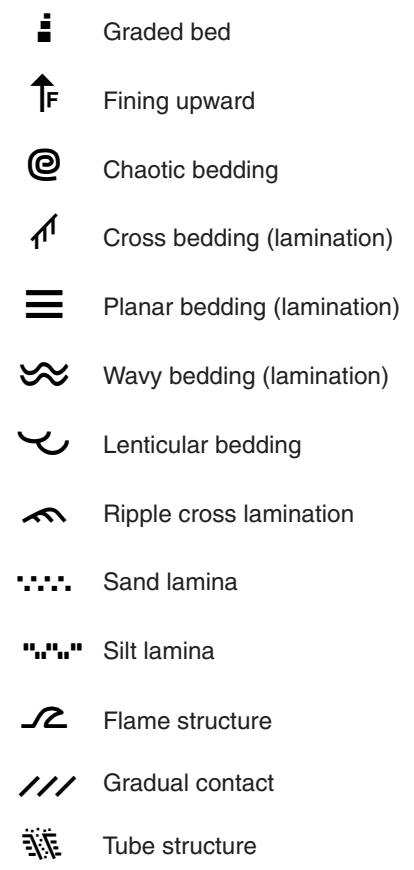

解 Tube structure

Deformation structure

\begin{tabular}{|c|c|}
\hline 坮 & Shear zone \\
\hline$\therefore$ & Fault breccia \\
\hline$-1 t$ & Extension fracture (tension fracture) \\
\hline & Shear fracture \\
\hline$B / s$ & Sediment-filled veins (vein structure) \\
\hline$\underline{I}$ & Clastic dike \\
\hline / & Dip-slip faults \\
\hline V/ & Normal fault \\
\hline $\mathbb{Z}$ & Reverse fault, thrust \\
\hline$X$ & Deformation bands \\
\hline$\Subset$ & Recumbent fold \\
\hline '尺̊' & Cylindroidal fold (cylindrical fold) \\
\hline$\equiv$ & Fissility \\
\hline 恣 & Striation, slickenline \\
\hline$=-$ & Bedding \\
\hline
\end{tabular}

Core disturbance (drilling and/or splitting)

: Slightly disturbed

! Moderately disturbed

+ Heavily disturbed

: Soupy

8 Biscuit

$1 /, \quad$ Slightly fractured

$\perp$ Moderately fractured

Highly fractured

๖ Drilling breccia

几 Flow-in

$\leftrightarrow \quad$ Gas expansion

Lithologic accessory
$\square$ Patch of minor lithology/Patch
Lth Synsedimentary clast (lithoclast)
GI Glauconite
? Other
(P) Pumice
......." Color banding
- Isolated pebble
$\$$ Crystalline precipitation
$\boldsymbol{\nabla \nabla}$ Mud clast
:-: Silt/Sand scattering
II Calcareous
- Black band
Py Pyrite 
Figure F5. Diffractograms of mixtures of standard minerals showing positions of diagnostic X-ray diffraction peaks used to calculate relative mineral abundances. $\mathrm{Cl}=$ total clay minerals, $\mathrm{Q}=$ quartz, $\mathrm{P}=$ plagioclase, $\mathrm{Cc}=$ calcite.
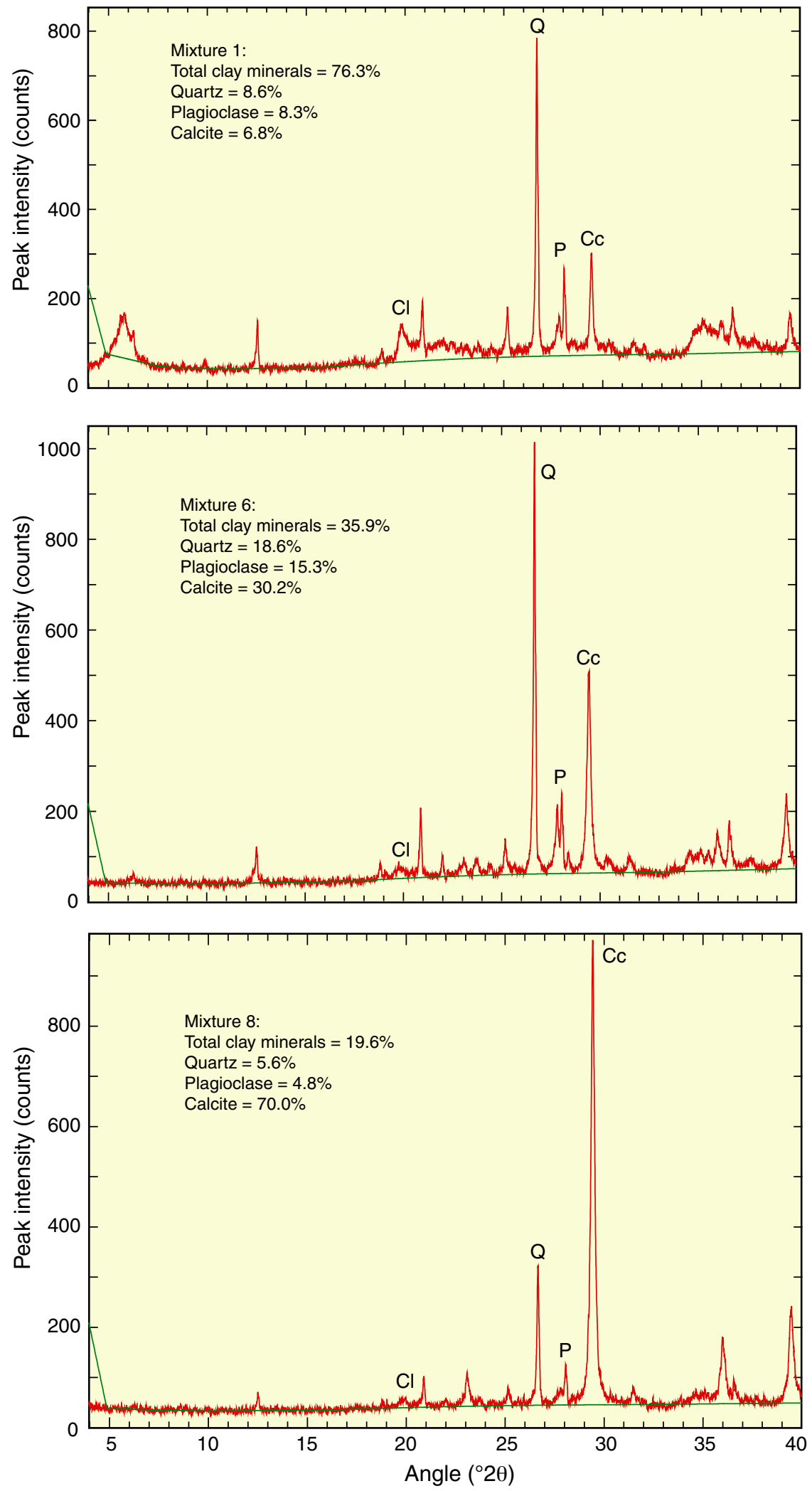
Figure F6. Modified protractor used to measure apparent dips, trends, plunges, and rakes on planar and linear features in a split core.

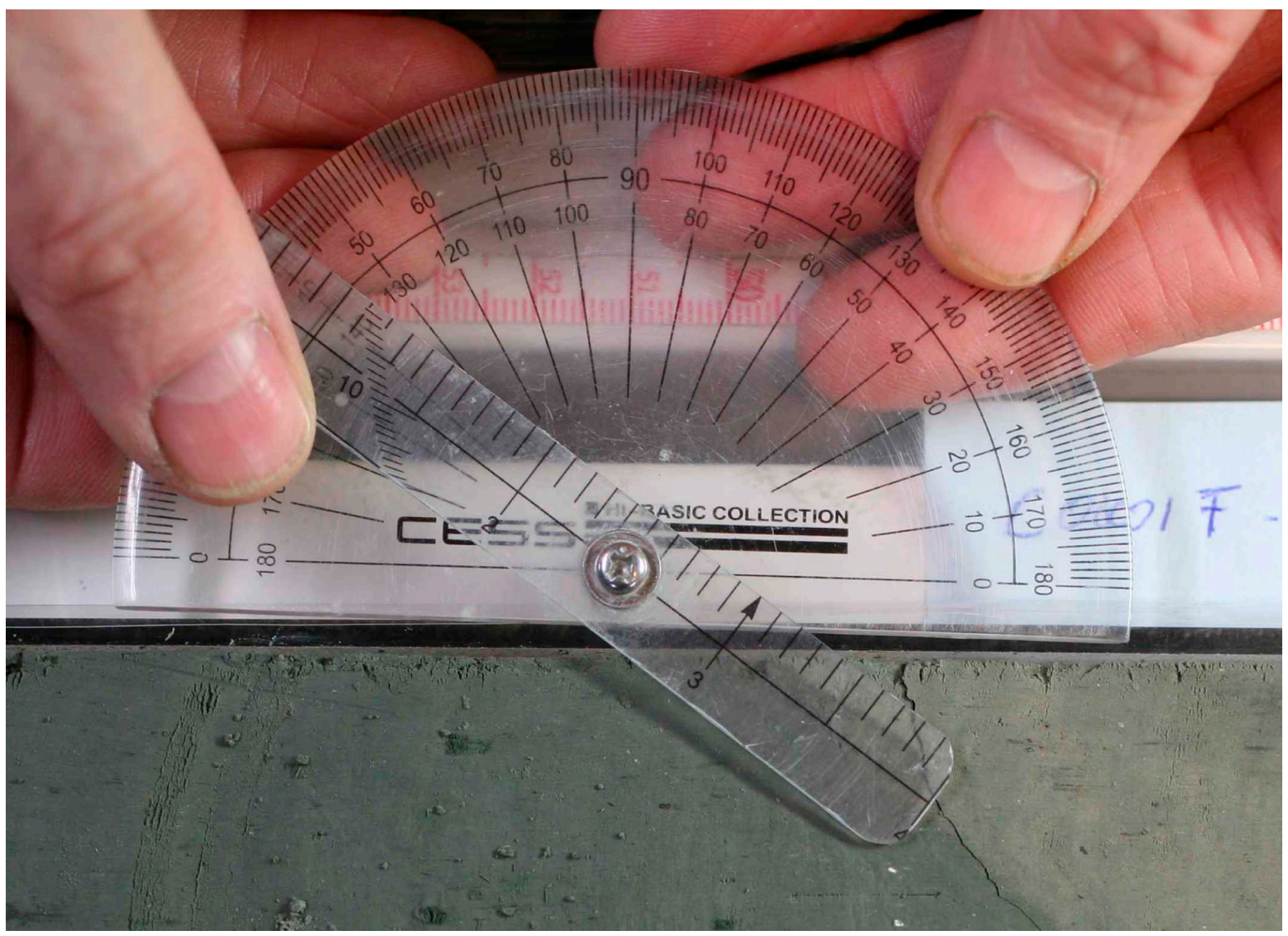




$$
\begin{aligned}
& \text { Structural Geology } \\
& \text { Exp:315 Site: } 00013 \text { Core: } 8 \mathrm{H} \text { Observer: Summary: }
\end{aligned}
$$

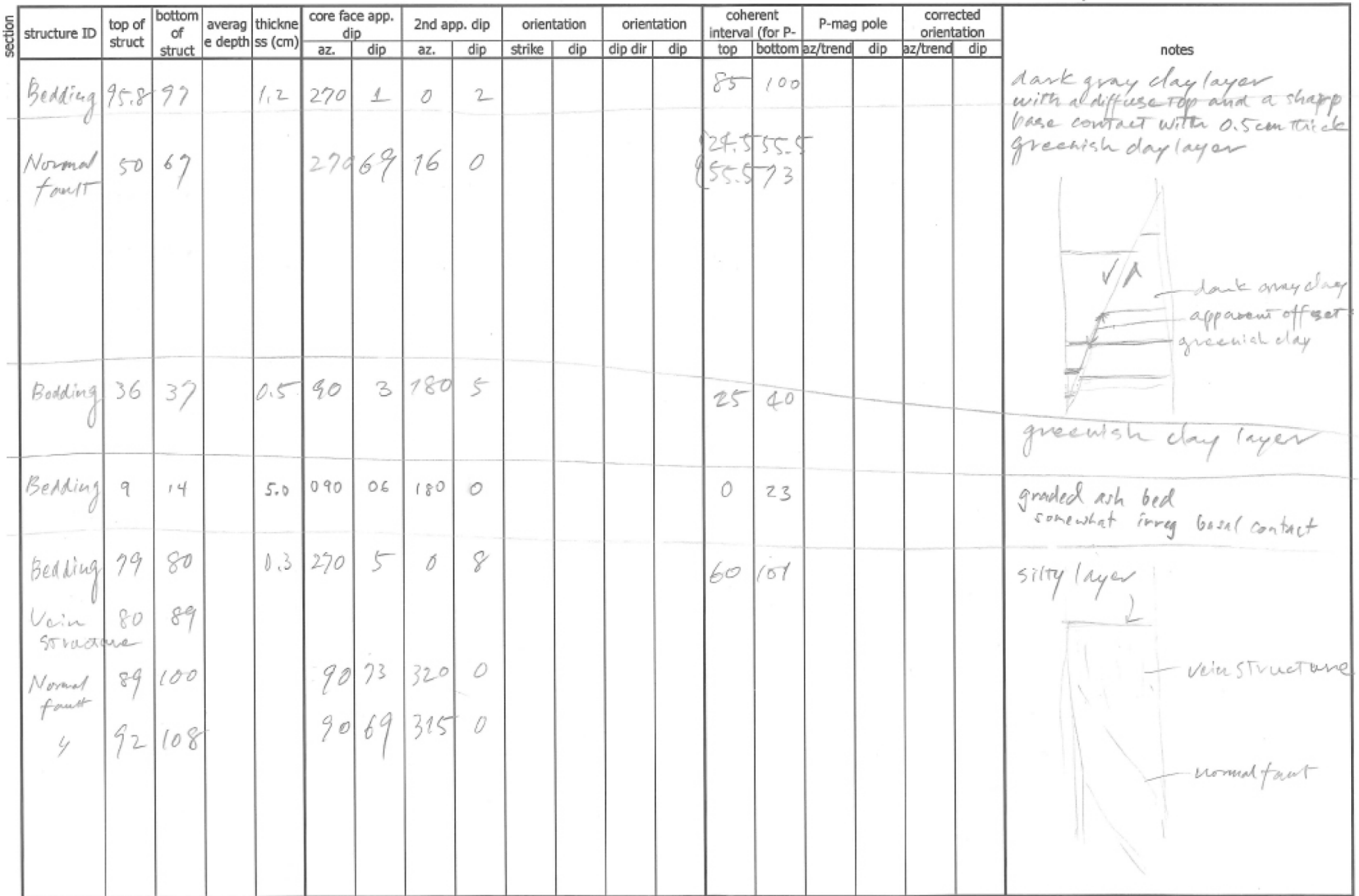


Figure F8. Spreadsheet used for recording and calculating orientation data. (This figure is also available in its original format; see STRUCT_FORM.EPS in 315_STRUCTURE in "Supplementary material.") (Continued on next page.)

\begin{tabular}{|c|c|c|c|c|c|c|c|c|c|c|c|c|c|c|c|c|c|c|c|c|c|c|}
\hline \multirow{2}{*}{$\frac{0}{0}$} & \multirow{2}{*}{ structure ID } & \multirow{2}{*}{$\begin{array}{l}\text { top of } \\
\text { struct }\end{array}$} & \multirow{2}{*}{$\begin{array}{c}\text { bottom of } \\
\text { struct }\end{array}$} & \multirow{2}{*}{$\begin{array}{c}\text { average } \\
\text { depth }\end{array}$} & \multirow{2}{*}{$\begin{array}{l}\text { thickness } \\
(\mathrm{cm})\end{array}$} & \multicolumn{2}{|c|}{$\begin{array}{c}\text { core face app. } \\
\text { dip }\end{array}$} & \multicolumn{2}{|c|}{ 2nd app. dip } & \multicolumn{2}{|c|}{$\begin{array}{c}\text { striation on } \\
\text { surface }\end{array}$} & \multicolumn{5}{|c|}{ plane-normal orientation } & \multicolumn{3}{|c|}{$\begin{array}{c}\text { plane orientation } \\
\text { (RHR) }\end{array}$} & \multicolumn{3}{|c|}{ fault } \\
\hline & & & & & & $\mathrm{az}$ & dip & $a z$ & dip & rake & from & I & $\mathrm{m}$ & $\mathrm{n}$ & $a z$ & dip & dip dir & strike & dip & csf rake & str rake & slip sense \\
\hline \multirow{19}{*}{$\begin{array}{ll} & 1 \mathrm{R} \\
& 13 \mathrm{R}\end{array}$} & \begin{tabular}{l|l}
1 \\
\end{tabular} & & & & & & & & & & & & & & & & & & & & & \\
\hline & 1 reverse fault & 124.0 & 140.5 & & $\leq 0.15$ & 270 & 78 & 341 & 0 & & & 0.32 & 0.92 & 0.20 & 71 & 11 & 251 & 161 & 79 & & 90 & $\mathrm{~T}$ \\
\hline & 2 reverse fault & 0.0 & 9.0 & & $\leq 0.3$ & & & & & & & 0.00 & 0.00 & 0.00 & 90 & 0 & 270 & 180 & 90 & & 90 & $\mathrm{~T}$ \\
\hline & 2 normal fault & 80.0 & 92.0 & & $\leq 0.2$ & 270 & 68 & 58 & 0 & & & -0.79 & 0.49 & 0.20 & 148 & 11 & 328 & 238 & 79 & & 90 & $\mathrm{~N}$ \\
\hline & 2 normal shear zone & 59.0 & 59.5 & & 0.50 & 90 & 4 & 0 & 0 & & & 0.00 & 0.07 & -1.00 & 90 & -86 & 90 & 0 & 4 & & 90 & $\mathrm{~N}$ \\
\hline & 2 bedding & 138.0 & 140.0 & & 0.50 & 90 & 5 & 180 & 5 & & & 0.09 & -0.09 & 0.99 & 315 & 83 & 135 & 45 & 7 & & & \\
\hline & 3 normal (?) fault & 16.5 & 26.0 & & 0.20 & 270 & 62 & 323 & 0 & & & 0.53 & 0.71 & 0.37 & 53 & 22 & 233 & 143 & 68 & & 90 & $\mathrm{~N}$ \\
\hline & 3 normal fault & 18.0 & 36.5 & & & 90 & 77 & 39 & 0 & 9 & 90 & -0.61 & 0.76 & -0.17 & 129 & -10 & 129 & 39 & 80 & 82 & 73 & $\mathrm{~N}$ \\
\hline & 3 shear band & 120.0 & 121.5 & & $\leq 0.1$ & 90 & 16 & 0 & 0 & 2 & 90 & 0.00 & 0.28 & -0.96 & 90 & -74 & 90 & 0 & 16 & 90 & 88 & \\
\hline & 3 normal (?) fault & 138.0 & 140.5 & & & 90 & 71 & 322 & 0 & & & 0.58 & 0.75 & -0.26 & 52 & -15 & 52 & 322 & 75 & & 90 & $\mathrm{~N}$ \\
\hline & 3 thrust & 135.0 & 139.5 & & & 270 & 38 & 180 & 12 & 7 & 270 & -0.16 & -0.60 & -0.77 & 255 & -50 & 255 & 165 & 40 & 102 & 109 & $\mathrm{~T}$ \\
\hline & 3 fault & 137.5 & 139.0 & & & 90 & 10 & 180 & 3 & 7 & 270 & 0.05 & -0.17 & 0.98 & 287 & 80 & 107 & 17 & 10 & 74 & 81 & $\mathrm{~T}$ \\
\hline & 4 normal (?) fault & 0.0 & 7.0 & & $\leq 0.3$ & 90 & 66 & 339 & 0 & & & 0.33 & 0.85 & -0.38 & 69 & -22 & 69 & 339 & 68 & & 90 & $\mathrm{~N}$ \\
\hline & 4 normal fault & 32.5 & 49.0 & & $\approx 0.1$ & 90 & 76 & 299 & 0 & 10 & 90 & 0.85 & 0.47 & -0.12 & 29 & -7 & 29 & 299 & 83 & 102 & 92 & $\mathrm{~N}$ \\
\hline & 6) thrust shear zone & 137.0 & 137.0 & & $\approx 0.1$ & 270 & 3 & 5 & 0 & & & 0.00 & 0.05 & 0.99 & 95 & 84 & 275 & 185 & 6 & & 90 & T \\
\hline & 6 shear zone & 138.0 & 138.0 & & & 270 & 2 & 2 & 0 & & & 0.00 & 0.03 & 1.00 & 92 & 87 & 272 & 182 & 3 & & & \\
\hline & 6 web structure & 138.0 & 140.5 & & & & & & & & & & & & & & & & & & & \\
\hline & 7 deformation band & 97.0 & 107.0 & & & 270 & 71 & 48 & 0 & & & -0.70 & 0.63 & 0.22 & 138 & 13 & 318 & 228 & 77 & & & \\
\hline & 7) deformation band & 97.0 & 107.0 & & & 270 & 90 & 0 & 0 & & & 0.00 & 1.00 & 0.00 & 90 & 0 & 270 & 180 & 90 & & & \\
\hline \multirow[t]{8}{*}{26} & \begin{tabular}{l|l}
1 & Loose breccia
\end{tabular} & & & & & & & & & & & & & & & & & & & & & \\
\hline & & & & & & & & & & & & 0.00 & 0.00 & 0.00 & 90 & 0 & 270 & 180 & 90 & & & \\
\hline & & & & & & & & & & & & 0.00 & 0.00 & 0.00 & 90 & 0 & 270 & 180 & 90 & & & \\
\hline & & & & & & & & & & & & 0.00 & 0.00 & 0.00 & 90 & 0 & 270 & 180 & 90 & & & \\
\hline & & & & & & & & & & & & 0.00 & 0.00 & 0.00 & 90 & 0 & 270 & 180 & 90 & & & \\
\hline & & & & & & & & & & & & 0.00 & 0.00 & 0.00 & 90 & 0 & 270 & 180 & 90 & & & \\
\hline & & & & & & & & & & & & 0.00 & 0.00 & 0.00 & 90 & 0 & 270 & 180 & 90 & & & \\
\hline & & & & & & & & & & $\leq 90$ & $\begin{array}{l} \pm 1,90 \\
\text { top-> }\end{array}$ & $\begin{array}{l}270 \\
"-1 "\end{array}$ & & & & & & & & & \multicolumn{2}{|c|}{ Red means uncertain dat } \\
\hline
\end{tabular}




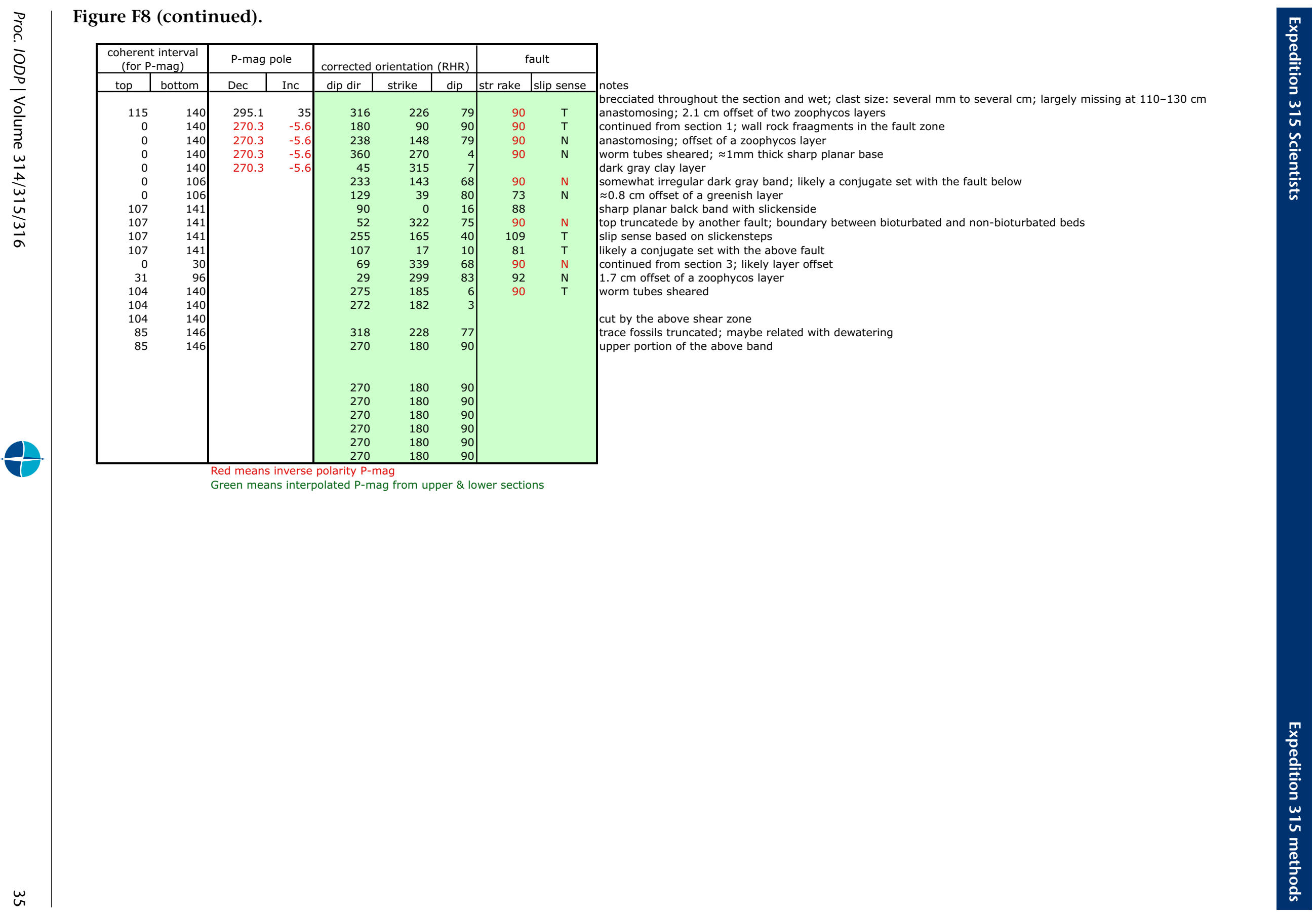


Figure F9. Core reference frame and $x-, y$, and $z$-coordinates used in orientation data calculations.

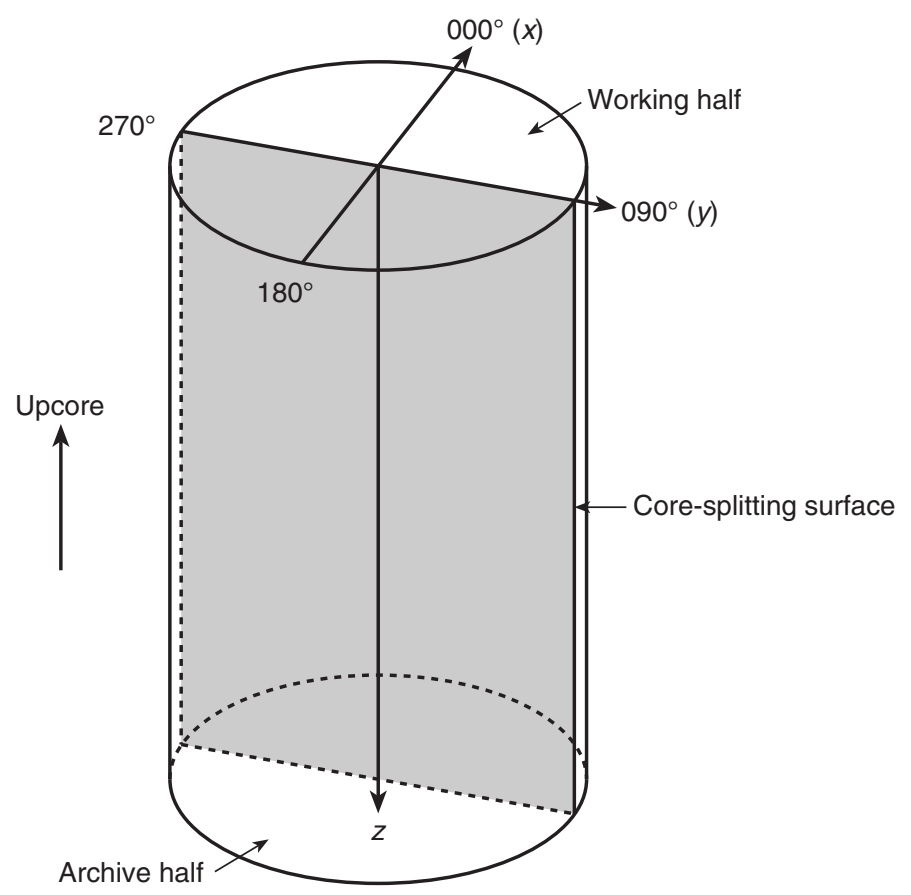


Figure F10. Calculation of plane orientation (shaded) from two apparent dips represented by unit vectors $v_{1}$ and $v_{2} . v_{1}$ and $v_{2}$ parallel the intersections of the plane of interest with two auxiliary planes, the split core surface and an imaginary plane perpendicular to the split core surface and parallel to the core axis. $\left(\alpha_{1}, \beta_{1}\right)$ and $\left(\alpha_{2}, \beta_{2}\right)$ $=$ trends and plunges $v_{1}$ and $v_{2}$ in core reference frame. $v_{\mathrm{n}}=$ unit vector normal to plane.

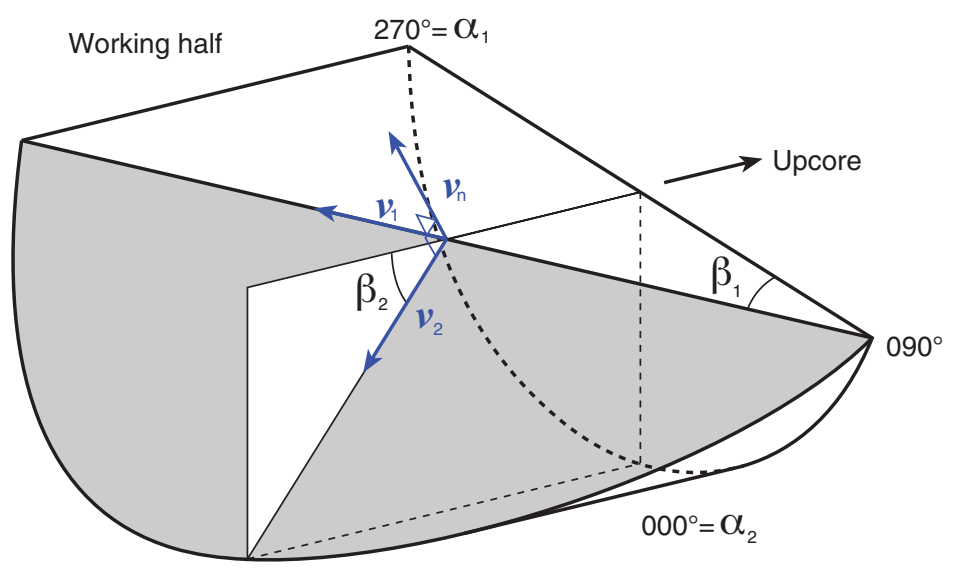


Figure F11. Dip direction $\left(\alpha_{d}\right)$, right-hand rule strike $\left(\alpha_{s}\right)$, and dip $(\beta)$ of a plane deduced from its normal azimuth $\left(\alpha_{n}\right)$ and $\operatorname{dip}\left(\beta_{n}\right)$. A. $\beta_{n}<0^{\circ}$. B. $\beta_{n} \pm 0^{\circ} . v_{n}=$ unit vector normal to plane.
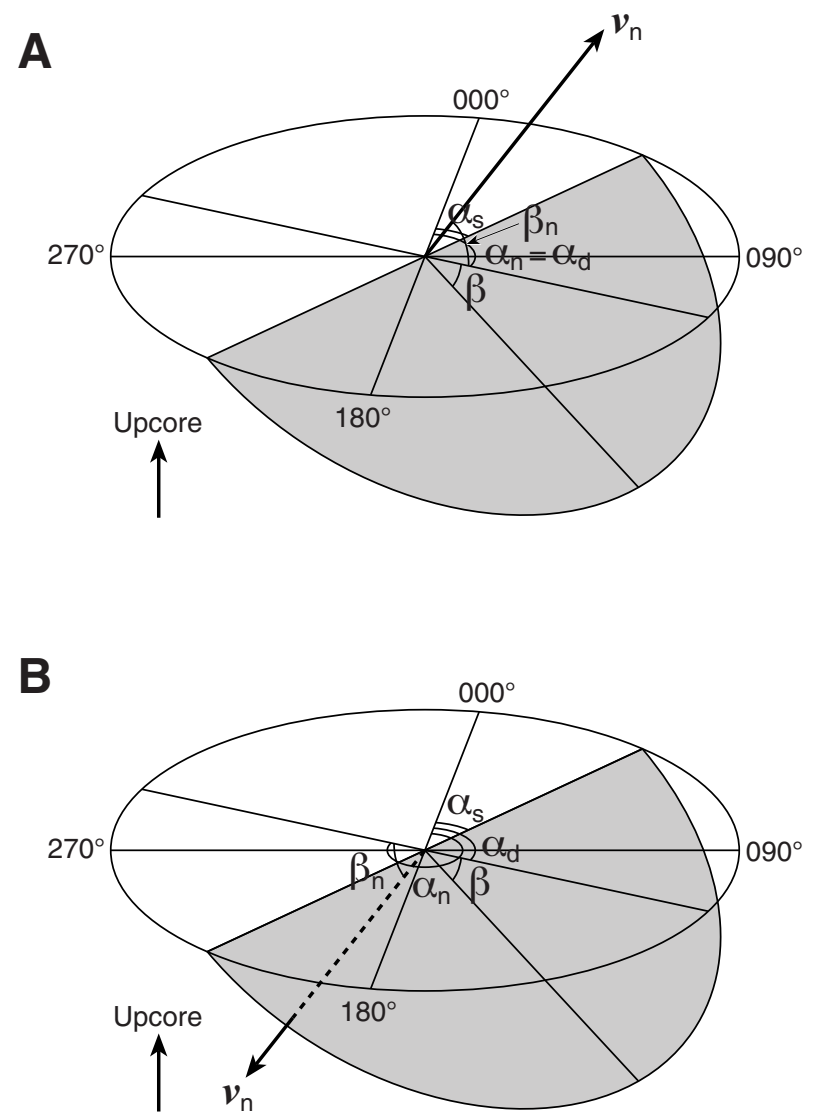
Figure F12. Apparent rake measurement of slickenlines on a fault surface from $270^{\circ}$ direction of split-core surface trace. $\phi_{\mathrm{a}}=$ apparent rake, $v_{\mathrm{n}}=$ unit vector normal to fault plane, $v_{\mathrm{c}}=$ unit vector normal to split core surface, $v_{\mathrm{i}}=$ unit vector parallel to intersection line between fault plane and split core surface.

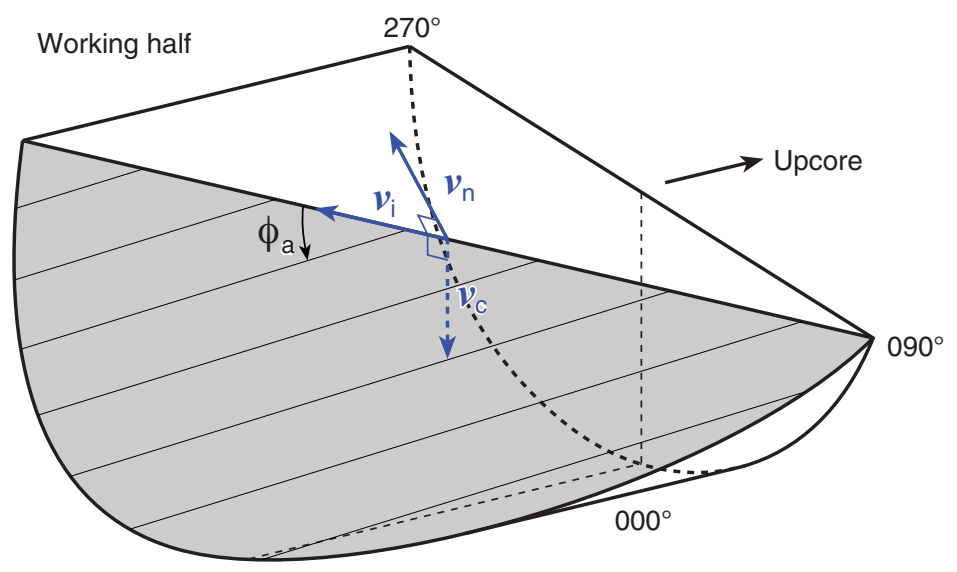


Figure F13. Rake of slickenlines $(\phi)$ deduced from rake of intersection line between fault plane and split-core surface $\left(\phi_{\mathrm{i}}\right)$ and apparent rake measured $\left(\phi_{\mathrm{a}}\right)$. A. Apparent rake measured from top or $090^{\circ}$ direction when fault plane dips toward west. B. Apparent rake measured from bottom or $090^{\circ}$ direction when fault plane dips toward east. C. Apparent rake measured from top or $270^{\circ}$ direction when fault plane dips toward east. D. Apparent rake measured from bottom or $270^{\circ}$ direction when fault plane dips toward west. $\alpha_{s}=$ right-hand rule strike of fault plane, $v_{\mathrm{n}}=$ unit vector normal to fault plane; $v_{\mathrm{c}}=$ unit vector normal to split core surface; $v_{\mathrm{i}}=$ unit vector parallel to intersection line between fault plane and split core surface.
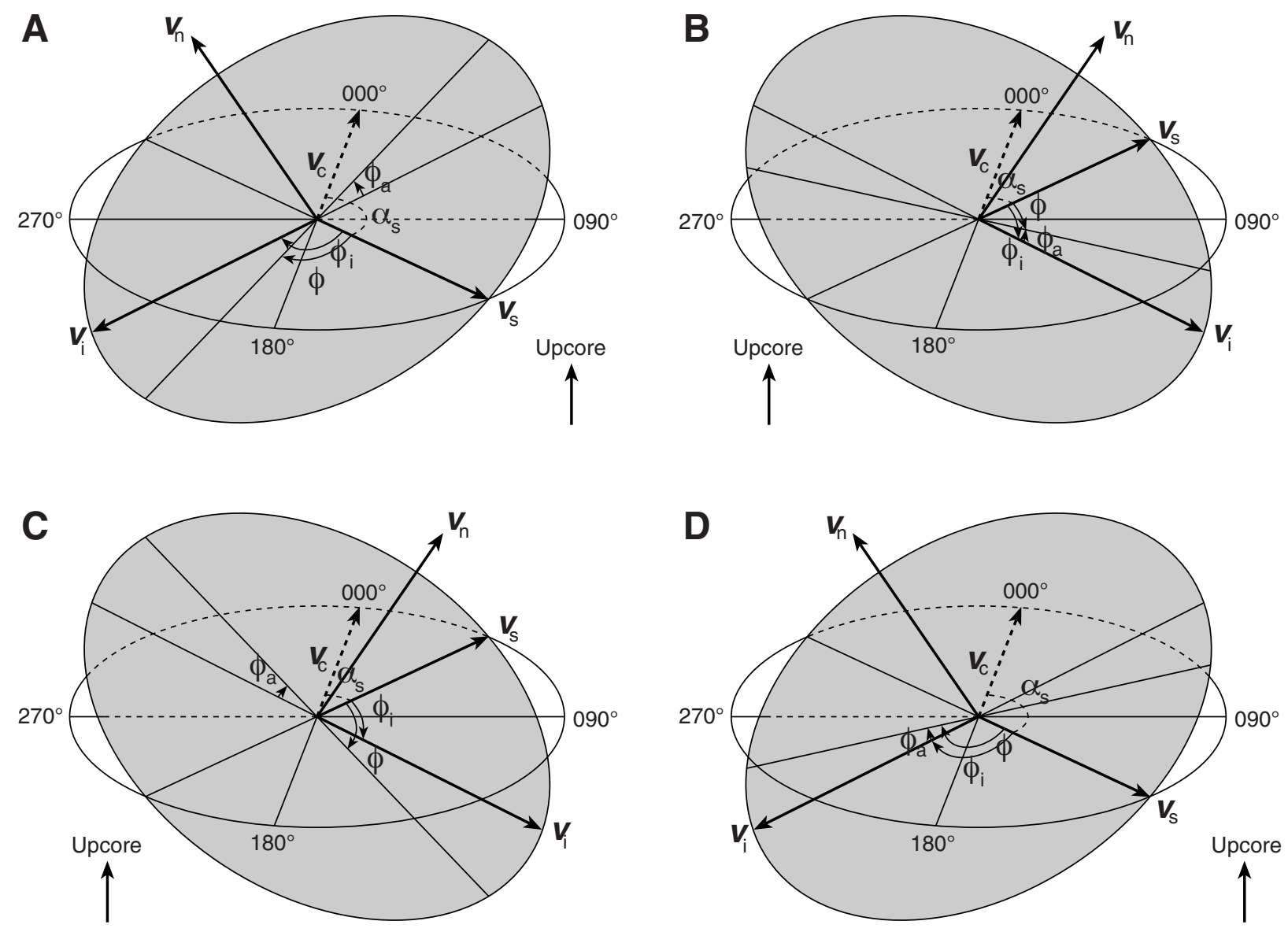
Figure F14. Azimuth correction based on paleomagnetic data. A. Paleomagnetic inclination $\beta_{p} \pm 0^{\circ}$. B. Paleomagnetic inclination $\beta_{p}<0^{\circ} . \alpha_{p}=$ paleomagnetic declination, $\alpha_{d}$ and $\alpha_{s}=$ dip direction and right-hand-rule strike of plane.
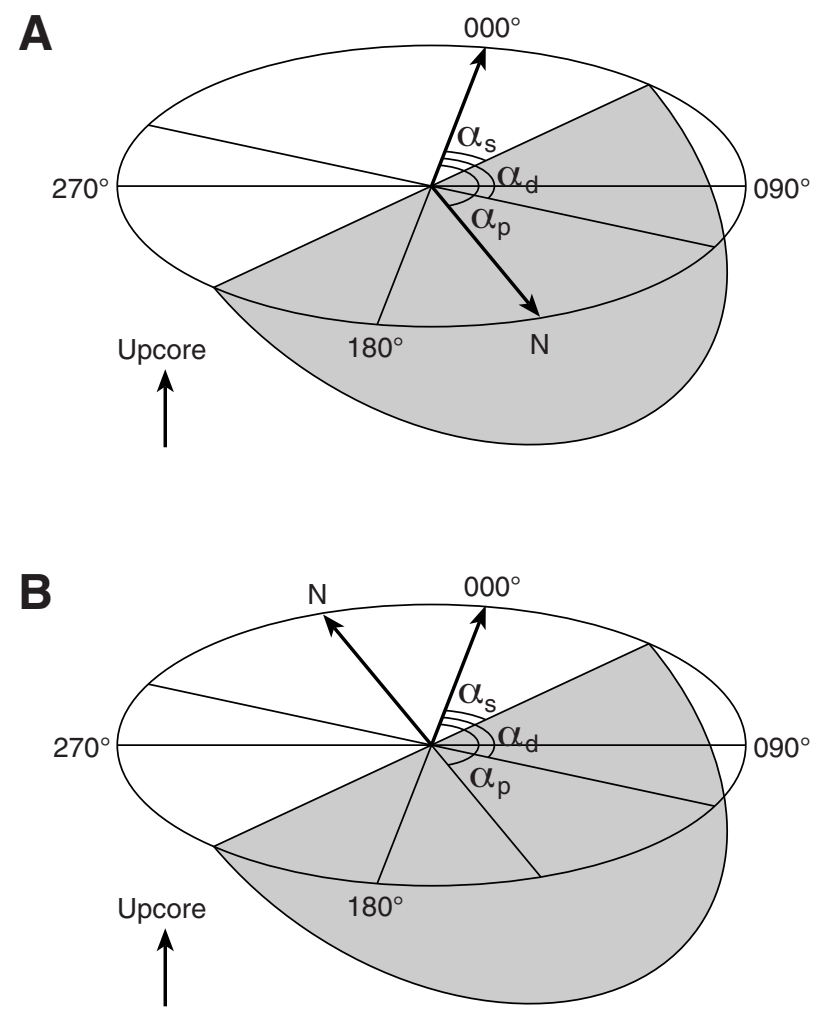
Figure F15. Structural geology window in J-CORES visual core description program. Fault data are entered two ways: fault and slickenline data separately or fault data including slickenline parameters as a comment.

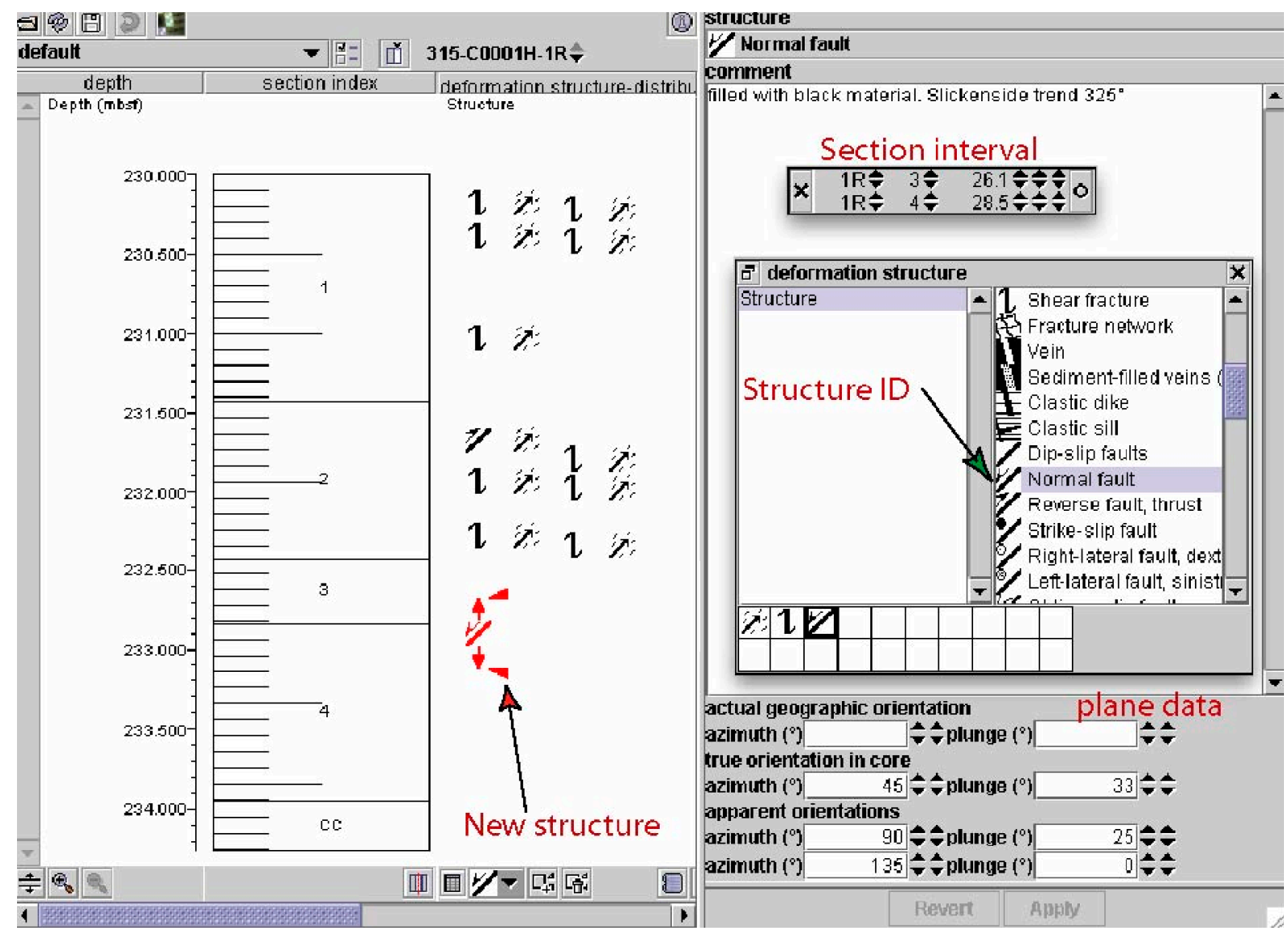


Figure F16. Overview of Cenozoic era magnetostratigraphic and biostratigraphic events. FO = first occurrence, $\mathrm{LO}=$ last occurrence. Black = normal polarity, white = reversed polarity.

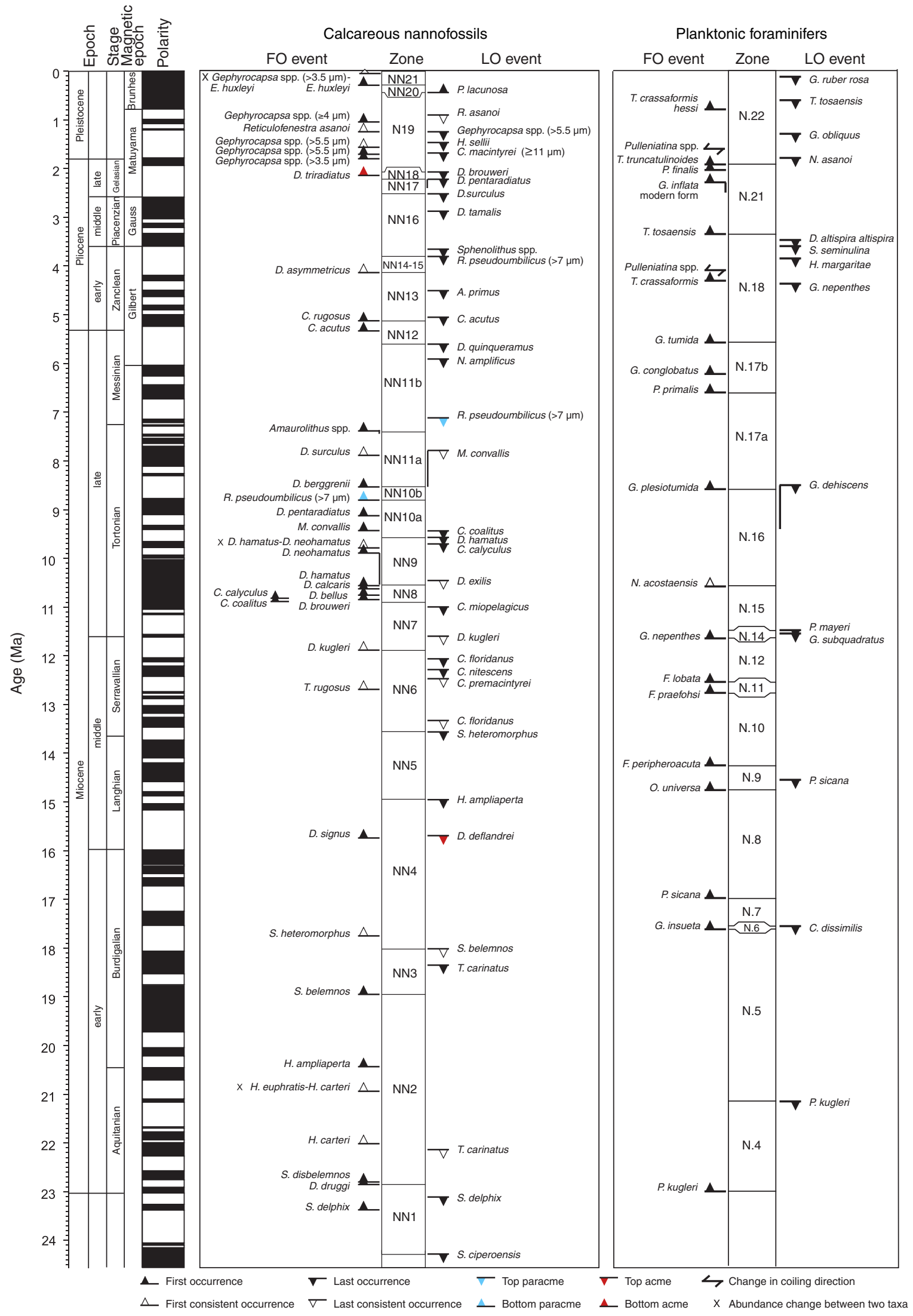


Figure F17. Sensor response of SQUID magnetometer with point source.

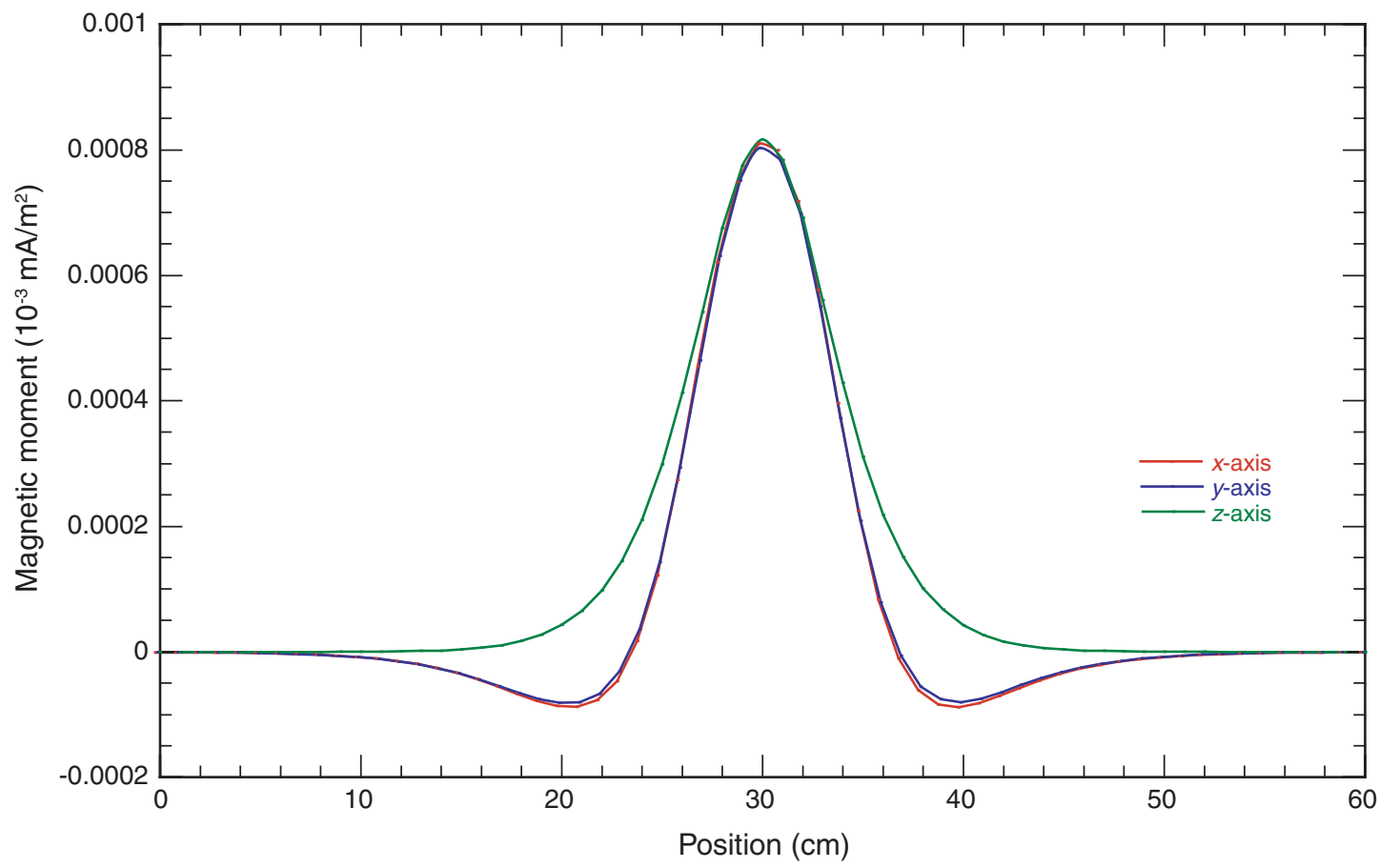


Figure F18. Superconducting rock magnetometer coordinates (modified from Richter et al., 2007). SQUID = superconducting quantum interference device.

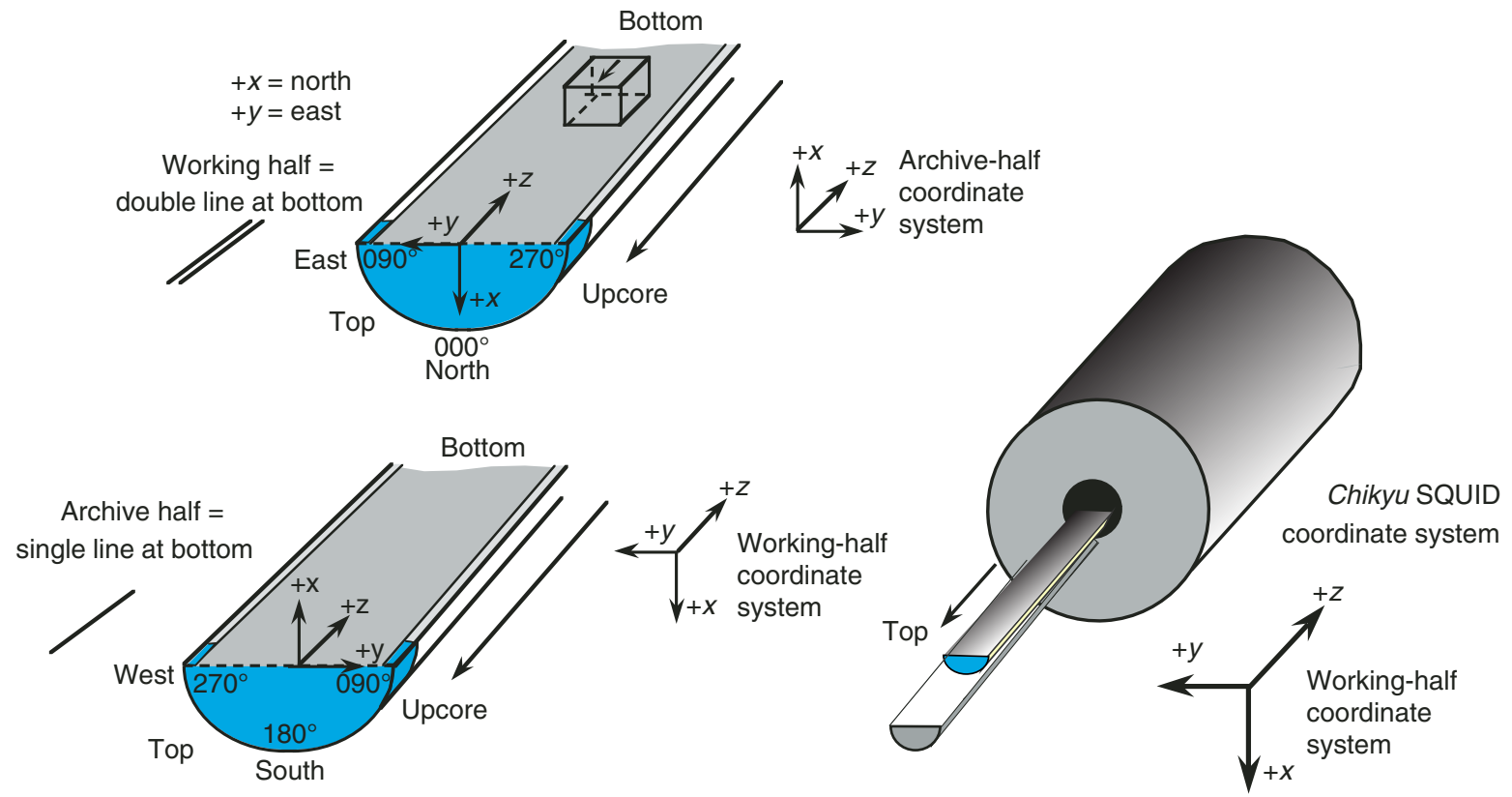


Figure F19. Declination and core twisting (Section 315-C0001F-7H-4). Data correspond to blanket AF demagnetization at $20 \mathrm{mT}$ as obtained in the long-core magnetometer. Note consistent rotation of declination with depth. Such core twisting has been habitually observed in cores obtained with the HPCS.

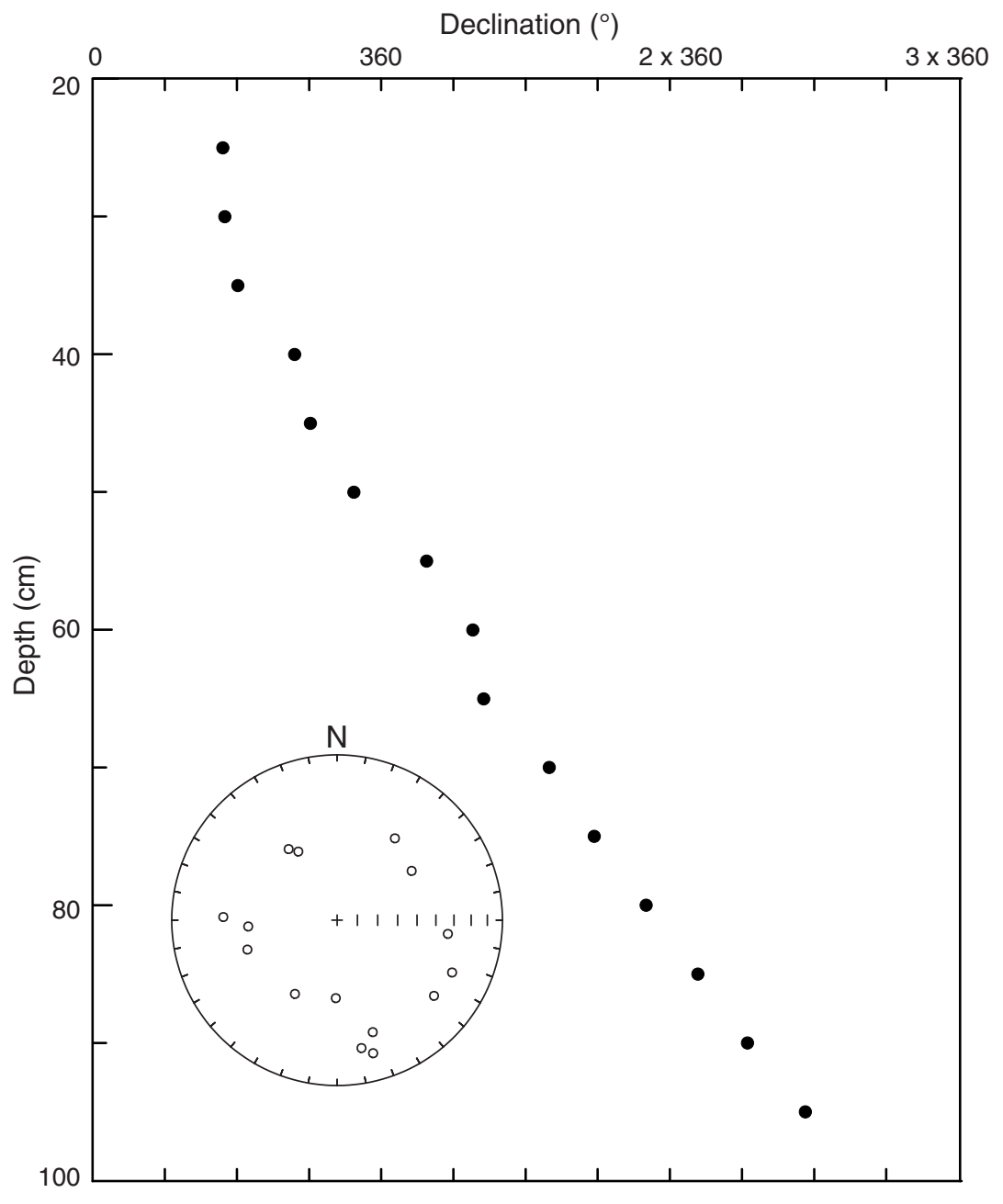


Figure F20. Advanced piston corer temperature tool, third generation (APCT3).

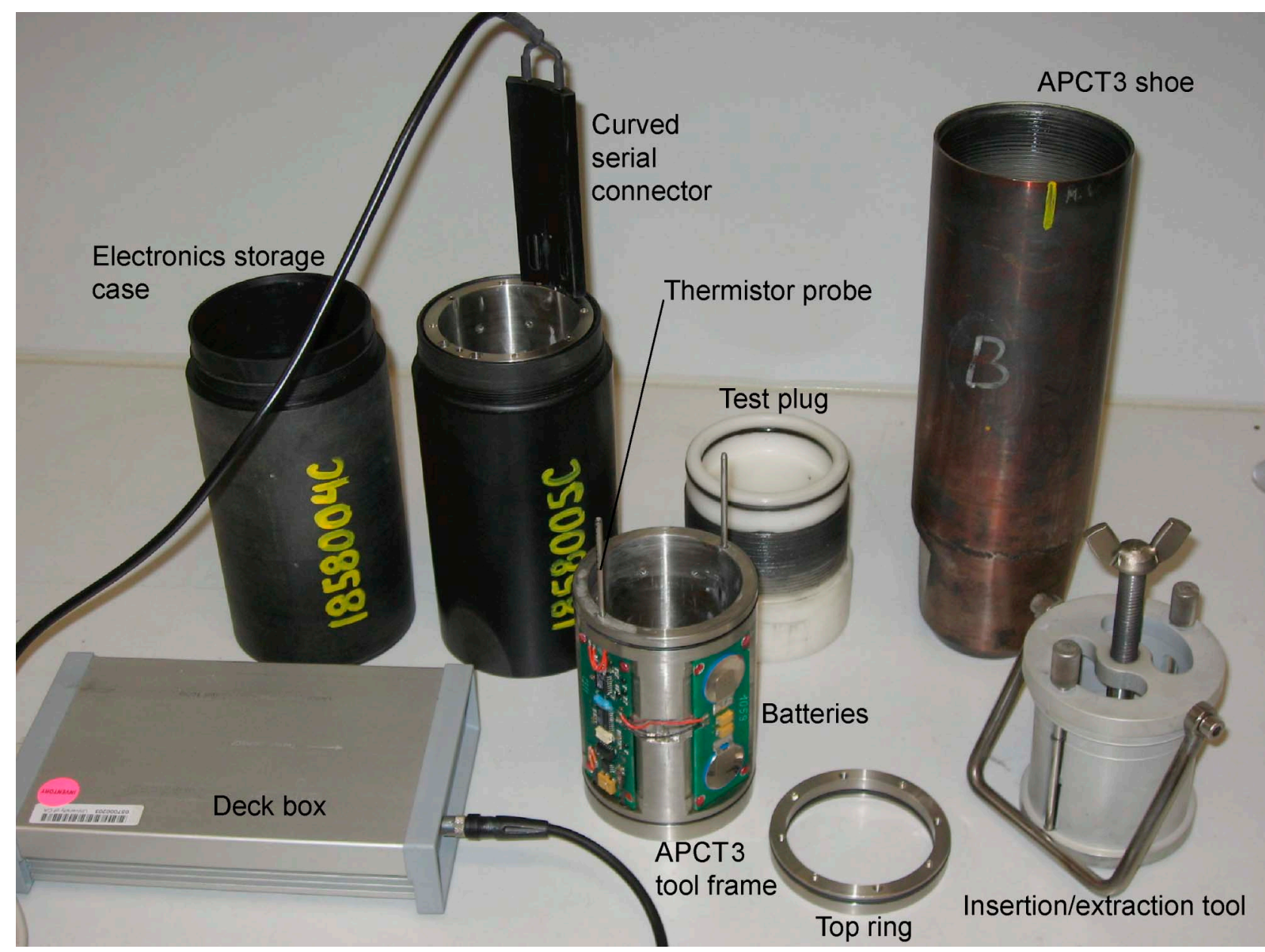


Figure F21. Typical penetration curve consisting of three parts: initial rise of temperature because of frictional heating, decay curve as sensor equilibrates to in situ temperature of sediment, and another rise while tool is pulled out.

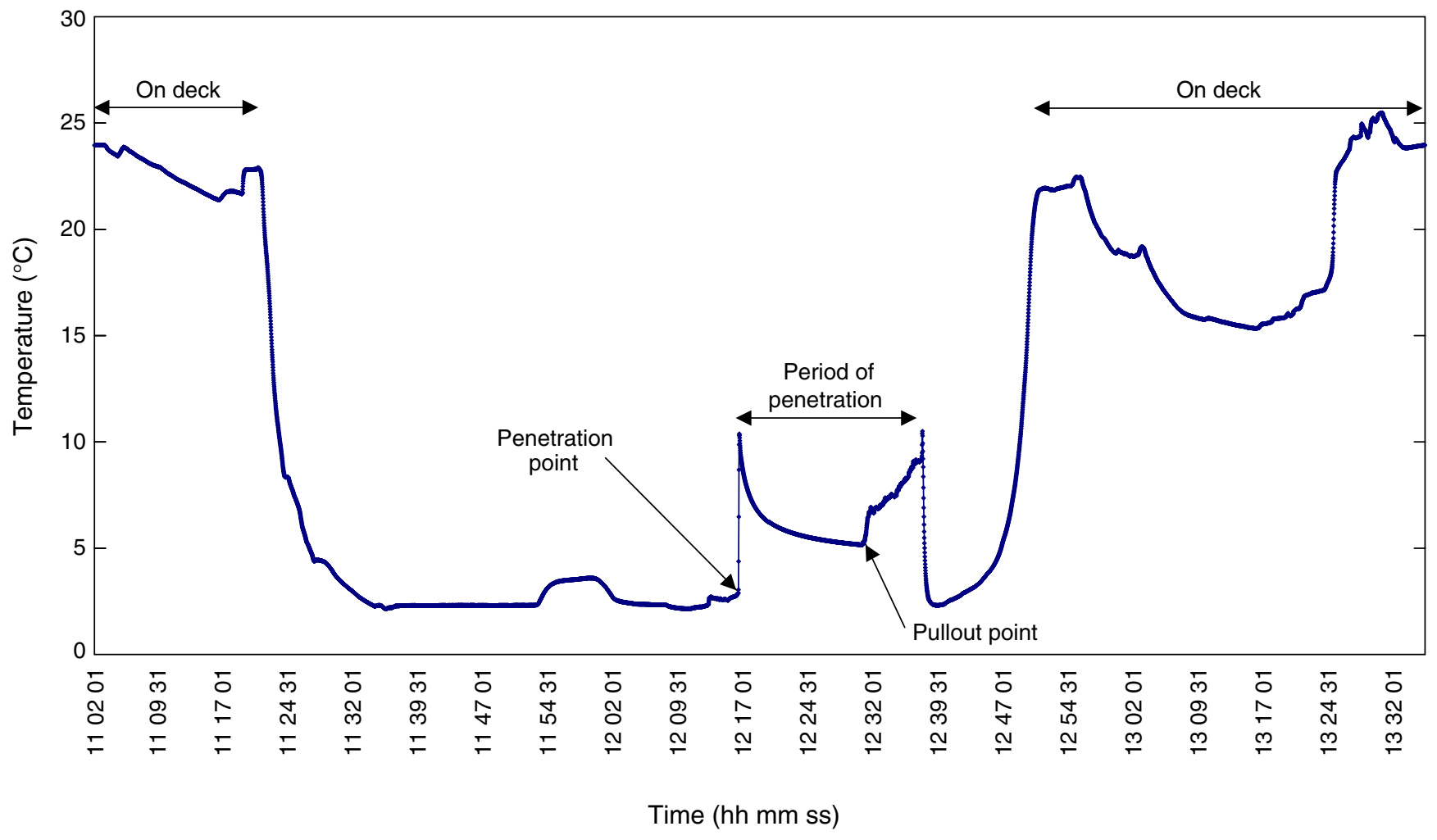


Figure F22. Comparison of natural gamma ray (NGR) activity measurements from MSCL measurements on whole-round and working-half cores and from logging-while-drilling (LWD) GVR tool, Hole C0001E. CSF-B = core depth below seafloor (IODP Method B), LSF = LWD depth below seafloor. Bold lines = correlations defining CSF-B to LSF transfer function, dashed lines = subsidiary correlations.

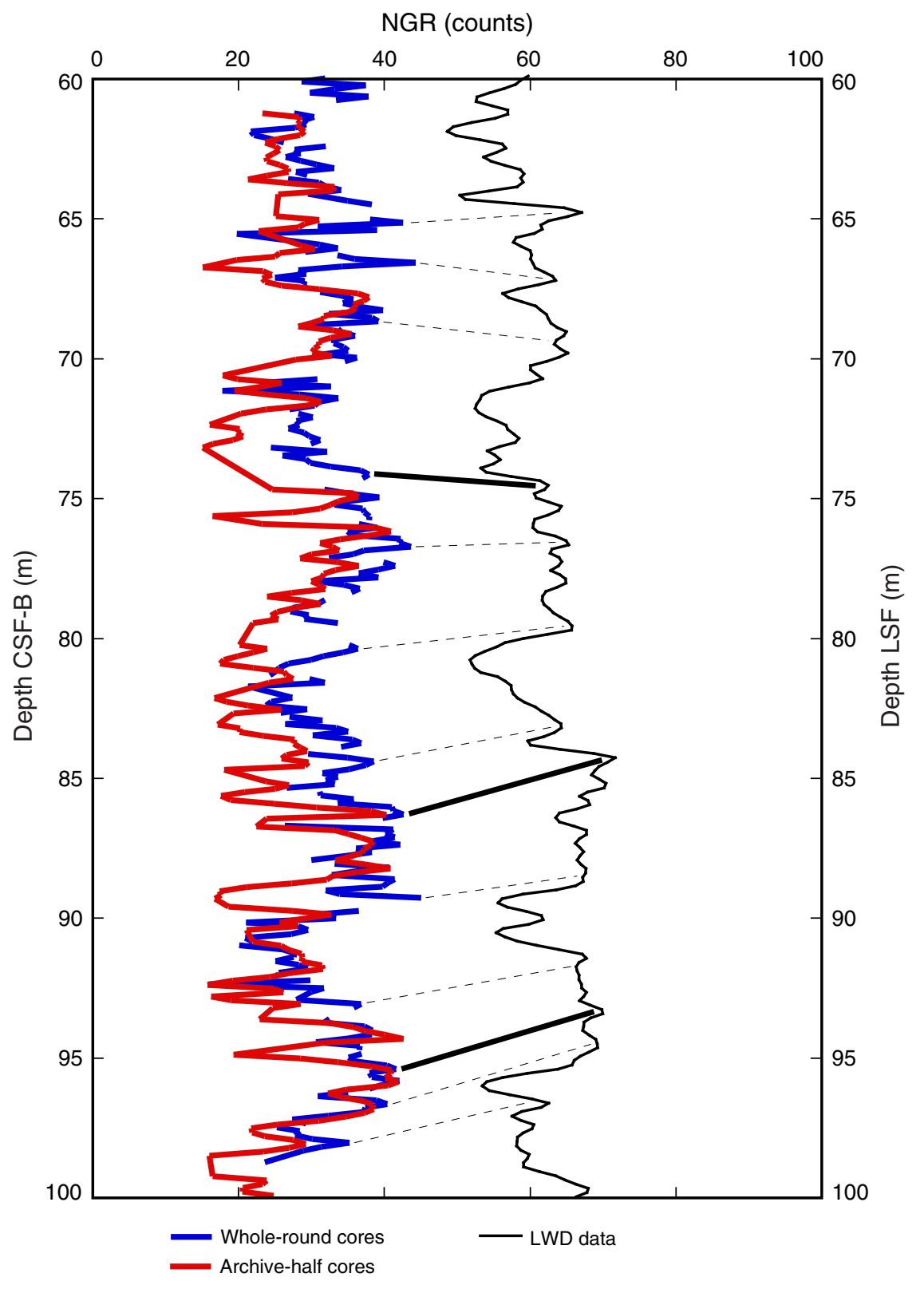


Movie M1. QuickTime movie of progressive downcore slicing of core damaged by delamination of core liner (Section 315-C0001F-7H-2).

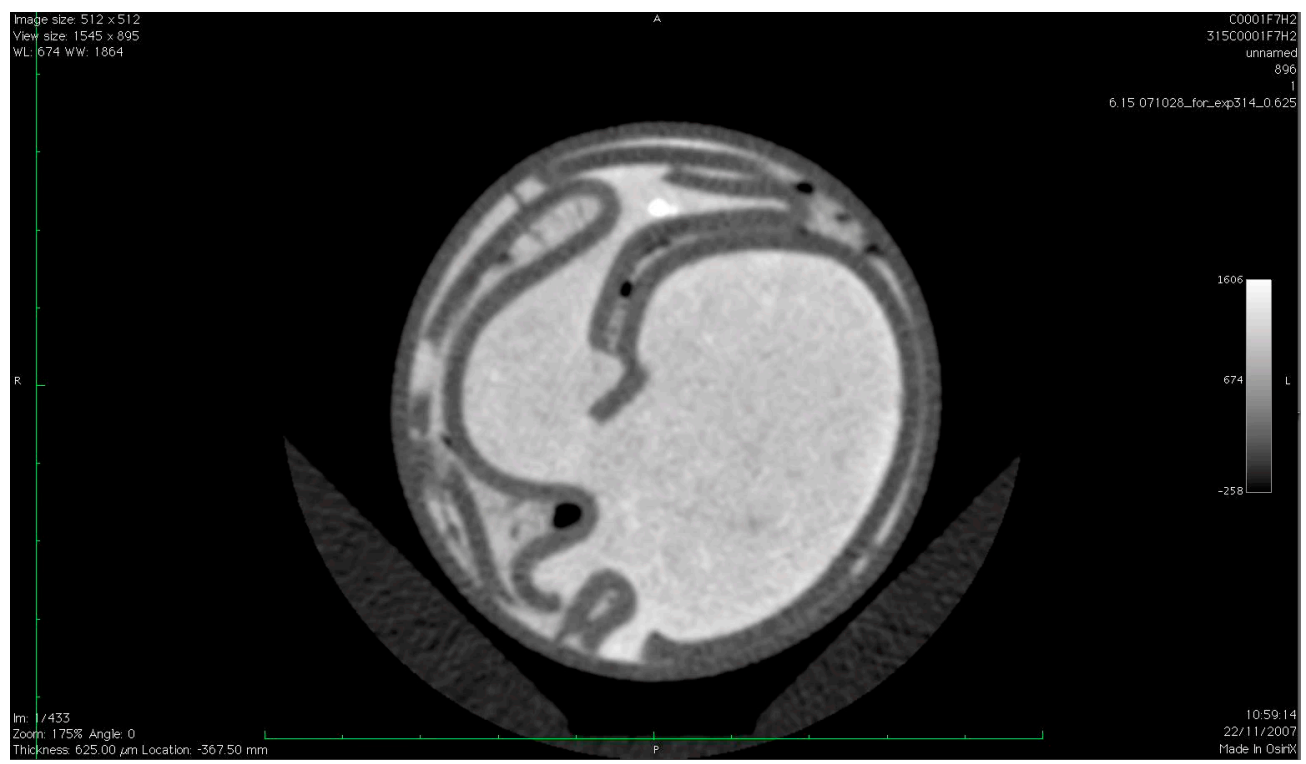


Movie M2. QuickTime movie of crosscutting faults imaged in 3-D using OsiriX (Section 315-C0001H-4R-3). Faults appear dark blue. More steeply dipping fault is cut and offset by more shallowly dipping fault.

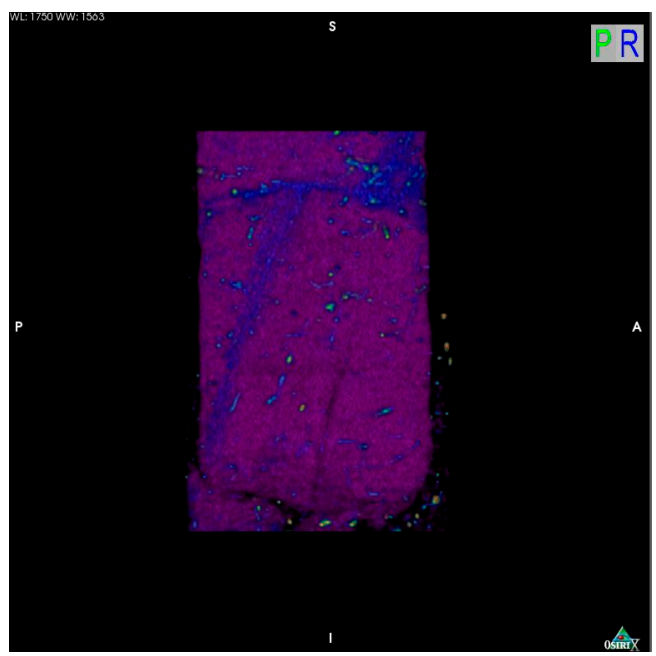


Table T1. Scan settings for X-ray CT scanner. (See table note.)

\begin{tabular}{ll}
\hline \multicolumn{1}{c}{ Setting } & \multicolumn{1}{c}{ Value } \\
\hline Tube voltage $(\mathrm{V})$ & 120 \\
Tube current $(\mathrm{mA})$ & 100 \\
Source revolution $(\mathrm{s})$ & 0.6 \\
Slices per revolution & 16 \\
Slice thickness (mm) & 0.625 \\
Reconstruction matrix & $512 \times 512$ \\
Pixel size (mm) & 0.1876 \\
Field of view (mm²) & $96 \times 96$ \\
Slice file format & DICOM \\
\hline
\end{tabular}

Note: DICOM = Digital Imaging and Communication in Medicine. 
Table T2. X-ray CT scanner standards. (See table notes.)

\begin{tabular}{|c|c|c|c|c|c|c|c|}
\hline \multirow[b]{2}{*}{ Date } & \multirow{2}{*}{$\begin{array}{l}\text { Local } \\
\text { time }(h)\end{array}$} & \multicolumn{6}{|c|}{$\mathrm{CT}$ number } \\
\hline & & Air & Air SD & Water & Water SD & Aluminum & Aluminum SD \\
\hline 29 Nov 2007 & 0025 & - & - & -1.32 & 10.30 & 2476.58 & 75.93 \\
\hline 30 Nov 2007 & 0140 & - & - & 1.47 & 13.27 & 2487.36 & 72.51 \\
\hline 1 Dec 2007 & 0035 & - & - & -1.51 & 12.85 & 2474.02 & 60.63 \\
\hline 2 Dec 2007 & 0120 & - & - & -0.91 & 12.95 & 2485.93 & 72.16 \\
\hline 3 Dec 2007 & 0045 & -1006.97 & 7.18 & -1.80 & 14.68 & 2464.83 & 58.96 \\
\hline 3 Dec 2007 & 0411 & -1005.18 & 9.18 & -0.56 & 15.40 & 2464.34 & 59.91 \\
\hline 4 Dec 2007 & 0044 & -1006.01 & 7.85 & -0.95 & 13.96 & 2480.22 & 68.76 \\
\hline 5 Dec 2007 & 0115 & -1006.34 & 8.03 & -2.45 & 12.59 & 2457.37 & 58.27 \\
\hline 6 Dec 2007 & 0035 & -1005.99 & 8.53 & -2.43 & 12.61 & 2471.55 & 73.09 \\
\hline 6 Dec 2007 & 2230 & -1006.28 & 7.65 & -1.10 & 14.81 & 2416.43 & 66.24 \\
\hline 7 Dec 2007 & 2355 & -1006.55 & 7.32 & 0.97 & 13.43 & 2482.68 & 51.00 \\
\hline 8 Dec 2007 & 2230 & -1006.37 & 7.98 & 1.32 & 13.94 & 2473.31 & 65.17 \\
\hline 8 Dec 2007 & 2305 & -1006.42 & 9.45 & 0.78 & 12.11 & 2477.33 & 60.64 \\
\hline 9 Dec 2007 & 2330 & -1007.67 & 9.42 & -1.89 & 11.27 & 2477.90 & 64.79 \\
\hline 11 Dec 2007 & 0530 & -1003.81 & 7.97 & 2.94 & 13.27 & 2471.29 & 71.91 \\
\hline 12 Dec 2007 & 0330 & -1002.25 & 8.29 & 1.56 & 13.36 & 2480.52 & 67.64 \\
\hline 13 Dec 2007 & 0025 & -1004.16 & 9.98 & 2.43 & 15.73 & 2471.53 & 65.62 \\
\hline 14 Dec 2007 & 0150 & -1006.17 & 7.93 & 1.17 & 14.30 & 2469.05 & 57.42 \\
\hline 14 Dec 2007 & 2127 & -1004.81 & 8.18 & 5.95 & 10.35 & 2464.15 & 61.73 \\
\hline 15 Dec 2007 & 0220 & -1002.44 & 8.08 & 3.32 & 12.82 & 2488 & 74 \\
\hline 16 Dec 2007 & 0305 & -1003.41 & 7.30 & 3.30 & 13.98 & 2466. & 24 \\
\hline 17 Dec 2007 & 0320 & -1003.48 & 7.62 & 2.30 & 12.85 & 2483.48 & 57.90 \\
\hline 17 Dec 2007 & 1905 & -1005.27 & 8.61 & 0.16 & 13.91 & 2486.22 & 62.75 \\
\hline 17 Dec 2007 & 2233 & -1003.26 & 7.73 & 5.28 & 11.65 & 2484.65 & 57.73 \\
\hline 19 Dec 2007 & 0105 & -1004.91 & 7.93 & 2.40 & 14.53 & 2473 & 65.36 \\
\hline 19 Dec 2007 & 2240 & -1004.20 & 8.40 & 2.72 & 12.82 & 2491.59 & 56.61 \\
\hline 20 Dec 2007 & 2125 & -1003.65 & 8.36 & -0.62 & 14.58 & 2471.07 & 67.74 \\
\hline 22 Dec 2007 & 0450 & -1003.09 & 8.51 & 3.43 & 14.18 & 2482.15 & 73.99 \\
\hline 23 Dec 2007 & 0015 & -1004.15 & 7.30 & 0.57 & 12.96 & 2486.75 & 71.53 \\
\hline 23 Dec 2007 & 2343 & -1003.98 & 9.30 & 3.85 & 12.12 & 2480.02 & 55.38 \\
\hline 24 Dec 2007 & 2320 & -1002.94 & 7.56 & -0.55 & 13.03 & 2471.83 & 60.78 \\
\hline 26 Dec 2007 & 0139 & -1004.18 & 8.01 & 2.95 & 12.40 & 2469.37 & 63.02 \\
\hline 27 Dec 2007 & 0032 & -1003.12 & 7.30 & 3.10 & 12.36 & 2491.96 & 74.09 \\
\hline 28 Dec 2007 & 0045 & -1003.02 & 9.37 & 2.94 & 14.07 & 2482.29 & 51.89 \\
\hline 29 Dec 2007 & 1230 & -1003.47 & 8.30 & 3.88 & 12.70 & 2474.84 & 61.07 \\
\hline 30 Dec 2007 & 0627 & -1003.45 & 8.62 & 1.20 & 13.74 & 2477.12 & 64.19 \\
\hline 31 Dec 2007 & 1217 & -1003.82 & 8.46 & 4.21 & 14.96 & 2479.53 & 65.73 \\
\hline 1 Jan 2008 & 1054 & -1003.95 & 8.11 & 3.44 & 13.22 & 2473.77 & 64.81 \\
\hline $2 \operatorname{Jan} 2008$ & 0139 & -1003.07 & 8.56 & 2.58 & 14.07 & 2478.18 & 61.81 \\
\hline $3 \operatorname{Jan} 2008$ & 0037 & -1003.87 & 9.90 & 2.72 & 14.48 & 2476.27 & 73.87 \\
\hline $4 \operatorname{Jan} 2008$ & 0100 & -1004.11 & 7.81 & 4.85 & 12.83 & 2479.77 & 73.58 \\
\hline $5 \operatorname{Jan} 2008$ & 0230 & -1003.29 & 10.44 & 3.78 & 12.07 & 2499.10 & 65.39 \\
\hline $6 \operatorname{Jan} 2008$ & 0100 & -1003.10 & 8.77 & 0.93 & 14.27 & 2490.04 & 63.26 \\
\hline $7 \operatorname{Jan} 2008$ & 0200 & -1003.88 & 8.93 & 3.15 & 11.91 & 2488.13 & 54.52 \\
\hline $8 \operatorname{Jan} 2008$ & 0300 & -1003.44 & 7.87 & 4.65 & 11.50 & 2481.04 & 69.99 \\
\hline $9 \operatorname{Jan} 2008$ & 0124 & -1004.66 & 9.26 & 2.17 & 13.84 & 2493.52 & 58.56 \\
\hline $10 \operatorname{Jan} 2008$ & 0155 & -1002.89 & 8.98 & 4.03 & 13.05 & 2478.90 & 59.86 \\
\hline 11 Jan 2008 & 0226 & -1003.08 & 8.45 & 3.57 & 12.13 & 2474.85 & 76.48 \\
\hline $12 \operatorname{Jan} 2008$ & 0458 & -1003.14 & 8.72 & 2.98 & 11.89 & 2478.49 & 61.49 \\
\hline $13 \operatorname{Jan} 2008$ & 0100 & -1002.43 & 8.67 & 5.79 & 15.66 & 2481.09 & 58.77 \\
\hline $14 \operatorname{Jan} 2008$ & 0045 & -1003.57 & 7.41 & 4.33 & 11.58 & 2478.08 & 69.03 \\
\hline $16 \operatorname{Jan} 2008$ & 0405 & -1004.73 & 8.65 & 3.99 & 13.35 & 2490.35 & 66.63 \\
\hline $17 \operatorname{Jan} 2008$ & 0400 & -1003.95 & 9.75 & 3.75 & 12.73 & 2482.42 & 61.65 \\
\hline $18 \operatorname{Jan} 2008$ & 0031 & -1003.11 & 8.80 & 3.55 & 12.76 & 2479.81 & 54.10 \\
\hline 19 Jan 2008 & 0022 & -1002.96 & 7.91 & 3.42 & 12.63 & 2467.33 & 65.76 \\
\hline $20 \operatorname{Jan} 2008$ & 0230 & -1004.15 & 8.33 & 4.25 & 12.88 & 2477.43 & 58.90 \\
\hline 21 Jan 2008 & 0112 & -1004.76 & 8.90 & 5.22 & 12.03 & 2475.83 & 61.85 \\
\hline $22 \operatorname{Jan} 2008$ & 0238 & -1004.38 & 7.73 & 2.38 & 15.35 & 2474.89 & 64.25 \\
\hline $23 \operatorname{Jan} 2008$ & 0037 & -1002.22 & 7.96 & 2.53 & 15.50 & 2486.50 & 62.49 \\
\hline $24 \operatorname{Jan} 2008$ & 0112 & -1004.52 & 8.57 & 1.58 & 12.55 & 2482.14 & 67.98 \\
\hline $25 \operatorname{Jan} 2008$ & 0105 & -1002.53 & 8.32 & 7.31 & 13.70 & 2478.10 & 68.51 \\
\hline $26 \operatorname{Jan} 2008$ & 0225 & -1003.77 & 8.69 & 3.52 & 14.62 & 2487.23 & 60.25 \\
\hline $27 \operatorname{Jan} 2008$ & 0340 & -1002.89 & 8.75 & 5.18 & 11.67 & 2474.84 & 66.95 \\
\hline $28 \operatorname{Jan} 2008$ & 0340 & -1002.44 & 6.27 & 0.99 & 13.17 & 2487.55 & 70.33 \\
\hline $29 \operatorname{Jan} 2008$ & 0358 & -1003.50 & 7.11 & 4.65 & 12.85 & 2483.66 & 65.14 \\
\hline $30 \operatorname{Jan} 2008$ & 0115 & -1003.30 & 7.58 & 2.01 & 14.99 & 2480.34 & 62.72 \\
\hline 31 Jan 2008 & 0122 & -1003.21 & 9.15 & 0.46 & 12.59 & 2483.98 & 71.88 \\
\hline
\end{tabular}

Notes: SD = standard deviation. $-=$ not determined. 
Table T3. Characteristic X-ray diffraction peaks for semiquantitative area analysis.

\begin{tabular}{lccc}
\hline \multicolumn{1}{c}{ Mineral } & Reflection & d-value $(\AA)$ & Peak position $\left({ }^{\circ} 2 \theta\right)$ \\
\hline Composite clay & Multiple & 4.478 & $19.4-20.4$ \\
Quartz & 101 & 3.342 & $26.3-27.0$ \\
Plagioclase & 002 & 3.192 & $27.4-28.2$ \\
Calcite & 104 & 3.035 & $29.1-29.7$ \\
\hline
\end{tabular}

Table T4. Normalization factors for calculation of relative mineral abundance using bulk powder X-ray diffraction analysis. (See table note.)

\begin{tabular}{|c|c|c|c|c|}
\hline \multirow{2}{*}{$\begin{array}{l}\text { Affected mineral in } \\
\text { standard mixture: }\end{array}$} & \multicolumn{4}{|c|}{ Normalization factors } \\
\hline & Total clay & Quartz & Plagioclase & Calcite \\
\hline \multicolumn{5}{|l|}{ Influencing mineral: } \\
\hline Total clay & $9.8956702 \mathrm{E}-03$ & $-1.5889532 E-04$ & $-2.8855808 \mathrm{E}-04$ & $-7.3842803 \mathrm{E}-04$ \\
\hline Quartz & $-4.7221169 \mathrm{E}-05$ & $5.8782392 \mathrm{E}-04$ & $-4.7869325 \mathrm{E}-05$ & $-3.1098843 \mathrm{E}-05$ \\
\hline Plagioclase & 7.2794763E-04 & $-4.2840613 \mathrm{E}-05$ & 1.3719777E-03 & $-3.6005495 \mathrm{E}-05$ \\
\hline Calcite & $4.2042411 \mathrm{E}-05$ & $3.3021188 \mathrm{E}-06$ & $-4.1329499 \mathrm{E}-06$ & $1.3071455 \mathrm{E}-03$ \\
\hline
\end{tabular}

Note: Singular value decomposition was used to compute factors, following Fisher and Underwood (1995).

Table T5. Astrochronological age estimates of nannofossil events used as biostratigraphic tie-points. (See table notes.) (Continued on next page.)

\begin{tabular}{|c|c|c|}
\hline Event & Zone (base) & Age (Ma) \\
\hline X Gephyrocapsa spp. (>3.5 $\mu \mathrm{m})$-Emiliania huxleyi & & 0.063 \\
\hline FO Emiliania huxleyi & NN21 & 0.291 \\
\hline LO Pseudoemiliania lacunosa & NN20 & 0.436 \\
\hline LCO Reticulofenestra asanoi & & 0.9 \\
\hline RE Gephyrocapsa spp. ( $\geq 4 \mu \mathrm{m})$ & & 1.04 \\
\hline FCO Reticulofenestra asanoi & & $1.078^{*}$ \\
\hline LO Gephyrocapsa spp. (>5.5 ㅆm) & & 1.24 \\
\hline LO Helicosphaera sellii & & 1.34 \\
\hline FCO Gephyrocapsa spp. (>5.5 um) & & 1.46 \\
\hline FO Gephyrocapsa spp. (>5.5 $\mu \mathrm{m})$ & & $1.560-1.617^{*}$ \\
\hline LO Calcidiscus macintyrei $(\geq 11 \mu \mathrm{m})$ & & 1.6 \\
\hline FO Gephyrocapsa spp. $(>3.5 \mu \mathrm{m})$ & & 1.67 \\
\hline LO Discoaster brouweri & NN19 & 2.06 \\
\hline AB Discoaster triradiatus & & $2.135-2.216^{*}$ \\
\hline LO Discoaster pentaradiatus & NN18 & $2.393-2.512^{*}$ \\
\hline LO Discoaster surculus & NN17 & 2.52 \\
\hline LO Discoaster tamalis & & 2.87 \\
\hline LO Sphenolithus spp. & & 3.65 \\
\hline LO Reticulofenestra pseudoumbilicus (>7 um) & NN16 & 3.79 \\
\hline FCO Discoaster asymmetricus & NN15-NN14 & 4.13 \\
\hline LO Amaurolithus primus & & 4.5 \\
\hline LO Ceratolithus acutus & & 5.04 \\
\hline FO Ceratolithus rugosus & NN13 & 5.12 \\
\hline FO Ceratolithus acutus & & 5.32 \\
\hline LO Discoaster quinqueramus & NN12 & 5.59 \\
\hline LO Nicklithus amplificus & & $5.9^{*}$ \\
\hline PE Reticulofenestra pseudoumbilicus (>7 um) & & $7.1^{*}$ \\
\hline FO Amaurolithus spp. = FO Amaurolithus primus & NN11b & $7.362-7.424^{*}$ \\
\hline FCO Discoaster surculus & & 7.88 \\
\hline LCO Minylitha convallis & & $7.78-8.3^{*}$ \\
\hline FO Discoaster berggrenii & NN11a & 8.52 \\
\hline PB Reticulofenestra pseudoumbilicus & NN10b & 8.785 \\
\hline FO Discoaster pentaradiatus & & 9.1 \\
\hline LO Catinaster coalitus & & 9.416 \\
\hline FO Minylitha convallis & & 9.416 \\
\hline LO Discoaster hamatus & NN10a & 9.56 \\
\hline LO Catinaster calyculus & & $9.687^{*}$ \\
\hline X Discoaster hamatus $-D$. neohamatus & & $9.762^{*}$ \\
\hline
\end{tabular}


Table T5 (continued).

\begin{tabular}{|c|c|c|}
\hline Event & Zone (base) & Age (Ma) \\
\hline FO Discoaster neohamatus & & $9.867-10.521^{*}$ \\
\hline LCO Discoaster exilis & & 10.427 \\
\hline FO Discoaster hamatus & NN9 & 10.541 \\
\hline FO Discoaster calcaris & & 10.676 \\
\hline FO Discoaster bellus gr. & & 10.72 \\
\hline FO Discoaster brouweri & & $10.734-10.764$ * \\
\hline FO Catinaster calyculus & & 10.785 \\
\hline FO Catinaster coalitus & NN8 & 10.886 \\
\hline LO Coccolithus miopelagicus & & $10.97-11.02^{*}$ \\
\hline LCO Discoaster kugleri & & 11.578 \\
\hline FCO Discoaster kugleri & NN7 & 11.863 \\
\hline LO Cyclicargolithus floridanus & & 12.037 \\
\hline LO Coronocyclus nitescens & & 12.254 \\
\hline LCO Calcidiscus premacintyrei & & 12.447 \\
\hline FCO Triquetrorhabdulus rugosus & & 12.671 \\
\hline LCO Cyclicargolithus floridanus & & 13.294 \\
\hline LO Sphenolithus heteromorphus & NN6 & 13.532 \\
\hline LO Helicosphaera ampliaperta & NN5 & $14.914^{*}$ \\
\hline AE Discoaster deflandrei & & $15.663^{*}$ \\
\hline FO Discoaster signus & & $15.702^{*}$ \\
\hline FCO Sphenolithus heteromorphus & & $17.721^{*}$ \\
\hline LCO Sphenolithus belemnos & NN4 & $17.973^{*}$ \\
\hline LO Triquetrorhabdulus carinatus & & $18.315^{*}$ \\
\hline FO Sphenolithus belemnos & NN3 & $18.921^{*}$ \\
\hline FO Helicosphaera ampliaperta & & $20.393^{*}$ \\
\hline X Helicosphaera euphratis-Helicosphaera carteri & & $20.894^{*}$ \\
\hline FCO Helicosphaera carteri & & $21.985^{*}$ \\
\hline LCO Triquetrorhabdulus carinatus & & $22.092^{*}$ \\
\hline FO Sphenolithus disbelemnos & & $22.760^{*}$ \\
\hline FO Discoaster druggi & NN2 & $22.824^{*}$ \\
\hline LO Sphenolithus delphix & & $23.065^{*}$ \\
\hline FO Sphenolithus delphix & & $23.328^{*}$ \\
\hline LO Sphenolithus ciperoensis & NN1 & $24.242^{*}$ \\
\hline
\end{tabular}

Notes: Based on Raffi et al. (2006). X = crossover in abundance, FO = first occurrence, LO = last occurrence, $L C O=$ last consistent occurrence, RE $=$ reentrance, $\mathrm{FCO}=$ first consistent occurrence, $\mathrm{AB}=$ acme beginning, $\mathrm{PB}=$ paracme beginning, $\mathrm{PE}=$ paracme end, $\mathrm{AE}=\mathrm{acme}$ end. ${ }^{*}=$ datum based on Atlantic or Mediterranean records. 
Table T6. Planktonic foraminiferal datum events. (See table note.)

\begin{tabular}{|c|c|c|}
\hline Event & Zone (base) & Age (Ma) \\
\hline LO Globigerinoides ruber rosa & & 0.12 \\
\hline LO Truncorotalia tosaensis & & 0.61 \\
\hline FO Truncorotalia crassaformis hessi & & 0.8 \\
\hline LO Globoturborotalita obliquus & & 1.3 \\
\hline SD2 Pulleniatina spp. & & $1.7-1.8$ \\
\hline LO Neogloboquadrina asanoi & & 1.8 \\
\hline FO Truncorotalia truncatulinoides & N.22 & 1.93 \\
\hline FO Pulleniatina finalis & & 2.04 \\
\hline FO Globoconella inflata modern form & & $2.3-2.5$ \\
\hline FO Truncorotalia tosaensis & N.21 & 3.35 \\
\hline LO Dentoglobigerina altispira altispira & & 3.47 \\
\hline LO Sphaeroidinellopsis seminulina & & 3.59 \\
\hline LO Hirsutella margaritae & & 3.85 \\
\hline SD1 Pulleniatina spp. & & 4.08 \\
\hline FO Truncorotalia crassaformis & & 4.31 \\
\hline LO Globoturborotalita nepenthes & & 4.37 \\
\hline FO Globorotalia tumida & N.18 & 5.57 \\
\hline FO Globigerinoides conglobatus & & 6.2 \\
\hline FO Pulleniatina primalis & N.17b & 6.6 \\
\hline FO Globorotalia plesiotumida & N.17a & 8.58 \\
\hline LO Globoquadrina dehiscens & & $8.5-9.4$ \\
\hline FCO Neogloboquadrina acostaensis & N.16 & 10.57 \\
\hline LO Paragloborotalia mayeri & N.15 & 11.47 \\
\hline LO Globigerinoides subquadratus & & 11.54 \\
\hline FO Globoturborotalita nepenthes & N.14 & 11.63 \\
\hline FO Fohsella lobata & N.12 & 12.53 \\
\hline FO Fohsella praefohsi & N.11 & 12.76 \\
\hline FO Fohsella peripheroacuta & N.10 & 14.24 \\
\hline LO Praeorbulina sicana & & 14.53 \\
\hline FO Orbulina universa & N.9 & 14.74 \\
\hline FO Praeorbulina sicana & N.8 & 16.97 \\
\hline LO Catapsydrax dissimilis & N.7 & 17.54 \\
\hline FO Globigerinatella insueta & N.6 & 17.59 \\
\hline LO Paragloborotalia kugleri & N.5 & 21.12 \\
\hline FO Paragloborotalia kugleri & N.4 & 22.96 \\
\hline
\end{tabular}

Note: $\mathrm{FO}=$ first occurrence, $\mathrm{FCO}=$ first consistent occurrence, $\mathrm{LO}=$ last occurrence, $\mathrm{SD}=$ change in coiling direction from sinistral to dextral. 
Table T7. Ages used for the geomagnetic polarity timescale (normal polarity interval). (See table note.)

\begin{tabular}{|c|c|c|}
\hline \multicolumn{2}{|c|}{ Age interval (Ma) } & \multirow{2}{*}{$\begin{array}{l}\text { Chron/ } \\
\text { Subchror }\end{array}$} \\
\hline Top & Bottom & \\
\hline 0.000 & 0.781 & $\mathrm{C} 1 \mathrm{n}$ \\
\hline 0.988 & 1.072 & C1r.1n \\
\hline 1.173 & 1.185 & C1r.2n \\
\hline 1.778 & 1.945 & $\mathrm{C} 2 \mathrm{n}$ \\
\hline 2.581 & 3.032 & C2An.1n \\
\hline 3.116 & 3.207 & C $2 A n \cdot 2 n$ \\
\hline 3.330 & 3.596 & C2An. $3 n$ \\
\hline 4.187 & 4.300 & C3n.1n \\
\hline 4.493 & 4.631 & $C 3 n \cdot 2 n$ \\
\hline 4.799 & 4.896 & $C 3 n .3 n$ \\
\hline 4.997 & 5.235 & C $3 n .4 n$ \\
\hline 6.033 & 6.252 & C3An.1n \\
\hline 6.436 & 6.733 & C $3 A n .2 n$ \\
\hline 7.140 & 7.212 & $\mathrm{C} 3 \mathrm{Bn}$ \\
\hline 7.251 & 7.285 & C3Br.1n \\
\hline 7.454 & 7.489 & $\mathrm{C} 3 \mathrm{Br} .2 \mathrm{n}$ \\
\hline 7.528 & 7.642 & C $4 n .1 n$ \\
\hline 7.695 & 8.108 & C $4 n .2 n$ \\
\hline 8.254 & 8.300 & C4r.1n \\
\hline 8.769 & 9.098 & C4An \\
\hline 9.321 & 9.409 & C4Ar.1n \\
\hline 9.656 & 9.917 & C $4 A r .2 n$ \\
\hline 9.779 & 9.934 & C5n.1n \\
\hline 9.987 & 11.040 & C $5 n .2 n$ \\
\hline 11.118 & 11.154 & C5r.1n \\
\hline 11.554 & 11.614 & C5r.2n \\
\hline 12.041 & 12.116 & C5An.1n \\
\hline 12.207 & 12.415 & C5An.2n \\
\hline 12.730 & 12.765 & C5Ar.1n \\
\hline 12.820 & 12.878 & C5Ar.2n \\
\hline 13.015 & 13.183 & C5AAn \\
\hline 13.252 & 13.466 & $\mathrm{C} 5 \mathrm{ABn}$ \\
\hline 13.734 & 14.095 & C5ACn \\
\hline 14.194 & 14.581 & C5ADn \\
\hline 14.784 & 14.877 & C5Bn.1n \\
\hline 15.032 & 15.160 & C5Bn.2n \\
\hline 15.974 & 16.268 & C5Cn.1n \\
\hline 16.303 & 16.472 & C5Cn.2n \\
\hline 16.543 & 16.721 & C5Cn.3n \\
\hline 17.235 & 17.533 & C5Dn \\
\hline 18.056 & 18.524 & C5En \\
\hline 18.748 & 19.722 & C6n \\
\hline 20.040 & 20.213 & C6An.1n \\
\hline
\end{tabular}

\begin{tabular}{|c|c|c|}
\hline \multicolumn{2}{|c|}{ Age interval (Ma) } & \multirow{2}{*}{$\begin{array}{l}\text { Chron/ } \\
\text { Subchron }\end{array}$} \\
\hline Top & Bottom & \\
\hline 20.439 & 20.709 & C6An.2n \\
\hline 21.083 & 21.159 & C6AAn \\
\hline 21.659 & 21.688 & C6AAr.2n \\
\hline 21.767 & 21.936 & C6Bn.1n \\
\hline 21.992 & 22.268 & C $6 B n .2 n$ \\
\hline 22.564 & 22.758 & C6Cn.1n \\
\hline 22.902 & 23.030 & C6Cn.2n \\
\hline 23.249 & 23.375 & C6Cn.3n \\
\hline 24.044 & 24.102 & C7n.1n \\
\hline 24.146 & 24.556 & C7n.2n \\
\hline 24.915 & 25.091 & C7An \\
\hline 25.295 & 25.444 & C8n.1n \\
\hline 25.492 & 26.154 & C8n.2n \\
\hline 26.714 & 27.826 & $C 9 n$ \\
\hline 28.186 & 28.450 & C10n.1n \\
\hline 28.525 & 28.715 & C10n.2n \\
\hline 29.451 & 29.740 & C11n.1n \\
\hline 29.853 & 30.217 & C11n.2n \\
\hline 30.627 & 31.116 & $\mathrm{C} 12 \mathrm{n}$ \\
\hline 33.266 & 33.738 & C13n \\
\hline 34.782 & 35.043 & C15n \\
\hline 35.404 & 35.567 & C16n.1n \\
\hline 35.707 & 36.276 & C16n.2n \\
\hline 36.512 & 37.235 & C17n.1n \\
\hline 37.345 & 37.549 & C17n.2n \\
\hline 37.610 & 37.771 & C17n.3n \\
\hline 38.032 & 38.975 & C18n.1n \\
\hline 39.041 & 39.464 & C18n.2n \\
\hline 40.439 & 40.671 & C19n \\
\hline 41.590 & 42.774 & C20n \\
\hline 45.346 & 47.235 & $C 21 n$ \\
\hline 48.599 & 49.427 & $\mathrm{C} 22 \mathrm{n}$ \\
\hline 50.730 & 50.932 & C $23 n .1 n$ \\
\hline 51.057 & 51.901 & C $23 n .2 n$ \\
\hline 52.648 & 53.004 & C24n.1n \\
\hline 53.116 & 53.167 & C $24 n .2 n$ \\
\hline 53.286 & 53.808 & C24n.3n \\
\hline 56.665 & 57.180 & $C 25 n$ \\
\hline 58.379 & 58.737 & $C 26 n$ \\
\hline 61.650 & 61.983 & $C 27 n$ \\
\hline 63.104 & 64.128 & $C 28 n$ \\
\hline 64.432 & 65.118 & $C 29 n$ \\
\hline
\end{tabular}

Note: Data from Gradstein et al. (2004) (See Fig. F16).

Table T8. Modified DSMZ medium 1040. (See table notes.)

\begin{tabular}{|c|c|c|}
\hline Component & $\begin{array}{c}\text { Concentration } \\
\text { per L }\end{array}$ & Comments \\
\hline Sigma sea salts & $35 \mathrm{~g}$ & \\
\hline Yeast extract & $1 \mathrm{~g}$ & \\
\hline Wolfe's mineral elixir & $1 \mathrm{~mL}$ & DSMZ medium 792 \\
\hline Resazurin & $0.5 \mathrm{~mL}$ & $1 \mathrm{~g} / \mathrm{L}$ stock solution \\
\hline \multicolumn{3}{|c|}{ Autoclave, then add the following: } \\
\hline $10 \% \mathrm{NaHCO}_{3}$ & $20 \mathrm{~mL}$ & \\
\hline Vitamin solution & $1 \mathrm{~mL}$ & 10 times concentrate of solution described in DSMZ medium 141; mixture of 10 vitamins \\
\hline $\mathrm{FeSO}_{4} \cdot 7 \mathrm{H}_{2} \mathrm{O}$ & $5 \mathrm{~mL}$ & $50 \mathrm{~g} / \mathrm{L}$ stock solution \\
\hline Na-dithionate & $1 \mathrm{~mL}$ & $25 \mathrm{~g} / \mathrm{L}$ stock solution \\
\hline Substrate & $10 \mathrm{~mL}$ & $1 \mathrm{M}$ stock solution of acetate, lactate, pyruvate, or ethanol \\
\hline
\end{tabular}

Notes: Adjust pH to 7.2 with $\mathrm{H}_{2} \mathrm{SO}_{4}$. Concentrations are per liter of Millipore $18.2 \mathrm{M} \Omega \cdot \mathrm{cm}$ Type 1 ultrapure water. 